\title{
DETERMINANTES INDIVIDUAIS E CONTEXTUAIS DO ALEITAMENTO MATERNO EXCLUSIVO NOS PRIMEIROS SEIS MESES DE VIDA EM CENTO E ONZE MUNICÍPIOS DO ESTADO DE SÃO PAULO
}

SONIA ISOYAMA VENANCIO

TESE APRESENTADA AO DEPARTAMENTO DE NUTRIÇÃO DA FACULDADE DE SAÚdE PÚBLICA DA UNIVERSIDADE DE SÃo PAULO PARA OBTENÇÃO DO GRAU DE DOUTOR

ORIENTADOR PROF. DR. CARLOS AUGUSTO MONTEIRO

ÁREA DE CONCENTRAÇÃO NUTRIÇÃO

SÃO PAULO

2002 
Dedico este trabalho

$$
\begin{array}{r}
\text { À minha filha Beatriz, } \\
\text { porque sua existência confere um novo } \\
\text { sentido a todas as coisas } \\
\text { e por tudo que tem me ensinado } \\
\text { sobre o amor e a vida. }
\end{array}
$$

$$
\begin{array}{r}
\text { Aos meus pais } \\
\text { por tudo, especialmente pelo } \\
\text { apoio e confiança, que foram fundamentais } \\
\text { para a concretização deste trabalho. }
\end{array}
$$


Agradecimentos

Ao Prof. Carlos Augusto Monteiro por sua dedicação à orientação deste trabalho e pelo aprendizado que tem me proporcionado ao longo de todos esses anos.

À Biba, Cirlei e Lilian, companheiras do Projeto Amamentação e Municípios, sem as quais esse trabalho não teria sido possível.

Ao Prof. Aluísio J. D. de Barros Que me encorajou a dar os primeiros passos na análise multinivel e por ter gentilmente me recebido no Departamento de Medicina Social da UFPel para prestar valiosas contribuições a este trabalho.

À Prof ${ }^{\circ}$ Maria Helena D'Aquino Benício pelo carinho, pelas preciosas sugestões dadas ao projeto inicial e pelo incentivo constante.

À Dra. Maria Lúcia R. Stefanini pelo apoio institucional dado ao Projeto Amamentação e Municípios e pela solidariedade nos momentos dificeis deste trabalho.

Aos colegas do Instituto de Saúde, em particular do NISMC e da Comissão de Aprimoramento em Saúde Coletiva. pelo apoio recebido nessa trajetória. 
Ao Marcelo e Gerônimo.

Pela dedicação à construção do aplicativo AMAMUNIC, que foi fundamental para a qualidade das informações analisadas neste trabalho.

Ao Rui de Paiva, pelo apoio e pela parceria em tantos projetos, que tem possibilitado fazer coisas que "valem a pena".

Ao Carlos Eduardo, Por ter compartilhado bons e maus momentos desse longo caminho.

Aos professores e amigos Keiko Teruya e Jayme Murahovischi, que pelo exemplo e dedicação ao trabalho, me despertaram o interesse pelo aleitamento materno.

A todos aqueles responsáveis pela realização da pesquisa sobre aleitamento materno nos 111 municípios, pela confiança depositada em nosso trabalho, pelo entusiasmo com que aderiram à proposta $e$, especialmente. por acreditarem na possibilidade de mudança do perfil da amamentação no nosso Estado e trabalharem para que isso aconteça. 


\section{INDICE}

1. INTRODUÇÃO 2

1.1. Vantagens do aleitamento materno.................................................... 2

1.2. Mecanismos de proteção do leite humano.......................................... 6

1.3. Vantagens do aleitamento materno exclusivo.................................... 9

1.4. Indicadores para a avaliação de práticas de alimentaçăo infantil..... 15

1.5. Situação do aleitamento matemo no Brasil e no mundo.................... 19

1.6. Proteção, promoçăo e apoio ao aleitamento materno......................... 23

1.7. Determinantes da prática do aleitamento matemo exclusivo........... 28

1.8. Justificativa do estudo....................................................................... 29

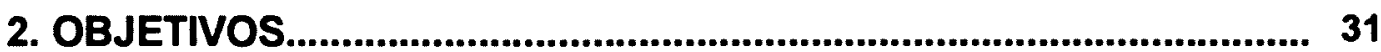

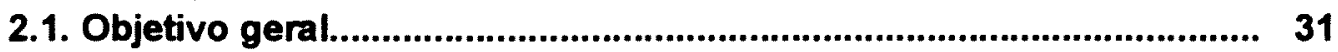

2.2. Objetivos específicos.................................................................... 31

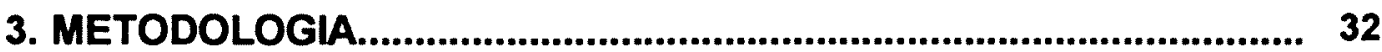

3.1. O Projeto Amamentaçăo e Municípios........................................... 32

3.1.1. Antecedentes........................................................................ 32

3.1.2. Implementação da proposta...................................................... 37

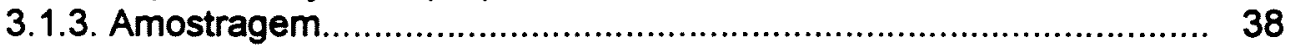

3.1.4. Instrumento de coleta de dados............................................. 40

3.1.5. Armazenamento dos dados..................................................... 41

3.2. Populaçảo do estudo................................................................................. 42

3.3. Variáveis do estudo....................................................................... 42

3.4. Procedimentos analíticos....................................................................... 48

3.4.1. Curvas de evolução do aleitamento materno em função da idade da criança.

3.4.2. Influência das características individuais (das crianças e de suas mães) sobre a freqüencia do aleitamento matemo exclusivo......... 49

3.4.3. Aleitamento materno exclusivo nos 111 municípios estudados...... 49

3.4.4. Influência das variáveis contextuais (municipais) sobre a freqüência do aleitamento matemo exclusivo.............................. 50

3.4.5. Fatores individuais e contextuais associados à prática do aleitamento matemo exclusivo: análise multinivel........................ 51

3.5. Plano geral da análise.................................................................... 55

3.6. Análise das interações entre variáveis individuais e contextuais.... 58

3.7. Aspectos éticos................................................................................. 60

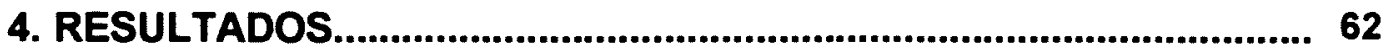

4.1. Características das crianças estudadas.......................................... 62

4.2. Curvas de aleitamento materno em função da idade da criança...... 65

4.3. A influência de atributos individuais sobre a freqüência do aleitamento materno exclusivo.

4.4. Características sociodemograficas e relativas ao incentivo ao aleitamento materno dos municipios estudados............................... 70

4.5. A influência do contexto sobre a frequiência do aleitamento materno exclusivo. 
4.6. Análise simultánea da influência de atributos individuais e do contexto sobre a freqüência do aleitamento matemo exclusivo

4.7. Efeito das interações entre as variáveis individuais e contextuais sobre o aleitamento materno exclusivo.

5. DISCUSSÃO

5.1. Limitações do estudo.

5.1.1. Validade interna.

5.1.2. Validade externa

5.2. Comparaçőes com a literatura.

5.2.1. A freqüència do aleitamento matemo nos 111 municípios estudados

5.2.2. Os determinantes individuais e contextuais do aleitamento materno exclusivo.

5.3. Implicações do estudo.

6. CONCLUSÕES

7. REFERÊNCIAS BIBLIOGRÁFICAS.

\author{
ANEXOS \\ Anexo 1- Manual do Supervisor \\ Anexo 2- Manual do Entrevistador \\ Anexo 3- Questionário sobre ações municipais pró-amamentação \\ Anexo 4- Questionário para aplicação em campanhas de vacinação \\ Anexo 5- Instruçōes sobre o aplicativo AMAMUNIC \\ Anexo 6- Modelos lineares multinivel com variância simples e com variável \\ resposta dicotômica \\ Anexo 7-Termo de consentimento dos municipios \\ Anexo 8- Prevalência do aleitamento matemo exclusivo nos municipios \\ estudados \\ Anexo 9- Comparação de indicadores sociodemográficos obtidos pelo \\ SINASC/1998 e pelo Projeto Amamentação e Municípios
}




\section{LISTA DE TABELAS}

Tabela 1 Amamentação exclusiva e duração mediana da amamentação no mundo, 1996.

Tabela 2 Distribuição (\%) de 66.133 crianças menores de 1 ano residentes em 111 municípios do Estado de São Paulo, segundo faixa etária, 1999

Tabela 3 Distribuição (\%) de 34.345 crianças menores de seis meses residentes em 111 municípios do ESP segundo faixa etária, sexo, peso ao nascer, tipo e local do parto e serviço ambulatorial 63 utilizado, 1999.

Tabela 4 Distribuição (\%) de 34.345 crianças menores de seis meses residentes em 111 municipios do ESP segundo idade, paridade, situação de trabalho e escolaridade matemas. São Paulo, 64 1999

Tabela 5 Estimativas sobre a freqüência de aleitamento matemo exclusivo (AME) e aleitamento matemo exclusivo ou predominante (AMEP) e respectivos intervalos de confiança (IC95\%) em idades selecionadas. Crianças residentes em 111 municipios do ESP, 65 1999

Tabela 6 Tabela 6 . Freqüência (\%) do aleitamento materno exclusivo segundo atributos individuais (das crianças e suas mães). 34.435 crianças menores de 6 meses de idade residentes em de 111 municípios do ESP, 1999

Tabela 7 Distribuição (\%) de 111 municípios do ESP segundo região, porte populacional e Indice Paulista de Responsabilidade Social (IPRS), 1999.

Tabela 8 Média das prevalências (\%) de AME em menores de 6 meses segundo características sociodemográficas dos municípios .111 municipios do ESP, 1999

Tabela 9 Média das prevalências (\%) de AME em menores de 6 meses segundo a existência de ações de incentivo à amamentação nos municipios. 111 municípios do ESP, 1999.

Tabela 10 Coeficientes de correlação (r) entre variáveis que expressam diferentes ações pró-amamentação. 111 municipios do ESP São Paulo, 1999 
Tabela 11 Média das prevalências de AME em menores de 6 meses segundo somatória das ações pró-amamentação no município.

111 municipios do ESP, 1999.

Tabela 12 Determinantes individuais e contextuais do AME e correspondentes razões de chance obtidas por modelo multinivel hierárquico. Crianças menores de 6 meses de 111 municípios do 88 ESP, 1999

Tabela 13 Fatores de risco para o desmame, com e sem o efeito da interação com a variável "somatória do $n^{\circ}$ de açōes próamamentação". Crianças menores de seis meses de 11199 municipios do ESP, 1999. 


\section{LISTA DE FIGURAS}

Figura 1 Evolução da participação dos municipios no Projeto Amamentação

E Municipios, 1998-2001.

Figura 2 Organização dos dados em niveis hierárquicos, São Paulo, 2002

Figura 3 Marco teórico para a investigação de determinantes do AME (atributos individuais estruturados em blocos hierarquizados.

Figura 4 Freqüências de Aleitamento Matemo Exclusivo (AME) e Aleitamento Matemo Exclusivo/Predominante (AMEP) segundo a idade da criança. 34.435 crianças menores de seis meses residentes em 111 municipios do Estado de São Paulo, 1999.

Figura 5 Figura 5 - Número de municípios segundo intervalos de prevalência do AME em crianças menores de seis meses de vida. 111 municípios do ESP, 1999... 70

Figura 6 Distribuição dos 111 municipios que realizaram a pesquisa "Avaliação das práticas alimentares no primeiro ano de vida em dias nacionais de vacinação" no ano de 1999, segundo a prevalência de AME em crianças de 0-6 meses. São Paulo, 1999.

Figura 7 Freqüência de ações de proteção, promoção e apoio ao aleitamento materno em 111 municípios do ESP, 1999.

Figura 8 Distribuição (\%) dos municípios segundo total apurado de ações próamamentação. 111 municipios do ESP, 1999.

Figura 9 Prevalência média de AME em menores de 6 meses segundo número de ações de proteção, promoção e apoio ao AM. 111 municipios do ESP, 1999...

Figura 10 Distribuição dos 111 municípios paulistas que participaram do projeto Amamentação e Municipios segundo intervalos de cobertura da campanha de vacinação na qual realizou-se a pesquisa, 1999.

Figura 11 Distribuição dos 91 municipios paulistas que participaram do projeto Amamentação e Municipios sem utilizar amostras segundo intervalos de perda de crianças menores de um ano que deveriam ser incluídas na pesquisa, 1999

Figura 12 Distribuição percentual de 111 municípios do ESP e de capitais brasileiras segundo intervalos de prevalência do AME em menores de quatro meses, 1999

Figura 13 Freqüência de crianças em AME em diferentes idades segundo hospital de nascimento (Hospitais Amigos da Criança - HAC ou outros hospitais). São Paulo, 2002.

Figura 14 Impacto das ações municipais de incentivo ao aleitamento materno sobre os principais obstáculos para a prática da amamentação exclusiva. São Paulo, 2002. 


\section{LISTA DE QUADROS}

Quadro 1 Grupos de idade para a medida de indicadores baseados nas recomendações sobre alimentação infantil. OMS, 1991.

Quadro 2 Indicadores propostos para avaliação das práticas de alimentação infantil. OMS, 1991

Quadro 3 Variáveis incluídas no estudo.

Quadro 4 Classificação dos Grupos de Municípios com Características Distintas de Riqueza, Longevidade e Escolaridade.

Quadro 5 Variáveis incluídas no estudo das interações. 


\section{LISTA DE SIGLAS}

AM

AME

AMP

BPN

BLH

HAC

IBFAN

IHAC

IPRS

MS

NBCAL

OMS

RC

SMAM

UNICEF
Aleitamento Materno

Aleitamento Materno Exclusivo

Aleitamento Materno Predominante

Baixo Peso ao Nascer

Banco de Leite Humano

Hospital Amigo da Criança

Rede Internacional em Defesa do Direito de Amamentar

Iniciativa hospital Amigo da Criança

Índice Paulista de Responsabilidade Social

Ministério da Saúde

Norma Brasileira de Comercialização de Alimentos

para Lactentes

Organização Mundial de Saúde

Razão de Chances

Semana Mundial de Aleitamento Materno

Fundo das Nações Unidas para a Infância 


\section{RESUMO}

Venâncio SI. Determinantes individuais e contextuais do aleitamento materno exclusivo nos primeiros seis meses de vida em cento e onze municípios do Estado de São Paulo. São Paulo, 2002 [Tese de Doutorado - Faculdade de Saúde Pública da Universidade de São Paulo].

Objetivo. Tendo em vista a importância do Aleitamento Materno Exclusivo (AME) para a redução da mortalidade infantil, analisou-se a influência de atributos individuais e caracteristicas contextuais sobre essa prática. Método. A amostra constituiu-se de 34.435 crianças menores de seis meses residentes em 111 municipios do Estado de São Paulo, os quais realizaram inquérito sobre práticas alimentares no primeiro ano de vida em dias nacionais de vacinação, em 1999. O efeito de atributos individuais (das crianças e suas mães) e do contexto (características municipais) sobre o AME foi analisado com modelos multinivel. Resultados. A prevalência do AME na amostra estudada foi de 13,9\% [IC $95 \% 13,6$ 14,3]. Foram fatores de risco para a intemupção do AME: baixa escolaridade materna, primiparidade, mães com idade inferior a 20 anos, crianças do sexo masculino, baixo peso ao nascer e acompanhamento ambulatorial na rede pública. Variáveis sociodemográficas municipais não influenciaram o AME. Verificou-se influência positiva da existência de ações municipais pró-amamentação sobre o $A M E$, após o controle para as variáveis individuais. A existência de pelo menos 4 ações pró-amamentação nos municípios foi capaz de atenuar o risco relativo de desmame da baixa escolaridade e do baixo peso ao nascer e transformar 0 acompanhamento na rede pública em fator de proteção para o AME. Conclusões. A identificação de grupos de risco para o desmame pode auxiliar na definição de intervençōes apropriadas para aumentar a prática do AME em nosso meio. Os municípios que implantaram ações pró-amamentação influenciaram positivamente o AME e atenuaram o impacto negativo de atributos individuais.

Descritores: Aleitamento materno. Aleitamento materno exclusivo. Epidemiologia. Determinantes. Análise multinivel. 


\section{SUMMARY}

Venâncio SI. Individual and contextual determinants of exclusive breastfeeding in the first six months of life in a hundred and eleven cities of the State of São Paulo. São Paulo, 2002 [Doctor's degree thesis - Faculdade de Saúde Pública da Universidade de São Paulo].

Objective. Because Exclusive Breast-feeding (EBF) is one of de most important strategies for reduction of infant mortality, the influence of individual attributes and contextual characteristics on this practice was studied. Method. The sample consisted of 34.435 children under six months of life living in 111 cities of the State of São Paulo, which had carried surveys on infant feeding practices in the first year of life in national days of vaccination, in 1999. The effect of individual attributes (of the children and their mothers) and of the context (characteristics of cities) on EBF was analyzed with multilevel models. Results. The prevalence of EBF was $13,9 \%$ [ IC95\%13,6-14,3 ]. Risk factors for the interruption of EBF were: low maternal schooling, primiparity, mothers under 20 years, males, low birth weight and ambulatorial accompaniment in public health services. Sociodemographic characteristics of the cities had not influenced EBF. Positive influence of the existence of breastfeeding actions in the cities was observed, after controlling for individual variables. The existence of at least 4 breast-feeding actions in the cities reduced the relative risk of weaning of low matemal schooling and low birth weight and modified the effect of accompaniment in the public health services as being a protection factor for EBF. Conclusions. The identification of risk factors for early weaning can help the definition of appropriate interventions to increase EBF. The cities that had implemmented breast-feeding actions had influenced positively EBF and had attenuated the negative impact of individual attributes.

Descriptors: Breast-feeding. Exclusive breast-feeding. Epidemiology. Determinants. Multilevel analysis. 


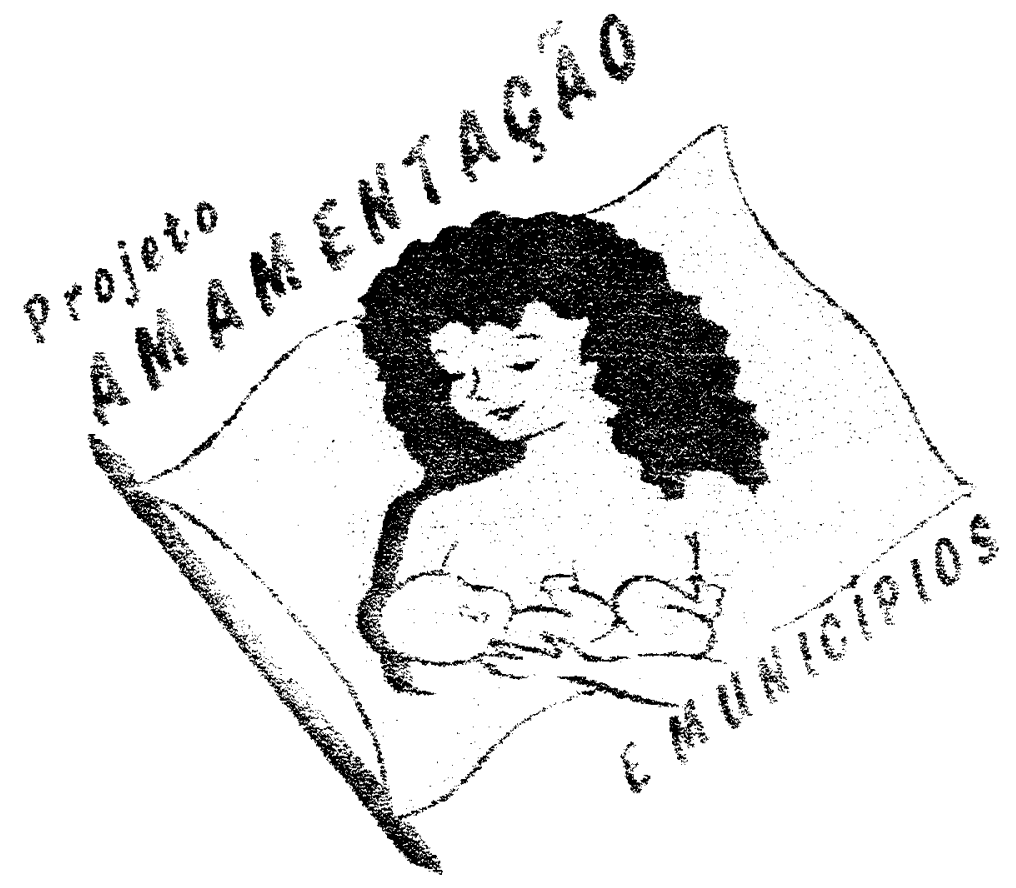

1. INTRODUÇÃO

Uma longa viagem começa

com um único passo...

Lao Tse 


\subsection{Vantagens do aleitamento materno}

As vantagens do aleitamento materno têm sido amplamente documentadas na literatura.

Pode-se dizer que o aleitamento materno associa perfeitamente três elementos fundamentais - alimentação, saúde e cuidados, constituindo-se na melhor alternativa para a nutrição das crianças após a gestação (UNICEF 1998).

Segundo a Organização Mundial de Saúde (OMS) o estímulo à prática da amamentação pode salvar mais vidas e prevenir mais doenças do que qualquer outra intervenção isolada. A amamentação atualmente salva a vida de seis milhōes de crianças a cada ano, prevenindo diarréia e infecçōes respiratórias agudas e é responsável por um quarto a um terço da diminuição da fertilidade observada nas últimas décadas (WHO, 1993).

Vários estudos e revisões de literatura mostram evidências sobre o papel protetor do aleitamento materno contra a mortalidade infantil VICTORA et al. 1987; YOON et al.1996; MONTEIRO et al. 1990; JELLIFE e JELLIFE 1978; FEACHEM e KOBLINSKY 1984; JASON et al 1984; CUNNINGHAM et al 1991; VICTORA, 1996)

Uma recente meta-análise baseada em seis estudos realizados em diferentes países em desenvolvimento (Brasil, Gâmbia, Gana, Paquistão, 
Filipinas e Senegal) estimou o risco relativo de morte por doenças infecciosas em crianças não amamentadas com menos de dois anos.

Segundo o estudo, crianças menores de dois meses não amamentadas têm 6 vezes mais chance de morrer quando comparadas às crianças amamentadas; esse risco declinou com a idade, sendo de $4,1\left[I C_{95 \%}=2,7-6,4\right]$ para crianças entre 2-3 meses; $2,6\left[I C_{95 \%}=1,6-3,9\right]$ entre $4-5$ meses; 1,8 $\left[I C_{95 \%}=1,2-2,8\right]$ entre 6-8 meses; $1,4\left[I C_{95 \%}=0,8-2,6\right]$ para aquelas entre 9 e 11 meses. Nos seis primeiros meses de vida, o excesso de mortalidade de crianças não amamentadas foi maior para mortes por diarréia $(6,1)$ do que para mortes por doenças respiratórias $(2,4)$. Já entre 6 e 11 meses, a proteção foi similar para as duas doenças (1,9 e 2,5 respectivamente). No segundo ano de vida, o excesso de mortalidade das crianças não amamentadas variou entre 1,6 e 2,1 WHO COLLABORATIVE STUDY TEAM ON THE ROLE OF BREASTFEEDING ON PREVENTION OF INFANT MORTALITY, 2000).

Estudos mostram que o leite materno protege contra a mortalidade neonatal, prevenindo enterocolites necrotizantes e septicemias, causas freqüentes de óbito em recém-nascidos prematuros (NARAYANAN et al, 1984; LUCAS e COLE, 1990; ASHRAF et al, 1991).

Há ainda algumas evidências de que o aleitamento materno confere proteção contra morte súbita na infância (MITCHEL et al, 1993; FORD et al, 1993).

Investigações têm sido realizadas sobre a proteção do aleitamento materno contra outras enfermidades, como infecções do trato urinário (MARILD 
et al, 1989; PISACANE et al, 1992); diabetes mellitus tipo 1 (KARJALAINEN et al, 1992; VIRTAMEN et al, 1993; ELLIS e ATKINSON, 1996; GIMENO e SOUZA, 1998); otite média aguda (DUNCAN el al, 1993); linfomas e leucemias (SHU et al, 1995; DAVIS et al, 1998; BENER et al, 2001), processos alérgicos (SAARINEN e KAJOSAARI, 1995) e asma (ROMIEU et al, 2000; WRIGHT el al 2001).

Estudos recentes têm investigado o efeito da amamentação sobre a prevenção da obesidade na infância. GILLMAN et al (2001), analisando uma coorte de aproximadamente 15.000 crianças, verificaram que adolescentes que tinham sido amamentados de forma exclusiva ou predominante nos primeiros seis meses de vida tiveram um risco significativamente menor de desenvolverem sobrepeso quando comparados àqueles que foram alimentos com fórmulas infantis.

É importante destacar que as vantagens do aleitamento matemo para a saúde infantil têm sido demonstradas mesmo em paises desenvolvidos, em particular seu efeito protetor contra diarréias, doenças respiratórias e infecções urinárias e seu importante papel para a sobrevivência de recém-nascidos prematuros (WOOLRIDGE et al.1993). Em paises desenvolvidos crianças alimentadas com fórmulas demandam até cinco vezes mais hospitalizações do que as crianças amamentadas (DE ZOYSA et al. 1990).

Além dos benefícios para a saúde das crianças, são também relatadas vantagens do aleitamento materno para a saúde materna, incluindo a proteção contra hemorragia no pós-parto (CHUA et al, 1994); osteoporose (BLAWW et al, 
1994; JONES et al, 2000); fratura de quadril (CUMMINGS e KLINEBERG, 1993); câncer de ovário (ROSENBLATT et al, 1993); câncer de mama (HARDY et al, 1993; ZHENG et al, 2000; CHANG-CLAUDE et al, 2000) e esclerose múltipla (PISACANE et al, 1994).

É importante lembrar que a amamentação propicia uma forte interação física e psicológica entre mãe-bebê, influenciando positivamente no desenvolvimento e socialização da criança (HARFOUCHE 1980; MARCOLINI 1993; LAWRENCE E LAWRENCE 1999).

A praticidade é outra vantagem citada por algumas mulheres, ao relatarem sua experiência em relação à amamentação (ARAÚJO, 1997).

Estudos evidenciam o impacto positivo do aleitamento materno sobre o desenvolvimento infantil e inteligência. HORWOOD e FERGUSON (1998), em estudo longitudinal realizado na Nova Zelândia, observaram associação entre a duração do aleitamento materno, habilidade cognitiva e rendimento escolar em crianças entre 8 a 18 anos de idade. Influência positiva sobre o desenvolvimento intelectual dos lactentes, utilizando-se a Escala de Baley, foi relatada por TEMBOURY et al (1994). LANTING et al (1994) ao analisarem crianças aos 9 anos de idade verificaram que aquelas que tinham sido alimentadas exclusivamente com fómulas ou que haviam recebido suplementação nas três primeiras semanas de vida apresentaram o dobro do risco de disfunção neurológica em relação àquelas que haviam sido amamentadas exclusivamente por pelo menos 21 dias. Estudo de seguimento de bebés prematuros, realizado na Inglaterra, relata que crianças alimentadas 
com leite matemo mostraram um quociente de inteligência significativamente maior aos 7,5-8 anos de idade comparadas àquelas que não o receberam (LUCAS et al.1992).

Vale a pena ressaltar que o aleitamento materno é extremamente vantajoso sob o ponto de vista econômico, tanto para as familias como para as instituições de saúde. Estudos realizados na Costa do Marfim e na França mostram que o custo para a manutenção de uma dieta adequada para a mãe lactante é muito inferior ao de adquirir substitutos do leite materno (NURTURE 1990; BITOUN 1994). HUFFMAN et al (1991) relatam que uma maternidade em Honduras passou a economizar 16.500 dólares ao ano após a implantação de um programa de promoção do aleitamento materno.

\subsection{Mecanismos de proteção do leite humano}

Os beneficios da amamentação para a saúde infantil são atribuídos especialmente a aspectos nutricionais e imunológicos.

O leite humano é o alimento ideal para o crescimento e desenvolvimento dos lactentes, devido às suas propriedades físico-quimicas e à sua especificidade em relação às necessidades nutricionais da criança.

Com relação aos aspectos imunológicos, sabe-se hoje que o leite humano é uma substância viva de grande complexidade biológica, ativamente protetora e imunomoduladora. Proporciona proteção exclusiva contra infecções e alergias e estimula o desenvolvimento adequado do sistema imunológico da 
criança, além de possuir inúmeros componentes antiinflamatórios (AKRÉ, 1994).

Os problemas metodológicos dos primeiros estudos sobre os efeitos protetores do leite materno em paises desenvolvidos levaram a uma série de dúvidas, pois não se distinguia precisamente o tipo de alimentação dos bebês. Dada a importância da flora intestinal nas doenças, é fundamental diferenciar bebês exclusivamente amamentados desde 0 nascimento daqueles que receberam suplementos no periodo neonatal e depois somente leite materno; bebês amamentados e suplementados desde o nascimento com leite artificial e bebês alimentados artificialmente desde o nascimento. Além disso, é necessário considerar todos os outros fluidos e sólidos fomecidos ao bebê, além do leite materno.

$\mathrm{Na}$ tentativa de solucionar esses problemas metodológicos, um estudo realizado na Escócia acompanhou 674 binómios mãe-filho por 2 anos. Esse estudo mostrou que bebês amamentados por 3 meses ou mais tinham substancialmente menos doenças gastrointestinais no primeiro ano de vida do que os artificialmente alimentados desde 0 nascimento ou que foram desmamados precocemente. Essa redução na morbidade foi encontrada independente da introdução de suplementos antes da $13^{\mathrm{a}}$ semana de vida e manteve-se após a interrupção da amamentação. Por outro lado, bebês amamentados por menos de 13 semanas apresentaram freqüência de doença gastrointestinal semelhante à observada nos bebês alimentados por mamadeira (HOWIE 1989). 
A proteção conferida pela amamentação é mais evidente em idade precoce, sendo proporcional à sua freqüência e duração. Ao nascer a criança enfrenta problemas de colonização por microorganismos, toxinas produzidas pelos patógenos e ingestão de antígenos macromoleculares, que podem causar reações patológicas se lhes for permitido cruzar a barreira gastrointestinal. Os mecanismos de defesa do bebê são imaturos aos nascer, mas a profusão de substâncias imunológicas e fatores de crescimento veiculadas no colostro e no leite materno maduro protegem a mucosa intestinal contra a invasão, modificam o meio ambiente intestinal, suprimem o crescimento de alguns microorganismos patogênicos, destroem outros, estimulam a maturação epitelial e aumentam a produção de enzimas digestivas (AKRÉ, 1994).

A proteção conferida ao bebê é substancial. Estimou-se que um bebê amamentado de forma exclusiva recebe $0,5 \mathrm{~g}$ de $\operatorname{lgA}$ secretória (IgAs) por $\mathrm{Kg}$ de peso por dia, a qual recobre a mucosa do intestino tomando-a impermeável a patógenos, ligando-se a toxinas, bactérias e antígenos macromoleculares, impedindo seu acesso ao epitélio (AKRÉ 1994).

Além das IgAs, outras substâncias têm papel imunológico, como a lactoferrina, que se liga ao ferro competindo com bactérias ferro-dependentes, sendo bacteriostática; o fator bífidus, que promove a colonização intestinal com lactobacilos na presença de lactose, resultando em baixo $\mathrm{pH}$ na luz intestinal e inibindo o crescimento de E. coli, bactérias Gram-negativas e fungos.

Estudos recentes indicam ainda a presença de outros fatores com funçōes imunológicas específicas (anticorpos especificos contra patógenos 
maternos, Rotavirus, G. lamblia e fragmentos virais não replicáveis que estimulam respostas antigênicas nos bebês).

Atualmente investiga-se a possibilidade da amamentação exclusiva proteger as crianças contra a transmissão vertical do HIV. Recentemente, na Africa, COUTSOUDIS et al. (1999) mostraram que crianças de mães HIV + amamentadas exclusivamente mostraram menor probabilidade de estarem infectadas aos 3 meses $(14,6 \%)$ quando comparadas com crianças que foram parcialmente amamentadas $(24,1 \%)$. Os autores sugerem que a alimentação artificial poderia danificar o intestino da criança, tanto por infecção quanto por reação alérgica, o que poderia facilitar a penetração do vírus.

\subsection{Vantagens do aleitamento materno exclusivo}

Embora fossem conhecidas as vantagens da amamentação, foi somente nos anos 80 que se tornou evidente que sua prática, de forma exclusiva, é muito mais segura do que o aleitamento misto. Além disso, evidenciou-se que oferecer água, chás e mingaus é igualmente prejudicial para a saúde das crianças (GIUGLIANI, 2001).

Nos últimos 15 anos, as evidências favoráveis à prática da amamentação exclusiva aumentaram consideravelmente. Atualmente já não existem mais dúvidas de que a ingestão de água, outros liquidos ou alimentos na vigência da amamentação aumenta os riscos de doenças, tem um impacto negativo sobre o 
crescimento, reduz a duração total da amamentação e encurta o período de amenorréia lactacional (GIUGLIANI, 2001).

A proteção do leite humano contra mortes por doenças infecciosas é muito mais evidente quando as crianças são exclusivamente amamentadas.

Em uma revisão de trinta e cinco estudos realizados em diferentes paises, FEACHEM e KOBLINSKY (1984) mostram que quando crianças não amamentadas são comparadas àquelas que recebem leite materno de forma exclusiva, a média de riscos relativos de morbidade por diarréia varia de 3,5 a 4,9 nos primeiros seis meses de vida, havendo evidências de aumento da severidade da diarrréia entre as crianças que recebem alimentação artificial.

Ainda na década de 80 , um estudo de casos e controles realizado no Brasil mostrou que, no primeiro ano de vida, crianças que não eram amamentadas tinham uma chance muito maior de morrer por diarréia (14 vezes maior) ou doença respiratória (3,6 vezes) quando comparadas com crianças exclusivamente amamentadas. O risco das crianças não amamentadas de morrer por diarréia era maior durante os primeiros dois meses de vida (22 vezes) (VICTORA et al, 1987).

ANIANSSON et al (1994), em um estudo realizado na Suécia, mostraram que crianças em aleitamento materno exclusivo tinham menos otite média do que crianças em aleitamento artificial. Entre 1 e 3 meses de idade, $6 \%$ das crianças já desmamadas tinham otite média contra $1 \%$ entre as que eram exclusivamente amamentadas. 
Resultados de recente estudo realizado no Brasil mostram que a chance de hospitalização em decorrência de pneumonia foi 17 vezes maior em crianças não amamentadas durante o primeiro ano de vida e 61 vezes maior nos três primeiros meses, quando comparadas a crianças exclusivamente amamentadas (CÉSAR et al 1999). Esses dados corroboram os achados de VICTORA et al (1996), de que a amamentação, além de diminuir a incidência de episódios de várias doenças infecciosas (como diarréia, infecções respiratórias, otite média e outras), atua também contra a severidade dessas doenças.

BETRÁN et al (2001), analisando o efeito do aleitamento matemo sobre a mortalidade infantil em 16 paises da América Latina, concluiram que, nesta região, $66 \%$ das mortes causadas por diarréia e infecções respiratórias seriam preveniveis pela amamentação exclusiva na faixa etária de 0-3 meses de idade.

Em Gâmbia, onde a mortalidade neonatal é de 39 por 1000 nascidos vivos, $57 \%$ dos óbitos neonatais são de causa infecciosa e $30 \%$ relacionados à prematuridade, sendo os alimentos pré-lácteos um importante fator de risco para esses óbitos (OR=3,4) (LEACH et al 1999).

$\mathrm{Na}$ Europa, um estudo multicêntrico prospectivo mostrou que a mortalidade devido à enterocolite necrotizante foi 10,6 vezes maior entre prematuros que recebiam somente leite artificial e 3,5 vezes maior entre os que estavam em aleitamento misto, quando comparados a recém-nascidos alimentados exclusivamente com leite materno (LUCAS e COLE 1990).

A proteção do leite matemo tem inicio logo após o nascimento, porém seu efeito protetor pode ser reduzido substancialmente se as crianças recebem 
qualquer outro líquido além do leite materno, incluindo água e chás. A prevalência de diarréia pode dobrar quando água e chás são oferecidos em adição ao leite matemo para crianças peruanas e filipinas com menos de seis meses de idade, comparadas a crianças em amamentação exclusiva (BROWN et al, 1989; POPKIN et al 1990).

Existem evidências de que não há necessidade de oferecer suplemento hídrico para crianças amamentadas exclusivamente (ALMROTH, 1978; GOLDBERG, 1983; BROWN et al, 1986). SACHDEV et al. (1991) mostraram que crianças exclusivamente amamentadas são capazes de manter a homeostase hidrica mesmo durante os meses de verão de um pais tropical, sob condições que aumentam as perdas de água (altas temperaturas e clima seco).

É importante lembrar que as crianças amamentadas que recebem outros alimentos e/ou líquidos não nutritivos acabam por ingerir uma quantidade menor de leite materno do que aquelas que são exclusivamente amamentadas, em decorrência de um número menor de mamadas e de uma ingestão menor de leite materno em cada mamada. (SACHDEV e et al, 1991).

Muitos estudos mostram que a introdução precoce de suplementos (água/chás) e alimentos complementares podem diminuir a duração total do aleitamento matemo (POPKIN et al, 1983; WINIKOFF et al, 1989; ZEITLLIN e ASHMED, 1995).

Um outro aspecto importante da amamentação exclusiva é relacionado à fertilidade da mulher, sendo já comprovado que a sua prática pode prolongar o período de amenorréia lactacional (GRAY et al 1990), aumentando o intervalo 
entre as gestações e conseqüentemente levando a uma diminuição da mortalidade infantil (HOBCRAFT et al 1985). É importante lembrar que o LAM (Lactational Amenormoeae Method) consiste na prática da amamentação exclusiva (inclusive no periodo noturno), na ausência de menstruação materna até os seis meses de vida do bebê. Quando praticado dessa forma, há indícios de que a proteção conferida contra uma nova gravidez seja semelhante à da pilula anticoncepcional, de $98 \%$ (WHO, 1993).

Somando-se às vantagens já apresentadas, a amamentação exclusiva reduz custos para as famílias e para o sistema de saúde. Hospitais economizam com mamadeiras, bicos e fórmulas infantis; menos medicamentos para favorecer a contratilidade uterina no pós-parto e para tratar infecções neonatais. SANGHVI (1996), após revisar os custos e benefícios da amamentação exclusiva em três hospitais no Brasil, Honduras e México, concluiu que a promoção dessa prática é altamente custo-efetiva para a prevenção de episódios de diarréia e para o ganho de "anos de vida ajustados por incapacidade".

Por todos os benefícios apresentados, a promoção do aleitamento materno exclusivo é considerada uma das mais vantajosas intervenções em saúde (SANGHVI, 1996).

A duração ideal da amamentação exclusiva tem sido objeto de debate entre especialistas ao longo de vários anos. Até recentemente, a OMS recomendava que as crianças deveriam ser amamentadas exclusivamente do nascimento até pelo menos quatro meses e, se possível, seis meses de idade. 
Algumas crianças poderiam requerer complementação alimentar antes dos seis meses se não estivessem ganhando peso adequadamente, apresentassem sinais de fome ou interesse por outros alimentos (WHO, 1998).

No ano 2000 a OMS iniciou uma revisão sistemática sobre o tema, que foi submetida à consulta de experts em reunião técnica que ocorreu de 28 a 30 de março de 2001. Essa consulta resultou na recomendação da "amamentação exclusiva por seis meses, com introdução de alimentos complementares e continuação da amamentação a partir de então. Esta recomendação é aplicável a populações. A Consulta de Experts reconhece que algumas mães poderão ser incapazes de, ou não optar por seguir esta recomendação. Essas mães deveriam também ser apoiadas a fim de otimizar a nutrição de seus filhos" (WHO, 2001).

O resultado da consulta foi aprovado pela $54^{\circ}$ Assembléia Mundial de Saúde, realizada em maio de 2001. Nessa reunião recomendou-se aos países membros "o fortalecimento de atividades e o desenvolvimento de novos caminhos para a proteção, promoção e apoio à amamentação exclusiva por seis meses como uma recomendação global da saúde pública, levando em consideração os achados da consulta de experts da OMS sobre a duração ótima da amamentação e o provimento de alimentação complementar segura e adequada, com a continuidade da amamentação por dois anos ou mais, enfatizando os canais de disseminação social desse conceitos a fim de levar as comunidades a aderir a essas práticas" (WHA54.2, 2001). 
1.4. Indicadores para a avaliação de práticas de alimentação infantil

O conhecimento dos benefícios da amamentação exclusiva criou a necessidade de que se estabelecessem indicadores mais precisos para estudar sua prática nas comunidades.

A OMS lançou em 1991 um documento propondo a padronização de categorias e indicadores para avaliação de práticas de alimentação infantil (WHO, 1991). Segundo essa proposta, as categorias de aleitamento materno seriam:

ALEITAMENTO MATERNO EXCLUSIVO OU (AME): a criança recebe apenas leite materno de sua mãe ou ama-de-leite, ou leite matemo ordenhado, e não recebe outros líquidos ou sólidos com exceção de vitaminas, suplementos minerais ou medicamentos.

ALEITAMENTO MATERNO PREDOMINANTE (AMP): a fonte predominante de nutrição da criança é o leite matemo. Porém, a criança também pode receber água e bebidas à base de água (água açucarada e com sabores, infusões, chá, etc); suco de frutas; solução de sais de hidratação oral (SRO); vitaminas, minerais e medicamentos em gotas ou xaropes, e liquidos cerimoniais (em quantidades limitadas). 


\title{
ALEITAMENTO MATERNO EXCLUSIVO OU ALEITAMENTO MATERNO PREDOMINANTE (AMEP): juntos constituem o aleitamento materno completo.
}

\begin{abstract}
ALEITAMENTO MATERNO (AM): a criança recebe leite matemo (diretamente do peito ou ordenhado), independentemente de receber ou não outros alimentos.
\end{abstract}

ALEITAMENTO MATERNO COMPLEMENTADO (AMCo) a criança recebe leite materno e alimentos sólidos (ou semi-sólidos).

Além das categorias citadas acima, consta ainda o item alimentação com mamadeira, que embora não se refira estritamente a uma categoria de alimentação da criança, foi incluído entre os indicadores devido ao seu impacto sobre o aleitamento matemo. A idéia é medir a prevalência do uso desse veículo para administração de qualquer líquido, incluindo o leite materno.

Em relação ao aleitamento materno completo, os participantes da reunião da Rede Interagencial de Informações para Saúde (RIPSA) organizada pela Organização Pan-americana de Saúde (OPAS) e o Ministério da Saúde do Brasil, em abril de 1999, julgaram que essa terminologia não expressa o significado real do indicador proposto e optaram por não recomendar, no Brasil, o uso desse termo. Nessa reunião foi recomendado o uso do termo "aleitamento materno exclusivo ou predominante", adotado nesse estudo. 
No presente estudo optamos também por utilizar os termos aleitamento materno e amamentação como equivalentes.

O documento da OMS apresenta uma proposta para a avaliação de práticas de alimentação infantil, segundo a qual são definidos quatro períodos de igual duração (4 meses) para o cálculo de indicadores, levando-se em consideração as recomendaçōes sobre alimentação infantil segundo grupos de idade.

Quadro 1 - Grupos de idade para a medida de indicadores baseados nas recomendações sobre alimentação infantil. OMS, 1991

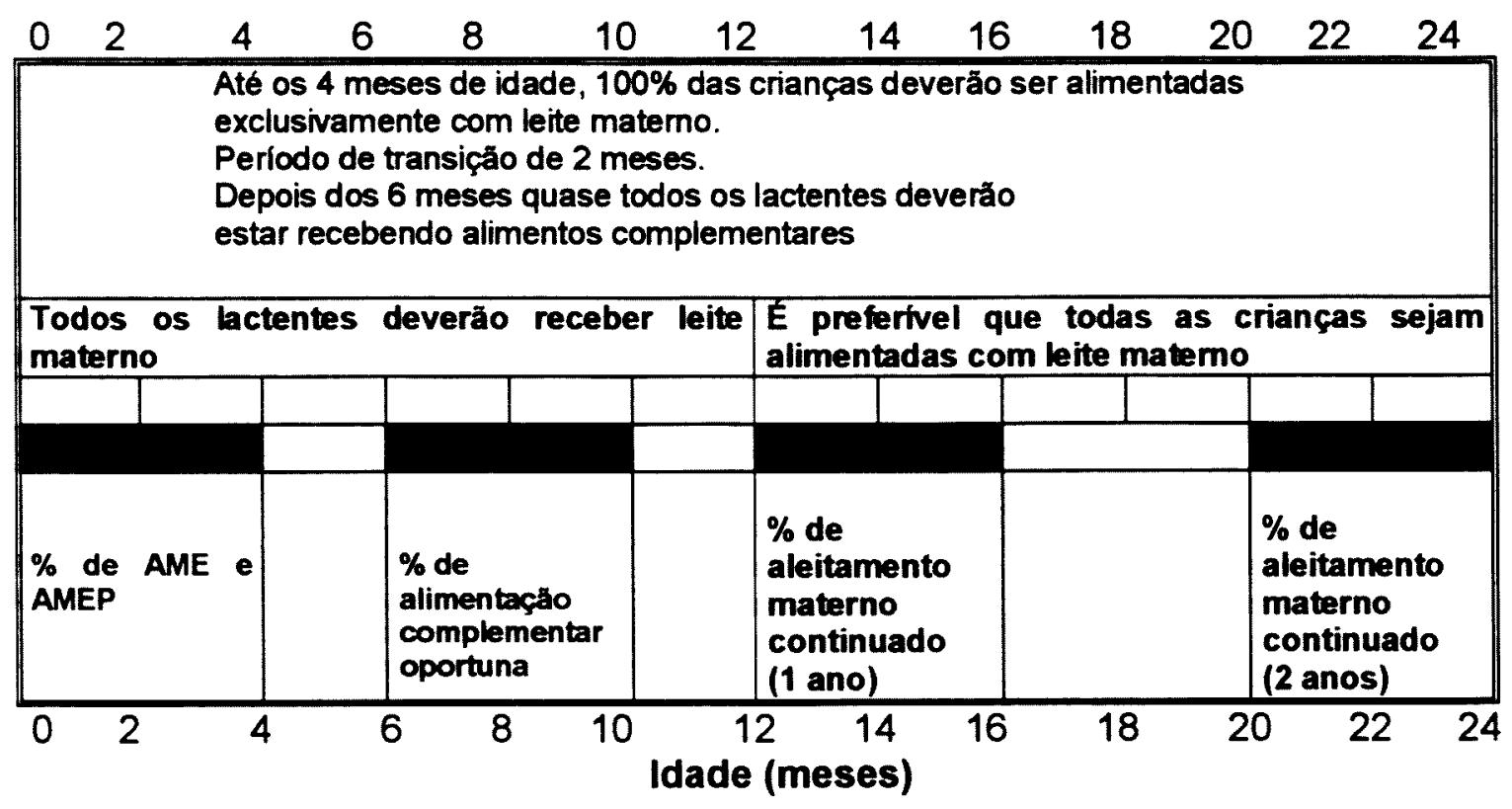


Propõe-se que os indicadores (listados a seguir) sejam obtidos utilizando-se dados atuais sobre alimentação infantil (current status), através de recordatório de 24 horas.

Quadro 2 - Indicadores propostos para avaliação das práticas de alimentação infantil. OMS, 1991.

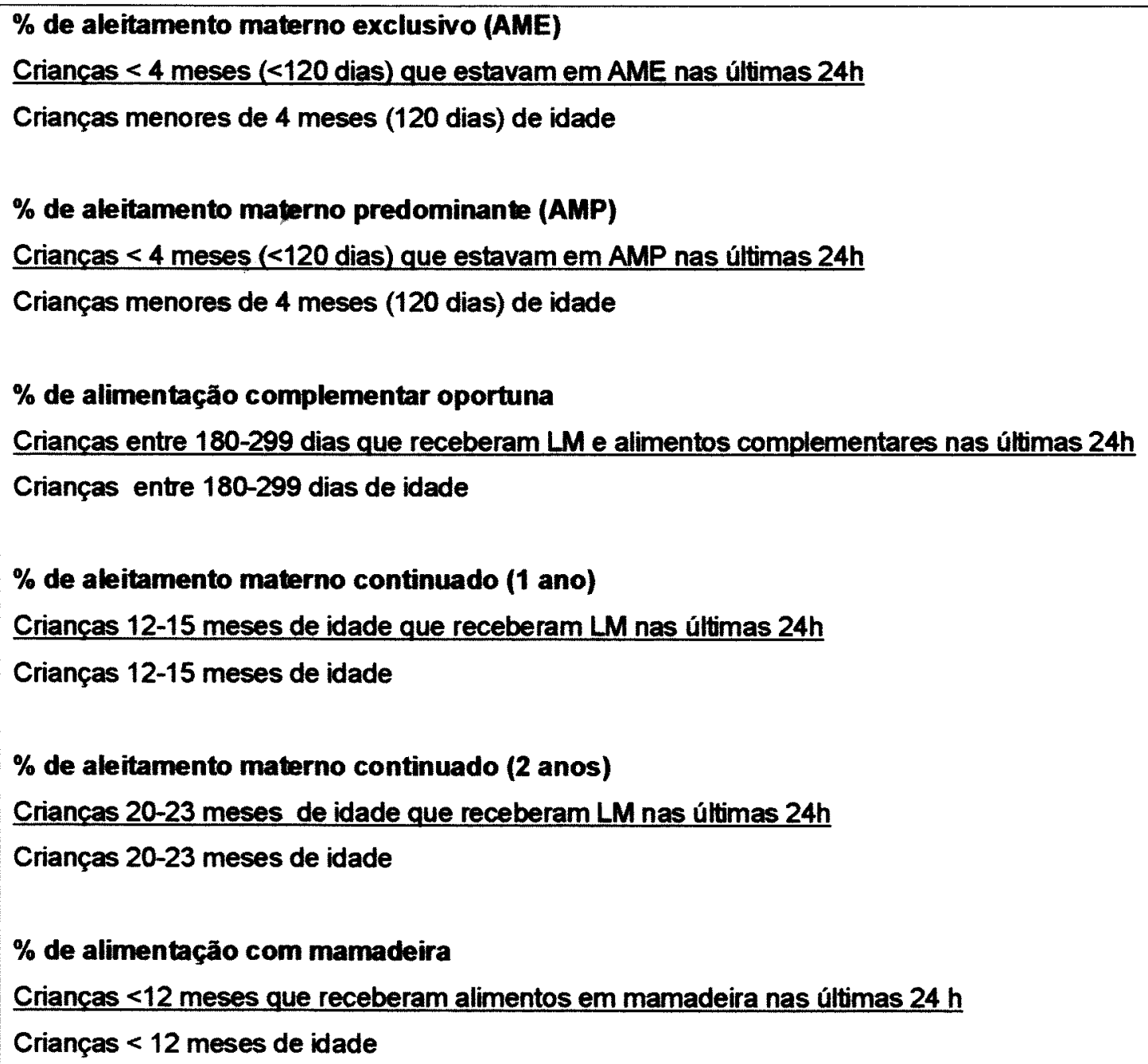


É importante frisar que, apesar de todos os esforços no sentido de popularizar uma definição precisa do aleitamento materno exclusivo, não é incomum que estudos considerem uma criança que recebe água/chá em amamentação exclusiva, o que pode subestimar o real impacto dessa prática para a saúde da criança.

Com a mudança recente da recomendação sobre a duração da amamentação exclusiva, é provável que, em breve, a OMS acrescente aos indicadores já propostos o indicador "crianças em amamentação exclusiva entre 0-6 meses".

\subsection{Situação do aleitamento materno no Brasil e no mundo}

No Brasil, apesar da escassez de dados sobre a tendência da amamentação anteriores à década de 70 , estudos regionais mostram essa prática sofreu um considerável declínio nos anos 60 e início dos anos 70 (SOUSA et al, 1975; ZUNIGA e MONTEIRO, 1995).

Estudos transversais, como o realizado por SIGULEM et al. (1980) mostram, por exemplo, que no município de São Paulo, em meados da década de 70 , a duração mediana da amamentação era de aproximadamente 1 mês.

Já a partir da década de 80 , estudos regionais mostram uma tendência de retorno à amamentação.(MONTEIRO et al. 1987; MARTINS FILHO e SANGED 1987; REA e BERQUÓ, 1990) 
A Pesquisa Nacional sobre Saúde e Nutrição (PNSN) de 1989 revelou que, apesar de a maioria das crianças brasileiras iniciar a amamentação, a introdução de outros alimentos era intensa logo nos primeiros dias de vida. A duração mediana da amamentação estava aquém do desejado, sendo de 134 dias (LEAO et al, 1989).

Estudo comparando estimativas nacionais da freqüência de aleitamento materno (independente do recebimento de outros alimentos) evidenciou uma tendência ascendente da amamentação no Brasil entre 1974 e 1989, com sua duração mediana aumentando de 2,5 para 5,5 meses. Esta tendência foi verificada principalmente em áreas urbanas, na região Centro-sul do país, entre mulheres de maior renda e maior escolaridade NENANCIO e MONTEIRO, 1998).

Estimativas nacionais mais recentes provenientes da Pesquisa Nacional sobre Demografia e Saúde realizada em 1996 (PNDS/1996) confirmam a tendência de aumento da prática da amamentação, identificando uma duração mediana do aleitamento materno (independente do recebimento de outros alimentos) de 7 meses (BEMFAM, 1997).

Informações sobre a situação do aleitamento materno exclusivo em nosso País e em todo o mundo têm sido coletadas somente nos últimos anos, porque a importância dessa prática tomou-se conhecida há pouco tempo e a padronização das categorias e indicadores de aleitamento matemo foi proposta recentemente. 
Aparentemente, a única estimativa nacional fidedigna sobre a freqüência do aleitamento materno exclusivo em nosso País, é a da Pesquisa Nacional sobre Mortalidade Infantil e Planejamento Familiar realizada em 1986 (PNMIPF/1986). Essa pesquisa evidenciou que apenas $3,6 \%$ das crianças brasileiras entre 0-4 meses de idade recebiam somente o leite materno, sem qualquer outro líquido ou alimento sólido. Em face da forma como foi estruturado o questionário alimentar da PNDS/1996, a real freqüência do aleitamento materno exclusivo foi superestimada, pois para as mães que declaravam ao entrevistador que "davam só peito", não se perguntava sobre o consumo de água, chá e outros alimentos nas últimas 24 horas (MONTEIRO, 1997).

Analisando a proporção de crianças entre 0-4 meses recebendo exclusivamente leite materno ou leite materno acrescido de água, chá ou suco nos inquéritos de 1986 e 1996, MONTEIRO (1997) verificou aumento de 33,3\% para $55,3 \%$. Ainda segundo esse autor a prática da amamentação no Brasil entre $10-14$ meses de idade aumentou de $27,5 \%$ para $37,1 \%$, e entre $22-26$ meses de $10,2 \%$ para $15,5 \%$, mostrando que a manutenção da amamentação por pelo menos dois anos de vida, tal como é recomendada, não é o que se verifica em nosso País até o momento.

As estimativas provenientes do Banco de Dados da Organização Mundial de Saúde, publicados em 1996, mostram a situação global da amamentação, com base em dados representativos de 61 dos 190 dos paises membros, com uma cobertura de $58 \%$ da população infantil mundial (WHO, 1996). 
Os principais achados são resumidos na Tabela 1. Estima-se que $35 \%$ das crianças abaixo de 4 meses sejam exclusivamente amamentadas no mundo, enquanto que a duração mediana da amamentação seria de 18 meses.

Na Europa verificou-se a pior situação de aleitamento matemo exclusivo ( $16 \%$ das crianças entre 0 e 4 meses). Na África, embora se estime uma duração mediana da amamentação de 21 meses, apenas $19 \%$ das crianças abaixo dos 4 meses estariam em aleitamento matemo exclusivo. Comportamento distinto foi verificado no Sudeste asiático, onde praticamente metade das crianças menores de 4 meses seriam exclusivamente amamentadas e a duração mediana da amamentação seria de 25 meses. A menor duração mediana de amamentação foi encontrada nas Américas (10 meses).

Estimativas para países da América Latina mostram que a prática da amamentação exclusiva em menores de 4 meses não é uniforme. Temos, por exemplo, a Bolívia e o Peru com prevalências relativamente altas (53\% e $41 \%$ respectivamente), e paises onde as prevalências são bastante baixas, como a Colômbia (17\%), República Dominicana (10\%) e Paraguai (7\%). 
Tabela 1. Amamentaçăo exclusiva e duração mediana da amamentaçăo no mundo, 1996

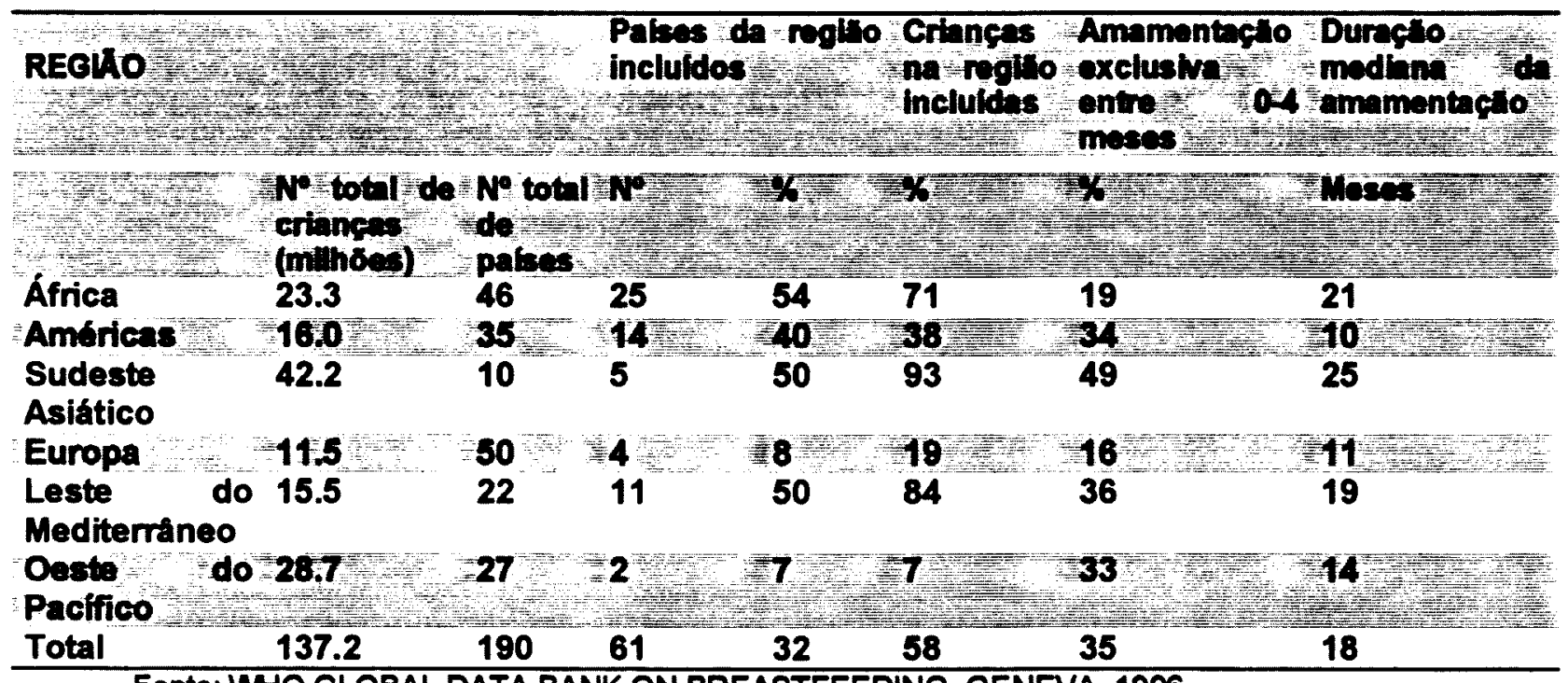

Fonte: WHO GLOBAL DATA BANK ON BREASTFEEDING, GENEVA, 1996.

\subsection{Proteçåo, promoçåo e apoio ao aleitamento materno}

Apesar da superioridade do leite matemo em relação aos leites artificiais, o declínio da amamentação é um fenômeno relatado em todo o mundo.

Embora esse fenômeno deva ser interpretado como resultado da interação complexa de diversos fatores sócio-culturais, algumas questōes merecem ser destacadas, como o processo de industrialização, que teve início no final do século XIX; as mudanças estruturais da sociedade que acontecerem em virtude da industrialização; a inserção da mulher no mercado de trabalho; o surgimento e a propaganda de leites industrializados; a adoção, nas matemidades, de rotinas pouco facilitadoras do aleitamento materno e a adesão 
dos profissionais de saúde à prescrição da alimentação artificial (MULLER 1974; JELLIFE e JELLIFE 1978; GOLDEMBERG 1989; PALMER, 1993).

As conseqüências desastrosas do desmame precoce, que passaram a ser evidenciadas nos países em desenvolvimento em meados da década de 70 , levaram à mobilização da sociedade para o retomo à amamentação.

A partir da década de 80 , a Organização Mundial de Saúde - OMS e o Fundo das Nações Unidas para a Infância - UNICEF direcionaram esforços para a instituição de uma política de incentivo à amamentação. Ações de proteção (ações políticas, normas ou leis), promoção (divulgação junto à mídia) e apoio (aconselhamento e orientação às mães) ao aleitamento materno passaram a ser implementadas como as bases dessa política.

Em nivel internacional, alguns fatos merecem destaque, como a adoção de um Código de Comercialização dos Substitutos do Leite Materno (OMS, 1981); a publicação do texto "Proteção, promoção e apoio ao aleitamento materno: o papel dos serviços de saúde (OMS/UNICEF 1989), que apresenta os Dez Passos para o Sucesso do Aleitamento Matemo e o lançamento da Iniciativa Hospital Amigo da Criança (OMS, 1991).

No Brasil, com a criação do Programa Nacional de Incentivo ao Aleitamento Materno (PNIAM) em 1981, tem início uma intensa campanha próamamentação junto à mídia e uma proposta de atuação abrangente, em diversos setores, como capacitação de profissionais de saúde, desenvolvimento de pesquisas, redirecionamento da estrutura das maternidades, criação da Norma de Comercialização de Alimentos para Lactentes (NBCAL), 
implementação de leis de proteção à mulher trabalhadora, dentre outras (REA, 1990).

Com a assinatura da Declaração de Innocenti (WHO, 1991), o Brasil assumiu o compromisso de desenvolver ações de proteção, promoção e apoio à amamentação.

No tocante à proteção do aleitamento matemo, os principais avanços conquistados na legislação são resumidos a seguir:

\section{Alojamento Conjunto}

- 1982 - Portaria 18 do Inamps/Ministério da Saúde, que estabeleceu a obrigatoriedade do alojamento conjunto.

- 1986 - Portaria do Ministério da Educação - MEC, tomando obrigatório o alojamento conjunto nos hospitais universitários.

1993 - Portaria GM/MS n 1016, com a atualização das normas.

\section{Norma de Comercialização}

- 1988 - Aprovação, pelo Conselho Nacional de Saúde, da Norma para Comercialização de Alimentos para Lactentes (Resolução No 5), elaborada com base no Código Internacional de Comercialização de Substitutos do Leite Materno.

- 1990 - Aprovação do Código de Defesa do Consumidor, que reforça vários artigos da Norma de Comercialização de Alimentos para Lactentes. 
1992 - Aprovação, pelo Conselho Nacional de Saúde, do novo texto da Norma Brasileira para Comercialização de Alimentos para Lactentes (Resolução $N^{0} 31$ ), que inclui item específico sobre o uso de bicos e mamadeiras.

- 1992 - Acordo mundial entre o UNICEF e OMS com a Associação Intemacional de Fabricantes de Alimentos, para cessar o fornecimento gratuito ou a baixo custo de leites artificiais a matemidades e hospitais.

- 1994 - Publicado parecer N $62 / 94$ da Consultoria Jurídica do Ministério da Saúde, que redefine as penalidades para as infrações à norma.

\section{Constituição}

- 1988 - Promulgação da constituição, que assegura licença-maternidade de 120 dias, licença-paternidade de cinco dias, proteção ao trabalho da mulher e o direito às presidiárias de permanecer com os filhos durante 0 período de amamentação

\section{Estatuto}

1990 - Aprovação do Estatuto da Criança e do Adolescente - Lei No 8069, que assegura à gestante, pelo Sistema Único de Saúde, o atendimento antes e após o parto. Também trata da obrigatoriedade do alojamento conjunto. 


\section{Hospital Amigo da Criança}

- 1994 - Portaria No 1.113, do Ministério da Saúde, que assegura pagamento de $10 \%$ a mais sobre a assistência ao parto, a Hospitais Amigo da Criança vinculados ao Sistema Único de Saúde.

- 1994 - Portaria No 155, da Secretaria de Assistência à Saúde (MS), que estabelece os critérios para o credenciamento dos Hospitais como Amigo da Criança.

Com relação à promoção do aleitamento matemo, o Brasil tem se destacado pela realização da Semana Mundial de Amamentação, sendo que anualmente ocorre grande mobilização em nosso pais em torno dos temas definidos pela WABA (Wond Alliance for Breastfeeding Action) para essa comemoração.

Várias estratégias têm sido utilizadas para ampliar o apoio dado às mães lactantes, dentre as quais destaca-se a Iniciativa Hospital Amigo da Criança, que conta atualmente com cerca de 200 hospitais credenciados; a instituição de uma rede de Bancos de Leite Humano (até o momento com 141 unidades), a capacitação de profissionais de saúde no manejo e aconselhamento em amamentação (através da multiplicação do curso de Aconselhamento em Amamentação OMSMellstart e do Curso de "18 horas" OMSIUNICEF). 


\subsection{Determinantes da prática do aleitamento materno exclusivo}

Embora os determinantes da prática do aleitamento materno tenham sido bem documentados em vários paises (FORMAN, 1984; POPKIN et al, 1983; WINIKOFF et al, 1989), os estudos realizados até então não faziam distinção entre aleitamento materno e aleitamento matemo exclusivo. Essa distinção é importante porque modalidades diferentes de aleitamento matemo podem ser determinadas por diferentes fatores (ADAIR et al, 1993; PEREZ-ESCAMILLA et al, 1993)

A prevalência da amamentação exclusiva pode variar de acordo com a situação socioeconômica da mulher, porém essa relação pode variar de uma cultura para outra. Em paises industrializados, mulheres com maior escolaridade tendem a amamentar mais, enquanto nos países em desenvolvimento parece ocorrer o oposto (WILLIANSON, 1989). Em relação à amamentação exclusiva pouco se conhece sobre sua relação com o nivel socioeconômico em diferentes paises.

No último estudo populacional realizado no Brasil verificou-se uma duração mediana da amamentação exclusiva de 0,6 meses entre mulheres com menos de três anos de escolaridade e 2,1 meses para mulheres com 12 ou mais anos de escolaridade (BEMFAM, 1997).

Estudo realizado na Nigéria analisou a associação entre o aleitamento materno exclusivo e idade matema, educação materna e peso de nascimento da criança. Dentre as variáveis analisadas, somente o peso de nascimento 
mostrou associação estatisticamente significativa (e inversa) com a amamentação exclusiva. Os autores sugerem que mais estudos sobre o papel da educação matema devem ser realizados, em diferentes culturas (EREGIE, 1998).

Outro estudo realizado na área rural do mesmo pais, onde a amamentação tem em geral uma duração prolongada (em tomo de dois anos), mostrou que a introdução de alimentos pré-lácteos, chás e líquidos ritualisticos são utilizados rotineiramente. Utilizando a técnica de grupos focais, identificouse que a amamentação exclusiva é considerada perigosa para os bebês, sendo que a suplementação com água, chá e outros alimentos faz-se necessária para saciar sua sede e garantir seu desenvolvimento (DAVIES-ADETUGBO, 1997).

No Sri Lanka, um inquérito populacional foi realizado entre trabalhadoras rurais, sendo que o retorno ao trabalho e a percepção de ter leite insuficiente mostraram-se negativamente associados com a prática da amamentação exclusiva (SORENSEN et al. 1998).

No Brasil verifica-se ainda a existência de poucos estudos sobre os determinantes da amamentação exclusiva.

\subsection{Justificativa do estudo}

Considerando os benefícios da amamentação exclusiva e as evidências de que estamos distantes do cumprimento da meta de que todas as crianças sejam exclusivamente amamentadas até os seis meses de vida, justifica-se a 
necessidade de realização de estudos sobre fatores associados a essa prática em nosso pais.

Os estudos sobre determinantes da amamentação têm se limitado a avaliar a influência de atributos individuais (das crianças e/ou das mães), deixando de considerar variáveis contextuais que poderiam igualmente influenciar a freqüência dessa prática, como por exemplo, a atuação dos serviços públicos de saúde e a caracterização socioeconômica e demográfica dos municipios onde as crianças residem.

A situação da amamentação exclusiva no Estado de São Paulo (ESP) merece especial atenção, por sua dimensão populacional e por situar-se em um contexto extremamente favorável à introdução precoce de suplementos, em função da maioria de sua população viver em áreas urbanas. $O$ efeito negativo da urbanização sobre a amamentação foi descrito em vários estudos (PÉREZESCAMILLA, DEWEY, 1992; PÉREZ-ESCAMILLA, 1993; TRUSSEL et al 1992).

O diagnóstico da situação da amamentação exclusiva no ESP, bem como a identificação de fatores individuais e contextuais associados a essa prática, poderão ser de grande utilidade para a definição de estratégias de proteção, promoção e apoio ao aleitamento materno. 


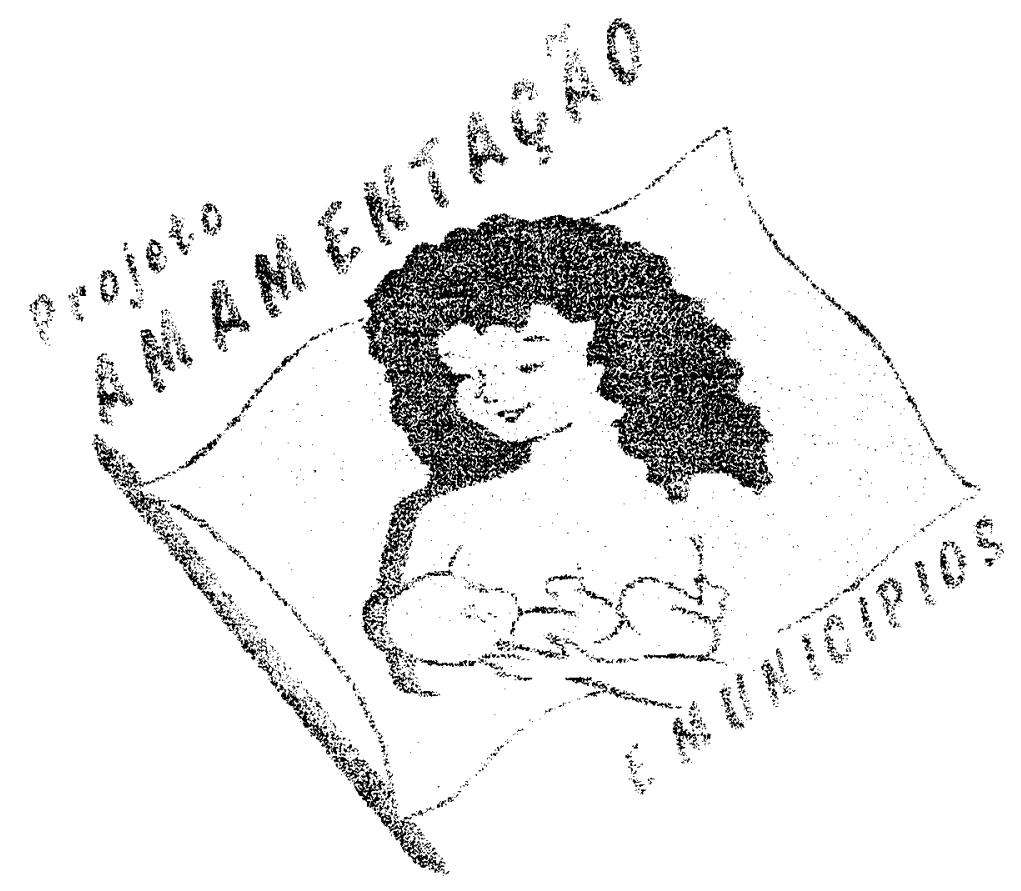

2. OBJETIVOS

A vida só é possivel reinventada.

(Cecillia Meireles) 


\subsection{OBJETIVO GERAL}

- Analisar a influência que fatores individuais e contextuais exercem sobre a freqüência do Aleitamento Matemo Exclusivo nos primeiros seis meses de vida em 111 municípios do Estado de São Paulo.

\subsection{OBJETIVOS ESPECÍFICOS}

- Identificar e quantificar a influência exercida por atributos individuais, relacionados às crianças e às suas mães;

- Identificar e quantificar a influência exercida por variáveis contextuais, relacionadas aos municípios onde residem as crianças e suas mães (variáveis sócio-econômico-demográficas e relacionadas à proteção, promoção e apoio ao aleitamento matemo);

- Identificar a influência exercida por possíveis interações entre variáveis individuais e contextuais. 


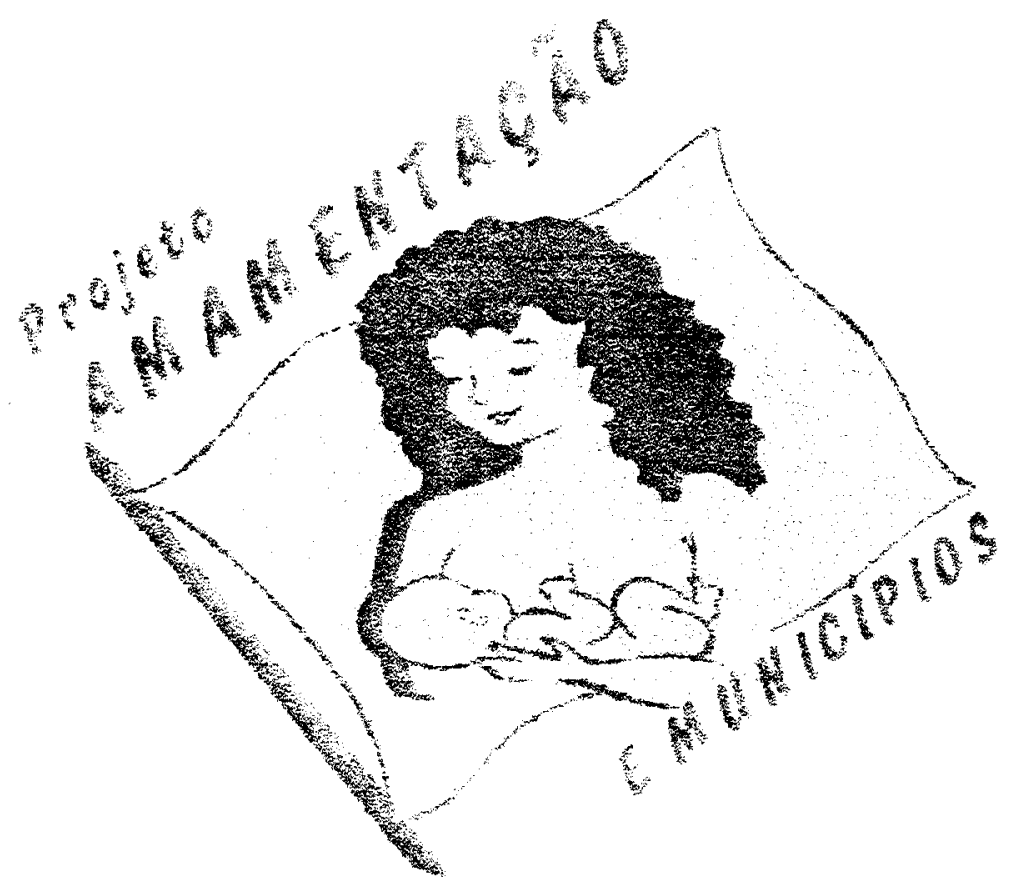

\section{METODOLOGIA}

Caminhante não há caminho,

se faz caminho ao andar...

(Antonio Machado) 


\subsection{O Projeto "Amamentação e Municipios": Avaliação de Práticas} Alimentares em menores de um ano em Dias Nacionais de Vacinação

\subsubsection{Antecedentes}

Pensar nos municípios como pólos de incentivo à amamentação parece ser uma alternativa bastante adequada dado o contexto atual da saúde no Brasil.

A Constituição de 1988 tem como pressupostos a descentralização, compreendida como um processo de transformação que envolve a redistribuição de poder e recursos, redefinição de papéis das três esferas de govemo, reorganização institucional, reformulação de práticas, estabelecimento de novas relações entre os níveis de govemo e controle social (BRASIL, 1993). Ao dispor sobre a descentralização, o texto constitucional atribui ao Município a condição de ente federado, reconhecendo e valorizando seu papel na provisão de serviços públicos essenciais. (BRASIL, 1993).

O uso de informações epidemiológicas na gestão dos serviços de saúde vem sendo enfatizado, no processo de municipalização, como um dos importantes mecanismos para a definição de políticas locais (ALMEIDA, 1995). Conseqüentemente foram elaboradas várias estratégias com o objetivo estimular os municípios a obterem seus indicadores de saúde. 
Alguns exemplos podem ser citados, como a instituição em todos os municípios do País, pelo Ministério da Saúde, dos Indicadores da Atenção Básica, com o objetivo de gerar informações necessárias para a avaliação e planejamento de ações no nivel municipal; a elaboração e implantação de diversos sistemas de informação municipais, como o SIM (Sistema de Informação sobre Mortalidade), SINASC (Sistema de Informação sobre Nascidos Vivos); SIAB (Sistema de Informação da Atenção Básica), etc.

No tocante às práticas de alimentação infantil, especialmente o aleitamento matemo, os municípios obtêm poucas informações utilizando os sistemas disponíveis. De fato, desde a implantação do SIAB, utilizado essencialmente pelos municípios que implantaram o PSF - Programa de Saúde da Família - os municípios dispõem de um único indicador de aleitamento materno, que diz respeito ao percentual de crianças entre 0-4 meses em amamentação exclusiva. Na realidade do Estado de São Paulo, que conta com uma cobertura do PSF de apenas $12 \%$, essa informação é claramente insuficiente para o planejamento e avaliação de ações pró-amamentação.

O interesse dos municípios na realização de pesquisas sobre práticas de aleitamento materno em campanhas de vacinação pôde ser identificado em vários trabalhos de assessoria desenvolvidos pelo Núcleo de Investigação em 
Saúde da Mulher e da Criança -NISMC - Instituto de Saúde/SES/SP e do Núcleo de Pesquisas Epidemiológicas em Nutrição e Saúde da Universidade de São Paulo -NUPENS - desde meados da década de 90 (CARVALHAES et al, 1998; MONEGO et al, 1998; KITOKO e et al, 2000).

A primeira experiência de assessoria ocorreu no municipio de Botucatu, localizado no interior do Estado de São Paulo, em 1995. Embora já se soubesse ser viável a realização de pesquisas em campanhas de vacinação, optou-se, para evitar interferências no funcionamento da campanha, por aplicar um questionário bastante simplificado, contendo apenas perguntas sobre o consumo atual de leite matemo, água, chá, suco, ou outros líquidos e outros tipos de leite. O inquérito foi realizado em todos os postos de vacinação do municipio, para um total de 1550 crianças menores de um ano. Os dados foram processados utilizando-se análise de probitos para estimar a probabilidade das diferentes modalidades de amamentação em função da idade da criança. Este estudo trouxe duas importantes contribuições para a elaboração da proposta do Projeto Amamentação e Municípios. A primeira foi a conclusão de que a realização do diagnóstico da situação do aleitamento matemo, concomitante à campanha de multivacinação, mostrou-se adequada, pois a investigação atingiu uma alta cobertura, não houve prejuízo ao desenvolvimento das atividades de vacinação e as informações foram obtidas de modo rápido e com baixo custo financeiro. (CARVALHAES et al, 1998). Além disso, verificou-se que a identificação de uma duração mediana de amamentação de 17 dias gerou uma 
ampla discussão no municipio e reforçou a necessidade de continuidade de um Projeto de Promoção e Apoio ao Aleitamento Matemo. Nos anos subseqüentes, vánias trabalhos de assessoria foram requisitados por diferentes municipios brasileiros (Goiânia - GO, Rio de Janeiro - RJ, João Pessoa- PB e Florianópolis - SC). A experiência de realização do levantamento sobre práticas de alimentação infantil em João Pessoa e Florianópolis, em 1997, dessa vez ousando aplicar um questionário mais completo, com 47 questões e tempo de aplicação de aproximadamente 4 minutos, trouxe contribuições adicionais para a definição da proposta metodológica do Projeto Amamentação e Municipios. Dada a escala populacional dessas cidades, houve a necessidade de se delinear uma estratégia de amostragem para tomar viável a pesquisa, optandose, então, por trabalhar com amostras por conglomerados (nesse momento em um único estágio). Os resultados obtidos mostraram, entre outros aspectos, a existência de grandes diferenças nas práticas de alimentação infantil nas duas cidades, destacando-se o fato de que o aleitamento materno exclusivo em menores de 4 meses era duas vezes maior em Florianópolis $(46,3 \%)$ do que em João Pessoa (23,9\%). Verificou-se, ainda, a possibilidade de identificação de diferentes perfis de aleitamento matemo com a proposta empregada, a necessidade de aprofundamento sobre os porquês de tais diferenças e as vantagens de se aplicar metodologias padronizadas, superando as dificuldades para a comparabilidade dos resultados das pesquisas (KITOKO et al, 2000).

Em 1998, a partir das experiências relatadas, o projeto Amamentação e Municípios foi implementado no Estado de São Paulo. Os objetivos desse 
projeto são 1) capacitar equipes municipais para realizar inquérito epidemiológico sobre as práticas de aleitamento matemo em campanhas de vacinação, estimulando sua autonomia no processamento e análise dos dados; 2) realizar discussão com os municipios sobre os resultados da pesquisa com vistas ao planejamento de ações de proteção, promoção a apoio ao aleitamento materno no nivel municipal e 3) formar um banco de dados sobre amamentação no Estado de São Paulo para subsidiar o planejamento de ações no nível estadual.O projeto não tem por objetivo a realização de uma pesquisa sobre aleitamento matemo representativa da população de menores de um ano no Estado de São Paulo, mas sim o envolvimento de todos os municipios interessados na implementação de programas de amamentação, fornecendoIhes uma ferramenta útil para o planejamento e avaliação de suas ações.

Os critérios para a inclusão de municípios no projeto Amamentação e Municipios são a participação obrigatória em um treinamento oferecido pela equipe de assessoria, a disponibilidade para a realização da pesquisa de campo e a demonstração de interesse em implementar ações de proteção, promoção e apoio à amamentação. No seu primeiro ano de implementação o Projeto conseguiu a adesão de 84 equipes municipais. A experiência exitosa dessas equipes motivou um número ainda maior de municipios a realizar a pesquisa de campo em 1999 (89 municípios novos e 22 que repetiram a pesquisa realizada em 1998). Até o momento, 208 municipios já realizaram o inquérito, sendo que 152 o fizeram uma vez, 48 o repetiram duas vezes e 8 
municípios o realizaram três vezes. A Figura 1 mostra a adesão dos municípios no período de 1998 a 2001.

Figura 1 - Evolução da participação dos municípios no Projeto Amamentação e Municípios, 1998-2001.

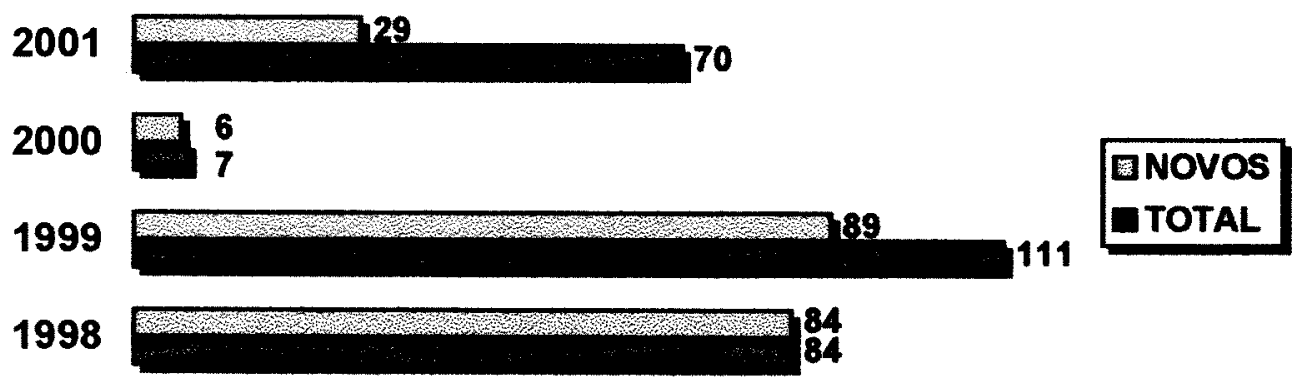

\subsubsection{Implementação da proposta}

Um treinamento é oferecido pela equipe de assessoria a todos os municípios interessados, visando à capacitação de uma equipe local para a organização da coleta de dados. Esse treinamento tem a duração de 8 horas, com o seguinte conteúdo programático: 1) Indicadores para avaliação de práticas de alimentação infantil; 2) Situação nacional do aleitamento materno; 3) Projeto Amamentação e Municípios: objetivos e metodologia; 4) Como realizar a pesquisa durante a campanha de vacinação: o papel dos supervisores locais; 5) Treinamento dos entrevistadores para a aplicação do instrumento de coleta de dados; 6) Apresentação da proposta para armazenamento e análise dos dados. 
Os participantes recebem um Manual do Supervisor (ANEXO 1), com as orientações sobre como organizar a coleta de dados no municipio e um Manual de Instruções para o Entrevistador (ANEXO 2), elaborado para padronizar o conteúdo do treinamento dos entrevistadores, fomecer orientações aos entrevistadores sobre as condutas no campo e esclarecer possiveis dúvidas sobre o instrumento de coleta de dados.

Durante o treinamento, os participantes respondem também a um questionário sobre a existência de ações de incentivo ao aleitamento materno nos municipios (ANEXO 3).

\subsubsection{Amostragem}

Os municípios com população de menores de um ano de até aproximadamente 1500 crianças (estimada em dados da campanha de vacinação do ano anterior ao da realização da pesquisa) realizam o levantamento em caráter universal, isto é, entrevistam todas as crianças menores de um ano que comparecem aos postos de vacinação.

Os municípios cuja população de menores de um ano excede 1500 crianças realizam o levantamento por meio de uma amostra por conglomerados em dois estágios, seguindo procedimentos recomendados por SILVA (1998). Estipulou-se um tamanho fixo de amostra de 1000 crianças, o qual permite estimar, com 95\% de certeza, a prevalência de diferentes eventos relacionados à saúde infantil, dentro de intervalos de confiança de no máximo mais ou menos 
3\% (COLTON, 1974) Vale lembrar que essa precisão é esperada para eventos cuja prevalência seja de $50 \%$, sendo que para eventos mais raros ou mais freqüentes a precisão é ainda maior. Esse tamanho de amostra vem sendo adotado em pesquisas realizadas pelo NUPENS/USP, para estimar diferentes indicadores de saúde e nutrição das crianças de São Paulo (MONTEIRO, 1988).

Considerando que as crianças não estão distribuídas uniformemente nos vários postos de vacinação (conglomerados), adota-se o sorteio em dois estágios, com probabilidade proporcional ao tamanho dos conglomerados. No primeiro estágio são sorteados os postos de vacinação e no segundo estágio são sorteadas as crianças em cada posto, de forma sistemática. A amostra desenvolvida é considerada equiprobabilística ou autoponderada, já que a fração amostral mantém-se constante a partir da expressão: $f=f_{1} . f_{2}$, ou seja, todas as crianças têm a mesma probabilidade de pertencer à amostra sorteada. Os postos maiores têm maior probabilidade de serem sorteados no primeiro estágio $\left(f_{1}\right)$ e as crianças dos postos menores têm maior probabilidade de sorteio no segundo estágio $\left(f_{2}\right)$. 


\subsubsection{Instrumento de coleta de dados}

O instrumento proposto (ANEXO 4) para coleta de dados evita questões abertas e inclui para todas as crianças questões sobre o consumo nas últimas 24 horas de leite matemo, outros tipos de leite e outros alimentos, incluindo água, chás e outros liquidos, seguindo as recomendações da OMS para levantamentos sobre amamentação (WHO, 1991). Permite, dessa forma, definir com precisão se a criança recebeu ou não leite matemo de forma exclusiva nas 24 horas que antecederam a pesquisa.

A utilização do "current status", ou seja, dos dados atuais sobre alimentação infantil, evita erros devido à memória do informante (NOTZON, 1984), sendo particularmente vantajosa quando se estuda amamentação exclusiva.

O questionário inclui também questões que caracterizam as crianças quanto à situação de nascimento, utilização da rede pública para a realização de puericultura e dados sócio-econômico-demográficos. Algumas questōes retrospectivas foram incluídas (somente para os menores de quatro meses de idade) para verificar a alimentação das crianças no primeiro dia em casa após a alta hospitalar. Com isso busca-se, de forma indireta, conhecer as orientações dadas às mães sobre amamentação exclusiva nas matemidades.

O instrumento elaborado é suficientemente simples para ser aplicado por pessoal não especializado como funcionários dos serviços de saúde, estudantes universitários ou mesmo estudantes de segundo grau. De qualquer 
forma, todos os entrevistadores recebem um treinamento e um manual de instruções com todos os procedimentos que devem ser seguidos em campo.

\subsubsection{Armazenamento dos dados}

No ano de 1999, com o apoio financeiro do UNICEF, elaborou-se um aplicativo no programa ACCESS denominado AMAMUNIC (ANEXO 5). Esse aplicativo armazena os dados registrados nos questionários e verifica inconsistências durante a digitação (permitindo ao digitador corrigir eventuais erros), melhorando assim a qualidade da informação.

O aplicativo AMAMUNIC 1.0 gera relatórios com os indicadores de práticas de alimentação infantil propostos pela OMS (WHO, 1991), o que possibilita uma padronização da análise dos dados e maior autonomia dos municípios para trabalhar com as informações obtidas a partir da pesquisa.

O programa possui também um módulo central, elaborado para possibilitar o gerenciamento dos dados e emissão de relatórios por município e do total de crianças menores de um ano que participaram do estudo.

Os bancos de dados dos municípios gerados pelo aplicativo são encaminhados à coordenação central do projeto (Instituto de Saúde), o que possibilita uma análise comparativa da situação da amamentação nos municípios. 


\subsection{População do estudo}

No ano de 1999, 111 municipios participaram do projeto Amamentação e Municípios, realizando pesquisa de campo para avaliar as práticas alimentares de crianças menores de um ano, perfazendo um total de 66.133 crianças, sendo 34.560 menores de seis meses. No presente estudo, cujo enfoque principal é a amamentação exclusiva, serão analisados dados de 34. 435 crianças menores de seis meses, tendo sido eliminadas 125 crianças por apresentarem inconsistências em relação à idade (impossibilidade do cálculo da idade exata da criança em função de erro no preenchimento do campo referente à data de nascimento).

\subsection{Variáveis do estudo}

As variáveis consideradas no estudo são apresentadas no Quadro 3. 
Quadro 3 - Variáveis incluidas no estudo.

\begin{tabular}{|c|c|c|c|}
\hline TIPO & & VARIÁVEL & CATEGORIAS \\
\hline Desfecho & & AME & Sim/Năo \\
\hline & & FADXA ETARIA & $\begin{array}{l}0-29 \text { dias } \\
30-59 \text { dias } \\
60-89 \text { dias } \\
90-119 \text { dias } \\
120-149 \text { dias } \\
150-179 \text { dias }\end{array}$ \\
\hline & Caracteristicas & SEXO & Feminino/Masculino \\
\hline & crianças & PESO AO NASCER & $\begin{array}{l}\text { Ate } 1499 \mathrm{~g} \\
1500-1999 \mathrm{~g} \\
2000-2499 \mathrm{~g} \\
2500-2999 \mathrm{~g} \\
3000 \mathrm{~g} \mathrm{e}+\end{array}$ \\
\hline & & TIPO DE PARTO & VaginaVCesárea \\
\hline & & HOSPITAL QUE NASCEU & $\begin{array}{l}\text { Amigo da Criança } \\
\text { Näo Amigo da Criança }\end{array}$ \\
\hline Explanatória individual & & IDADE MATERNA & $\begin{array}{l}11-17 \text { anos } \\
18-19 \text { anos } \\
20-24 \text { anos } \\
25-29 \text { anos } \\
30-34 \text { anos } \\
35 \text { anos e }+ \\
\end{array}$ \\
\hline & Características & PARIDADE & PrimiparalMulkipara \\
\hline & mäes & SITUAÇÁO DE TRABALHO & $\begin{array}{l}\text { Dona de casa } \\
\text { Trab. Formal } \\
\text { Trab. Informal }\end{array}$ \\
\hline & & ESCOLARIDADE MATERNA & $1^{\circ} \mathrm{grau}$ incompleto \\
\hline & & & $1^{\circ}$ grau completo \\
\hline & & & $2^{\circ}$ grau incompleto \\
\hline & & & $2^{\circ}$ grau complato \\
\hline & & & $3^{\circ}$ grau inckcompleto \\
\hline & & SEGUIMENTO AMBULATORLAL & Rede SUSIRede privada \\
\hline & & REGIAO & Interiorl Metropolitana \\
\hline & & PORTE POPULACIONAL & Ate $10.000 \mathrm{hab}$ \\
\hline & & & $10.000 / 50.000 \mathrm{hab}$ \\
\hline & & & $50.000 \mid-100.000 \mathrm{hab}$ \\
\hline & Caracteristicas & & 100.000 hab e + \\
\hline Explanatória contextual & & $\begin{array}{l}\text { INDICE PAULISTA DE } \\
\text { RESPONSABILIDADE SOCIAL }\end{array}$ & $1 / 2 / 3 / 4 / 5$ \\
\hline & & POLITICA MUNICIPAL & Sim/Năo \\
\hline & $\begin{array}{l}\text { Açóes municipais de } \\
\text { proteção, promoçäo e } \\
\text { apoio ao aleitamento }\end{array}$ & $\begin{array}{l}\text { MONITORIZAÇĀO DA NORMA } \\
\text { BRASILEIRA DE COMERCIALLZAÇÃO } \\
\text { DE ALUMENTOS PARA LACTENTES }\end{array}$ & Sim/Näo \\
\hline & matemo & $\begin{array}{l}\text { SEMANA MUNDIAL DA } \\
\text { AMAMENTACAAO } \\
\end{array}$ & Sim/Năo \\
\hline & & HOSPITAL AMIGO DA CRIANCAA & Simnäo \\
\hline & & BANCO DE LEITE HUMANO & Sim Nä́o \\
\hline & & CURSOS & Sim/NaO \\
\hline & & EQUIPE MULTIPROFISSIONAL & SimNá \\
\hline & & PESQUISA SOBRE AM & Sim/Não \\
\hline
\end{tabular}


A variável desfecho (ou variável dependente) do estudo é o Aleitamento Materno Exclusivo (AME). Somente para a descrição inicial do perfil do Aleitamento Matemo nos 111 municipios serão analisadas as variáveis Aleitamento materno (AM) e Aleitamento materno exclusivo/predominante (AMEP).

Foram considerados dois tipos de variáveis explanatórias (ou independentes): as relacionadas a atributos das crianças (ou de suas mães), denominadas variáveis explanatórias individuais, e as relacionadas aos municipios onde residem essas crianças, denominadas variáveis explanatórias contextuais.

As variáveis individuais expressam atributos relativos às crianças, coletados a partir dos questionários aplicados na campanha de vacinação. Apenas a variável sexo não constava originalmente do questionário, sendo recuperada a partir da análise do nome da criança no banco de dados (com $0,4 \%$ de perdas por impossibilidade de classificação). A informação sobre o peso ao nascer foi coletada da carteira de vacinação, ou, na ausência de registro dessa informação na carteira, através da informação do acompanhante da criança. Devido ao baixo percentual de partos fórceps, optou-se por criar duas categorias para a variável tipo de parto: vaginal ou cesárea. 0 questionário incluía o nome e o município de nascimento da criança, o que possibilitou identificar se a criança havia nascido ou não em um Hospital Amigo da Criança. Verificou-se também através do questionário se a criança realizava consultas de rotina na rede pública de serviços de saúde (SUS) ou na rede 
privada. As questões relacionadas a atributos maternos foram aplicadas somente quando o acompanhante da criança era a própria mãe.

As variáveis contextuais caracterizam os municipios e foram obtidas de diferentes fontes. Informações sobre a região e porte populacional foram obtidas na Secretaria Estadual de Saúde de São Paulo (www.saude.sp.gov.br). A classificação dos municípios segundo o Índice Paulista de Responsabilidade Social (IPRS) foi obtida na Fundação SEADE (www.seade.sp.gov.br). Informações sobre a existência de ações de proteção, promoção e apoio ao aleitamento materno nos municipios foram obtidas a partir de questionário respondido pelos coordenadores locais da pesquisa treinados pela equipe de assessoria.

O IPRS foi desenvolvido pela Fundação SEADE, a pedido da Assembléia Legislativa do Estado de São Paulo, dada a necessidade da existência de um indice (à semelhança do Índice de Desenvolvimento Humano - IDH) que auxiliasse o monitoramento dos compromissos assumidos pelo Fórum São Paulo Século XXI, recentemente instituído para mobilizar a sociedade paulista para a discussão de temas e problemas relevantes. A reprodução pura e simples da metodologia de cálculo do IDH, tal como sugerida inicialmente por participantes do Fórum São Paulo Século $X X I$, não foi adotada em razão da inexistência de informações atualizadas sobre renda per capita dos municípios paulistas. Esse obstáculo foi superado de forma satisfatória pela utilização de variáveis proxies da renda per capita do Censo Demográfico de 1991. 
O índice foi composto a partir das variáveis longevidade, escolaridade e riqueza municipal, sendo a classificação dos municípios apresentada no Quadro 4.

Quadro 4 - Classificação dos Grupos de Municípios com Características Distintas de Riqueza, Longevidade e Escolaridade.

\begin{tabular}{|c|c|c|c|c|}
\hline \multicolumn{5}{|c|}{ Classificação dos Grupos } \\
\hline \multirow[t]{2}{*}{ Riqueza municipal } & \multirow[b]{2}{*}{ Longevidade } & \multicolumn{3}{|c|}{ Escolaridade } \\
\hline & & Baixa: até 59 & $\begin{array}{l}\text { Média: } 60 \\
\text { a } 69\end{array}$ & $\begin{array}{l}\text { Alta: } 70 \text { e } \\
\text { mais }\end{array}$ \\
\hline \multirow[t]{3}{*}{$\begin{array}{l}\text { Baixa - escore até } \\
49\end{array}$} & ixa: até 59 & 5 & 4 & 4 \\
\hline & $\begin{array}{l}\text { Média: } 60 \text { a } \\
69\end{array}$ & 4 & 3 & 3 \\
\hline & $\begin{array}{lll}\text { Alta: } & 70 \quad \mathrm{e} \\
\text { mais } & & \end{array}$ & 4 & 3 & 3 \\
\hline \multirow[t]{3}{*}{$\begin{array}{l}\text { Alta - escore de } 50 \\
\text { e mais }\end{array}$} & Baixa: até 59 & 2 & 2 & 1 \\
\hline & $\begin{array}{l}\text { Média: } 60 \text { a } \\
69\end{array}$ & 2 & 1 & 1 \\
\hline & $\begin{array}{l}\text { Alta: } 70 \quad \epsilon \\
\text { mais }\end{array}$ & 1 & 1 & 1 \\
\hline
\end{tabular}

Fonte: Fundação SEADE. 
As ações incluídas nos questionários respondidos pelos coordenadores locais da pesquisa envolvem a proteção, promoção e o apoio ao aleitamento materno e refletem em grande parte as proposiçōes de organismos intemacionais (OMS, UNICEF, IBFAN, WABA) para a construção de uma política abrangente de incentivo à amamentação.

Quanto às ações de proteção do aleitamento matemo, perguntou-se sobre a existência de monitoramento da Norma Brasileira para Comercialização de Alimentos para lactentes -NBCAL e sobre a existência de uma política municipal forma (escrita) de amamentação. Com relação à promoção do aleitamento materno perguntou-se sobre a participação do município da Semana Mundial da Amamentação - SMAM. No caso das atividades de apoio ao aleitamento materno perguntou-se sobre a existência, no município, de Hospital Amigo da Criança - HAC e Banco de Leite Humano - BLH, assim como sobre a realização de treinamento para profissionais de saúde (Curso de 18 horas ou Aconselhamento em Amamentação) e presença de um núcleo multiprofissional dedicado à promoção e lou à pesquisa sobre amamentação. Considerou-se ainda como ação de incentivo à amamentação o fato de as autoridades de saúde do município terem realizado um ou mais levantamentos sobre a prevalência do aleitamento materno nos dois anos imediatamente anteriores a 1999. 


\subsection{Procedimentos analíticos}

Os bancos de dados dos municípios foram encaminhados ao Instituto de Saúde e importados para o módulo central do AMAMUNIC 1.0. Após verificação de consistência, os dados foram exportados para os programas EPI INFO 6.0 e SPSS 6.0, para proceder-se inicialmente à análise descritiva das variáveis que compõem o estudo.

\subsubsection{Curvas de evolução do AME e AMEP em função da idade da criança}

Existem várias altemativas para a obtenção de estimativas de AM, AMEP e AME em função da idade da criança. As alternativas vão desde técnicas extremamente simples, como o cálculo de médias móveis das proporções de crianças amamentadas nos várias idades (WHO, 1991) até formas mais complexas de modelagens estatísticas, que empregam a análise de regressão de logística, logito ou probito (FERREIRA et al, 1996; VENANCIO \& MONTEIRO, 1998; KITOKO et al, 2000; SENA, 2002). No presente estudo foram testados os modelos de probito, logito e regressão logistica incluídos no Programa SPSS 6.0 (NORUSIS, 1993), não tendo sido verificadas diferenças relevantes nas estimativas obtidas pela três técnicas. Optou-se pela regressão logística, que estima a probabilidade $P(Y=1)$ de amamentação em determinada idade, como uma função logística: $P(Y=1)=1 / 1+\exp (-\alpha-\beta x)$, onde $\alpha$ e $\beta$ são 
coeficientes de regressão e $x=$ =idade (SILVA-AYÇAGUER, 1995). As probabilidades das diferentes modalidades de AM ao longo das idades serão

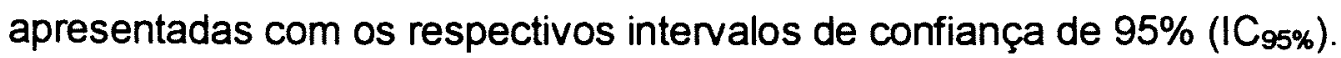

\subsubsection{Influência das caracteristicas individuais (das crianças ou de suas mães) sobre a prevalência do AME}

A associação entre caracteristicas individuais e o AME foi analisada no programa MLwiN (YANG et al, 1999), por possibilitar a obtenção de coeficientes e erros padrão que levam em consideração o processo complexo de amostragem. Inicialmente calculou-se a prevalência de AME segundo as diferentes categorias de cada uma das variáveis individuais. A seguir, tomandose as categorias que apresentaram as menores prevalências como categorias de referência, estimou-se a partir dos coeficientes e erros padrão as correspondentes razões de chance (RC) de AME e seus intervalos de confiança de $95 \%$

\subsubsection{Aleitamento Materno Exclusivo no 111 municipios estudados}

As prevalências da amamentação exclusiva nos municípios foram calculadas para os menores de 4 meses (por ser o indicador proposto pela OMS para a avaliação dessa prática) e menores de 6 meses, pois acreditamos 
que, com a nova recomendação (de AME até o $6^{\circ}$ mês), em breve o indicador passará a ser "prevalência do AME na faixa etária de 0 |-6 meses".

Os municipios que realizaram o estudo utilizando amostras tiveram seus intervalos de confiança ajustados levando em consideração o efeito de delineamento amostral. Isso se faz necessário, pois o sorteio de elementos por meio de conglomerados resulta em alterações na precisão dos intervalos de confiança (SILVA, 1998).

As prevalências e respectivos intervalos de confiança, considerando o efeito de delineamento, foram obtidas através do programa CSAMPLE do software EPIINFO 6.0. (DEAN e cols, 1994)

A distribuição geográfica dos municipios conforme a intensidade da prática do aleitamento materno foi realizada com o uso do programa TABWIN 2.0. (BRASIL, 2001)

\subsubsection{Influência das variáveis contextuais sobre a prevalência do AME}

Procedeu-se inicialmente à descrição das médias das prevalências municipais de AME conforme a classificação dos municípios diante das variáveis contextuais selecionadas, realizando-se a análise de variância para verificar a significância estatística das diferenças entre as médias, controlandose como co-variável a média das idades das crianças em cada município.

No caso das variáveis contextuais relativas a ações municipais de incentivo ao aleitamento matemo, diante da elevada correlação existente 
quanto à presença dessas ações no município, optou-se por criar, em adição às variáveis que descrevem as ações individuais, um índice representado pela somatória das ações de incentivo ao aleitamento materno encontrada em cada município. Este índice foi criado com o intuito de sumarizar a "intensidade" da atuação dos municípios no tocante ao incentivo à amamentação.

A associação entre a presença de ações de incentivo ao aleitamento materno (individuais e sumarizadas) e a freqüência do $A M E$ em crianças menores de 6 meses nos municipios foi analisada por meio de regressão linear simples e múltipla. No caso da regressão linear múltipla controlou-se o efeito das demais variáveis contextuais: média das idades das crianças; região, porte populacional e IPRS do município. A significância estatistica das associações foi analisada pelos coeficientes de regressão( $\beta)$, bruto e ajustado, e respectivos intervalos de confiança (IC95\%).

\subsubsection{Fatores individuais e contextuais associados à prática da} amamentação exclusiva: análise multinível

O estudo dos fatores individuais e o estudo simultâneo dos fatores individuais e contextuais associados à amamentação exclusiva foi realizado mediante o emprego de análise contextual, ou análise multinivel (DIEZ-ROUX 1998). Os estudos desse tipo são também denominados "estudos mistos", por 
investigarem os efeitos de variáveis independentes ecológicas sobre variáveis dependentes no nível individual (SUSSER, 1994).

A análise multinivel trabalha com o conceito de que os individuos interagem com os contextos sociais a que pertencem, ou seja, que os indivíduos são influenciados pelos grupos sociais a que pertencem e as características desses grupos sociais, por outro lado, são influenciadas pelos individuos que deles fazem parte. Usualmente os indivíduos e os grupos são conceituados como um sistema hierárquico de individuos e grupos, com individuos e grupos definidos em níveis separados desse sistema hierárquico. Esses sistemas podem ser observados em diferentes niveis hierárquicos e como resultado podem ter variáveis definidas em cada nível. Esse conceito conduz a uma investigação sobre a interação entre as variáveis que descrevem os indivíduos e as variáveis que descrevem os grupos sociais, um tipo de investigação que é agora freqüentemente referida como "pesquisa multinivel" (HOX, 1995)

Em uma pesquisa multinivel, a estrutura dos dados na população é hierárquica e os dados amostrais são vistos como uma amostra de vários estágios dessa população hierárquica. Por exemplo, em pesquisas na área da educação, a população consiste de escolas e alunos matriculados nessas escolas e o procedimento amostral inclui duas etapas: primeiramente toma-se uma amostra de escolas e em seguida toma-se uma amostra de alunos de cada escola (HOX, 1995). GOLDSTEIN (1995) define hierarquia como unidades 
agrupadas em diferentes niveis. Nesse exemplo, os alunos seriam as unidades de nivel 1 agrupadas nas escolas, que seriam o nivel 2 da estrutura hierárquica.

Nesses estudos as variáveis independentes (explanatórias) podem ser definidas em cada nível da hierarquia. As variáveis globais referem-se somente ao nivel em que foram definidas e as variáveis agregadas são aquelas definidas em um nivel inferior da hierarquia (HOX, 1995).

É muito importante reconhecer e levar em conta a estrutura hierárquica dos dados. Em muitos casos, o estudo do "contexto", ou seja, de características de níveis superiores da hierarquia é o principal objetivo da análise (DIEUXROUX, 1998). Em outras situações, levar em conta a hierarquia é importante porque não fazê-lo pode implicar subestimação da variância dos coeficientes do modelo, levando a intervalos de confiança mais estreitos e, conseqüentemente à falsa significância estatística. (BARROS, 2001).

Modelos de regressão tradicionais baseiam-se na suposição de que os individuos em estudo são independentes entre si em relação ao desfecho estudado. Quando os dados são estruturados em hierarquias, unidades do mesmo grupo raramente são independentes. Isto acontece porque as unidades em cada nivel compartilham de um mesmo ambiente ou apresentam características semelhantes. Isto pode acontecer por "convivência" (como no caso de crianças em creches) ou por construção (como em escolas onde as classes são formadas de acordo com o desempenho dos alunos em anos anteriores). $O$ fato de as unidades compartilharem o ambiente ou serem mais semelhantes entre si do que em relação a outras unidades pode levar a uma 
maior similaridade também em relação aos desfechos de interesse. Quando isso acontece, a suposição de independência é violada, passando a existir correlação entre as unidades dentro do grupo. Este problema é ainda mais importante quando as variáveis explanatórias de niveis superiores da hierarquia são de interesse, de forma que todas as unidades de um grupo estão expostas de forma idêntica ao fator. Os modelos multinivel foram desenvolvidos com o intuito de superar as dificuldades na análise quando os dados estão organizados hierarquicamente e existe correlação intra-grupo. Uma das vantagens dos modelos multinível em relação aos modelos tradicionais é que eles acomodam a hierarquia dos dados na estrutura do modelo, de forma que é possivel levar essa hierarquia em conta e estimar corretamente as variâncias dos coeficientes do modelo, assim como analisar fatores de risco de níveis superiores ao primeiro de forma direta e eficiente, superando nesse sentido a análise ecológica ou agregada (BARROS, 2001).

Optou-se neste estudo pela utilização da análise multinivel em função da organização hierárquica da população de crianças (nível 1) em municípios (nível 2). Além disso, acreditamos que a investigação dos fatores associados à amamentação exclusiva deve levar em consideração o ambiente onde vivem essas crianças, ou seja, as características dos municípios onde residem (variáveis contextuais).

Mais detalhes sobre modelos lineares multinivel com variância simples e também de modelos cuja variável resposta é dicotômica são apresentados em no ANEXO 6. 


\subsection{Plano geral da análise}

Como já foi mencionado, optou-se por analisar a associação dos fatores individuais e contextuais com amamentação exclusiva utilizando-se o modelo multinivel, devido à estrutura hierárquica dos dados (Figura 2) e porque havia interesse em analisar a influência de características dos municípios, especialmente o papel das ações de incentivo ao aleitamento materno desenvolvidas no nível local.

Figura 2 - Organização dos dados em niveis hierárquicos, São Paulo, 2002.

\section{As crianças no contexto dos municipios}

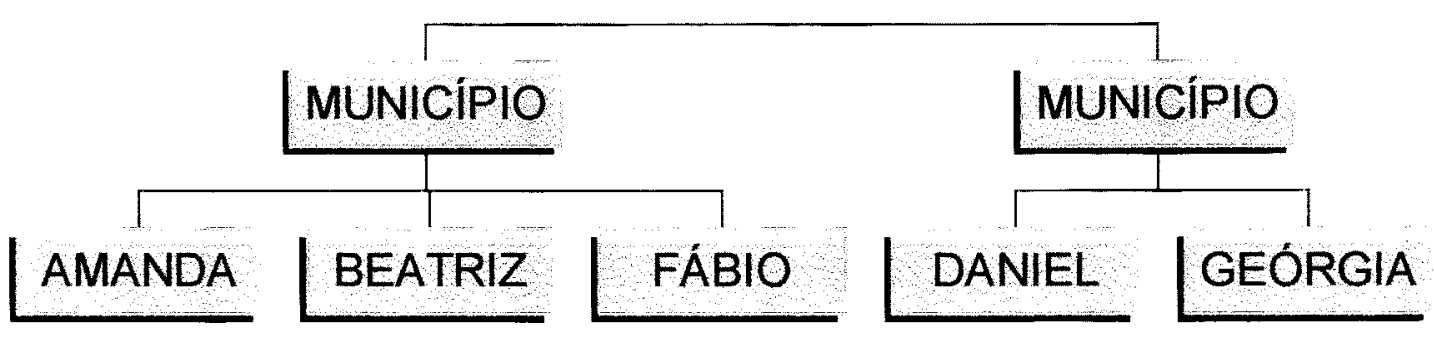

Para a análise multinível, as variáveis explanatórias foram agrupadas em dois níveis, sendo o nível 1 o que comporta as características dos individuos (crianças e mães) e o nível 2 o que contém as variáveis que caracterizam o contexto municipal, sendo o desfecho o AME (sim/não). As variáveis individuais, do nivel 1, foram organizadas em blocos hierarquizados conforme procedência temporal, como mostra a Figura 3. 
Figura 3 -Marco teórico para a investigação de determinantes individuais e contextuais do Aleitamento Materno Exclusivo
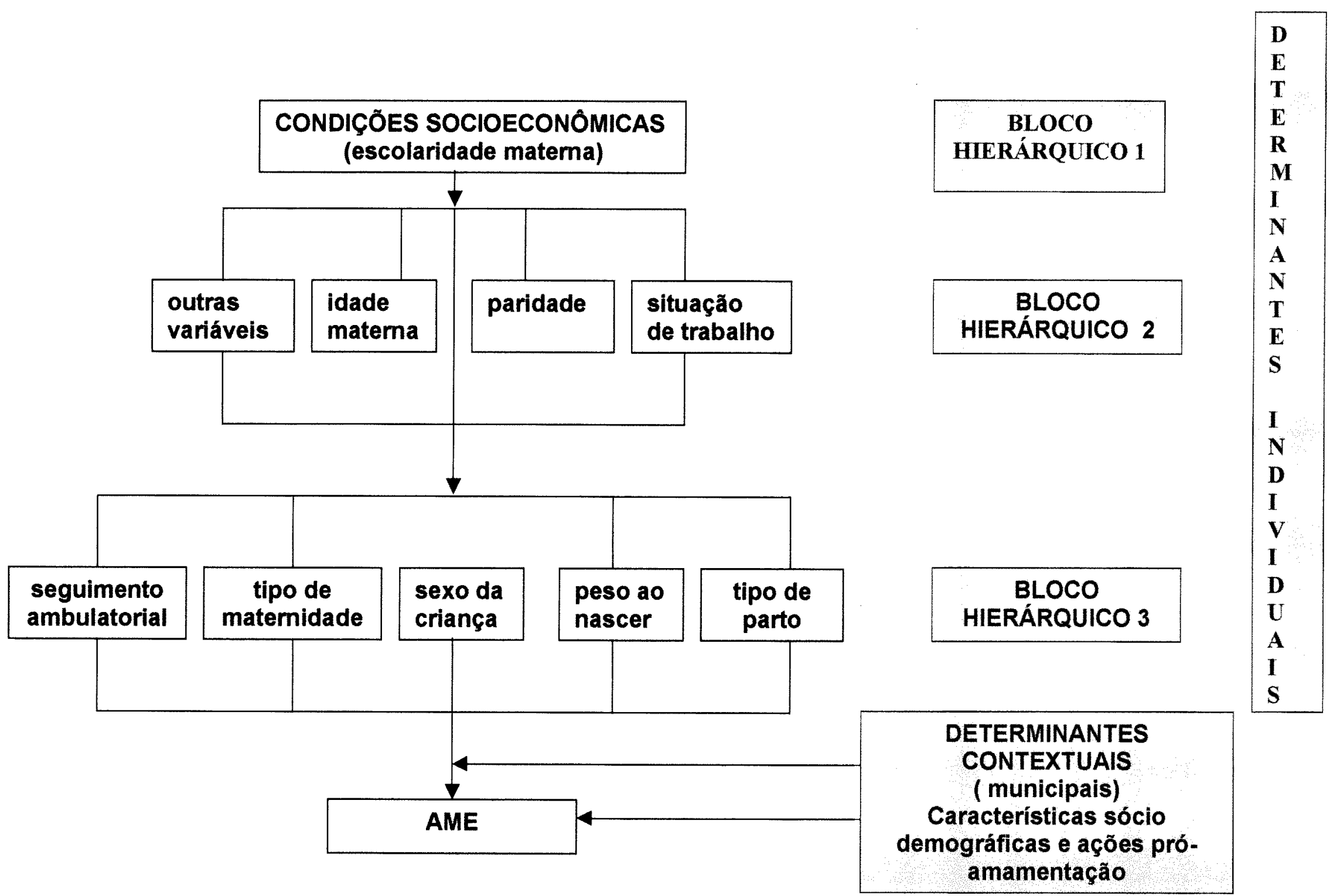
Utilizou-se, para a inclusão das variáveis individuais no modelo, a estratégia de modelagem hierarquizada. Nessa abordagem, a hierarquização das variáveis independentes é previamente estabelecida em um marco conceitual, e a escolha de critérios para a seleção das variáveis de confusão ultrapassa o aspecto puramente estatístico. A hierarquização das variáveis independentes é mantida durante a análise dos dados permitindo a seleção daquelas mais fortemente associadas ao desfecho de interesse (FUCHS et al, 1996; VICTORA et al, 1997).

Segundo o marco teórico apresentado na Figura 3, o AME sofreria influência das variáveis do nível 1, agrupadas em três blocos: 1) condição socioeconômica, 2) atributos maternos e 3) atributos das crianças. A variável "escolaridade materna", que no presente estudo expressaria a condição socioeconômica familiar, além de influenciar diretamente o AME, teria influência sobre as variáveis do bloco 2 (atributos maternos) e do bloco 3 (atributos das crianças). Prevê-se ainda a influência do contexto (características dos municipios onde residem as crianças e sua mães), representado pelas variáveis sociodemográficas e pelas ações municipais pró-amamentação, ambas inseridas no nível 2.

Procedeu-se à modelagem em etapas, utilizando a estratégia de seleção para trás (backward selection) dentro de cada nível do modelo hierarquizado. A variável "escolaridade matema" foi introduzida na primeira etapa da modelagem, sendo ajustada somente para a variável "idade da criança". A segunda etapa consistiu da inclusão do bloco das variáveis relacionadas aos 
atributos maternos e na etapa seguinte foram incluidos os atributos da criança. A inclusão das variáveis contextuais ocorreu na última etapa da modelagem.

Optou-se por incluir inicialmente no modelo todas as variáveis que, na análise univariada, apresentaram valores de $p$ menores do que 0,15.

A análise dos dados foi feita com o software MLwiN 1.1, utilizando-se um modelo de regressão logística multinível com estimação por um procedimento interativo de quadrados mínimos generalizados (YANG et al, 1999).

A significância estatística de cada variável no modelo logístico multinivel foi analisada pelo teste de Wald, que é obtido pela comparação das estimativas de máxima verossimilhança do parâmetro $\beta_{1}$, em relação à estimativa de seu erro padrão. A razão resultante, sob a hipótese de que $\beta_{1}=0$, seguirá uma distribuição normal. Os coeficientes foram considerados significativos quando essa razão $W=\beta_{1} / S E\left(\beta_{1}\right)$ foi superior a dois (HOSMER; LEMESHOW, 1989).

\subsection{Análise das interações entre variáveis individuais e contextuais}

O efeito de possíveis interações entre as variáveis individuais e contextuais foi testado, utilizando-se o programa MLwiN.

Para facilitar a interpretação do efeito das interações, todas as variáveis explanatórias que permaneceram no modelo final ainda sem interações foram categorizadas como dicotômicas. Além disso, optou-se por privilegiar o teste da hipótese segundo a qual as variáveis contextuais (em particular as ações pró- 
amamentação) seriam capazes de minorar o risco de desmame precoce (entendido como ausência de AME nos primeiros seis meses de vida) associado a determinados atributos individuais da criança ou da mãe. Para tal, foi necessário modificar a variável desfecho de "presença de AME" para "ausência de AME" ou "desmame" (introdução na alimentação de qualquer outro líquido ou alimento além do leite materno) e inverter as categorias correspondentes à "referência" e de "risco" no caso das variáveis explanatórias, conforme explicitado no Quadro 5.

Os termos de interação entre as variáveis contextuais e individuais foram incluídos em cada uma das etapas da modelagem hierárquica, sendo considerado um nivel de significância de $10 \%$. 
Quadro 5 - Variáveis incluídas no estudo das interações.

\begin{tabular}{|c|c|c|c|}
\hline \multirow{2}{*}{\multicolumn{2}{|c|}{$\frac{\overline{T I P O}}{\text { Desfecho }}$}} & \multirow{2}{*}{\begin{tabular}{|l} 
VARIÁVEL \\
Desmame
\end{tabular}} & \multirow{2}{*}{$\begin{array}{l}\text { CATEGORIAS } \\
0=N A \bar{O} \\
1=S I M\end{array}$} \\
\hline & & & \\
\hline \multirow{7}{*}{$\begin{array}{l}\text { Explanatória } \\
\text { individual }\end{array}$} & \multirow[t]{2}{*}{ Bloco 1/nível 1} & Faixa etária & $\begin{array}{l}0-29 \text { dias } \\
30-59 \text { dias } \\
60-89 \text { dias } \\
90-119 \text { dias } \\
120-149 \text { dias } \\
150-179 \text { dias }\end{array}$ \\
\hline & & Escolaridade materna & $\begin{array}{l}0=\text { alta (8 anos ou }+) \\
1=\text { baixa (até } 8 \text { anos) }\end{array}$ \\
\hline & \multirow[b]{2}{*}{ Bloco 2/nível 1} & Idade materna & $\begin{array}{l}0=\text { inferior a } 18 \text { anos } \\
1=18 \text { anos } e+\end{array}$ \\
\hline & & Paridade & $\begin{array}{l}0=\text { multípara } \\
1=\text { primipara }\end{array}$ \\
\hline & \multirow[b]{3}{*}{ Bloco 3/nivel 1} & Sexo da criança & $\begin{array}{l}0=\text { feminino } \\
1=\text { masculino }\end{array}$ \\
\hline & & Peso ao nascer & $\begin{array}{l}0=\text { igual/superior a } 2500 \mathrm{~g} \\
1=\mathrm{BP} \text { (abaixo de } 2500 \mathrm{~g} \text { ) }\end{array}$ \\
\hline & & Acompanhamento ambulatorial & $\begin{array}{l}0=\text { rede privada } \\
1=\text { SUS }\end{array}$ \\
\hline \multirow{4}{*}{$\begin{array}{l}\text { Explanatória } \\
\text { Contextual }\end{array}$} & \multirow{4}{*}{ Nivel 2} & $\begin{array}{l}\text { Somatória do } \mathrm{n}^{\circ} \text { de açóes pró- } \\
\text { amamentação }\end{array}$ & $\begin{array}{l}0=4-5 \text { ações } \\
1=0-3 \text { açōes }\end{array}$ \\
\hline & & Região & $\begin{array}{l}0=\text { Interior } \\
1=\text { Metropolitana }\end{array}$ \\
\hline & & Porte populacional & $\begin{array}{l}0=A t e ́ 10.000 \text { hab } \\
1=10.000 \text { hab ou mais }\end{array}$ \\
\hline & & IPRS & $\begin{array}{l}0=3,4,5 \\
1=1,2\end{array}$ \\
\hline
\end{tabular}

\subsection{Aspectos éticos}

Os dados, provenientes do Projeto Amamentação e Municípios, fazem parte de um inquérito populacional, observacional, que não envolve riscos de natureza física, psíquica, moral, intelectual, social ou cultural. Dada a estratégia da pesquisa, realizada através da aplicação de um questionário rápido nas filas 
de vacinação, os acompanhantes das crianças menores de um ano são informados sobre os objetivos da pesquisa e, a seguir, solicita-se seu consentimento verbal para a aplicação do questionário.

Os representantes dos municípios envolvidos no Projeto assinam um termo de consentimento (ANEXO 7), no qual declaram que os dados coletados em nivel local poderão ser utilizados para publicações que analisem a situação da amamentação no Estado de São Paulo. 


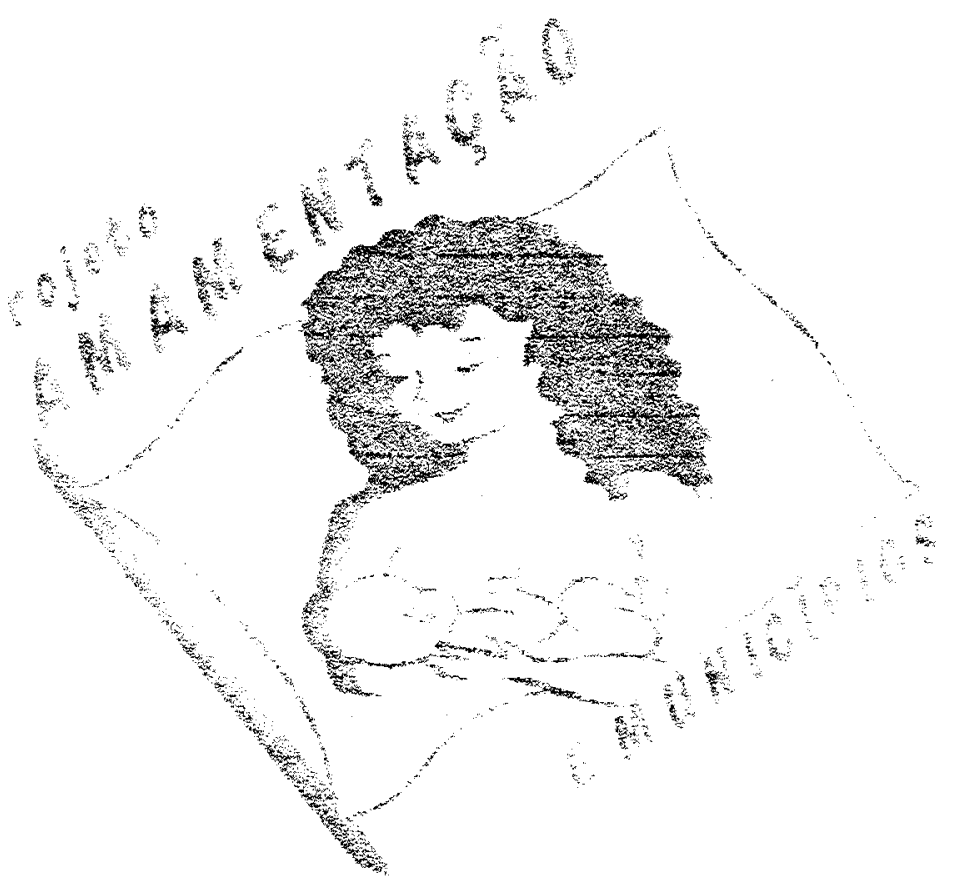

\section{RESULTADOS}

Não basta saber, é preciso também aplicar;

Não basta querer, é preciso também agir.

(Goethe) 


\subsection{Características das crianças estudadas}

A distribuição do conjunto das crianças menores de um ano estudadas nos 111 municípios do Estado de São Paulo segundo a faixa etária é apresentada na Tabela 2.

Tabela 2 - Distribuição (\%) de 66.133 crianças menores de 1 ano residentes em 111 municipios do Estado de São Paulo, segundo faixa etária, 1999.

\begin{tabular}{lll}
\hline Idade (dias) & $N^{\circ}$ de crlancas & $\%$ \\
\hline $0-29$ & 4402 & 6,7 \\
$30-59$ & 5820 & 8,8 \\
$60-89$ & 5665 & 8,6 \\
$90-119$ & 6093 & 9,2 \\
$120-149$ & 6063 & 9,2 \\
$150-179$ & 6389 & 9,7 \\
$180-209$ & 5861 & 8,9 \\
$210-239$ & 5685 & 8,6 \\
$240-269$ & 5151 & 7,8 \\
$270-299$ & 4818 & 7,3 \\
$300-329$ & 4813 & 7,3 \\
$330-364$ & 5373 & 8,1 \\
TOTAL & 66,133 & 100,0 \\
\hline
\end{tabular}

Verifica-se que todas as faixas etárias estão uniformemente representadas, inclusive a de crianças menores de um mês, que poderiam ter menor probabilidade de freqüentar as campanhas de vacinação.

As tabelas a seguir oferecem um perfil detalhado do conjunto das crianças menores de seis meses que serão consideradas na análise dos 
determinantes da amamentação exclusiva, as quais compōem a casuística do Projeto Amamentação e Municipios, em 1999.

A Tabela 3 mostra a distribuição dos menores de seis meses segundo atributos infantis.

Tabela 3. Distribuição (\%) de 34.345 crianças menores de seis meses residentes em 111 municipios do ESP segundo faixa etária, sexo, peso ao nascer, tipo e local do parto e serviço ambulatorial utilizado, 1999.

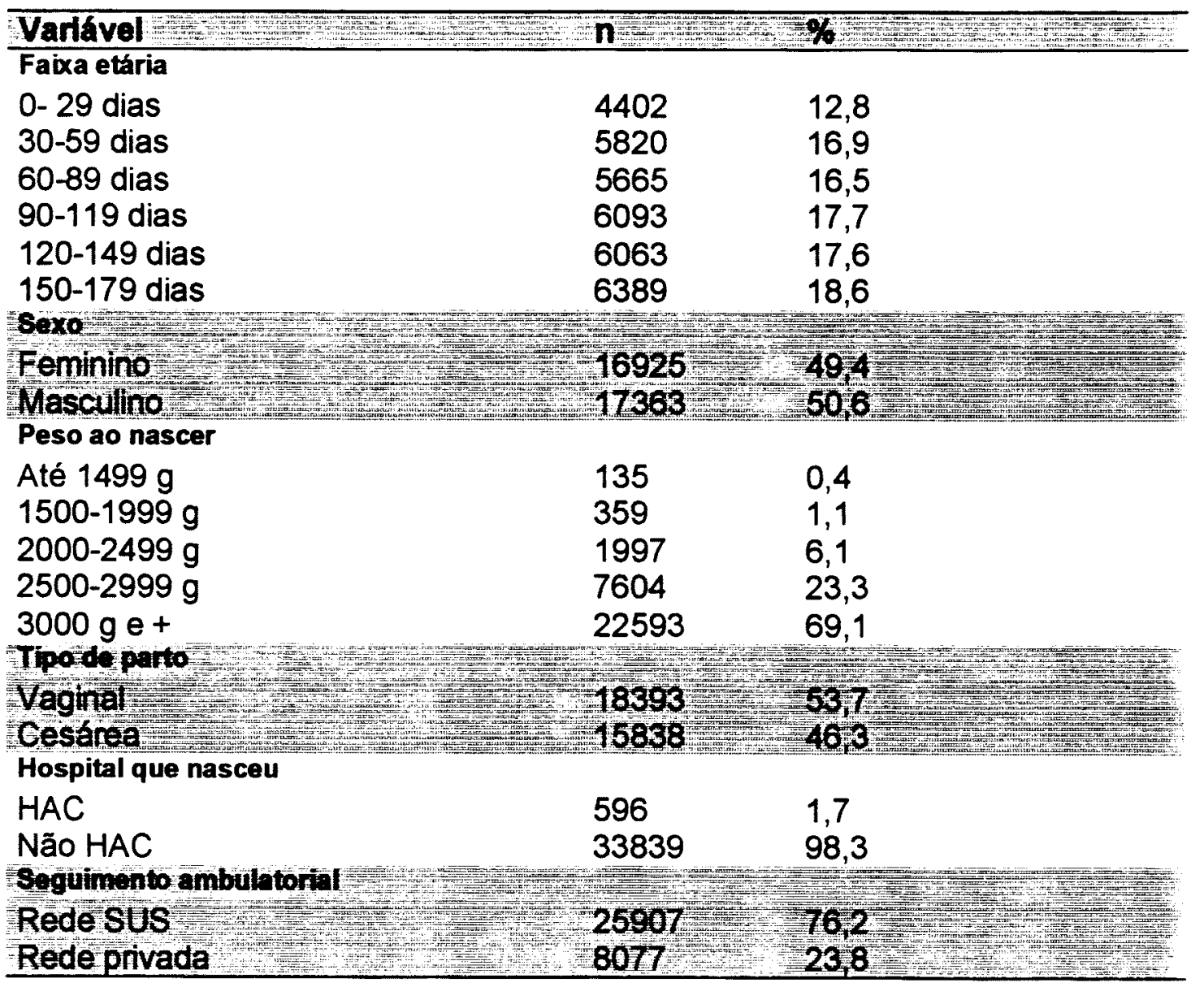


Verifica-se virtual igualdade entre meninos e meninas; preponderância de peso de nascimento igual ou superior a $3000 \mathrm{~g}$ e um baixo percentual de recém-nascidos de baixo peso $(7,6 \%)$, alta freqüência de cesareanas $(46,3 \%)$, com ligeiro predomínio de parto vaginais; proporção diminuta $(1,7 \%)$ de nascimentos ocomidos em HAC e predomínio do seguimento ambulatorial da criança na rede SUS.

A Tabela 4 mostra a distribuição dos menores de seis meses segundo características maternas.

Tabela 4. Distribuição (\%) de 34.345 crianças menores de seis meses residentes em 111 municipios do ESP segundo idade, paridade, situação de trabalho e escolaridade matemas. São Paulo, 1999.

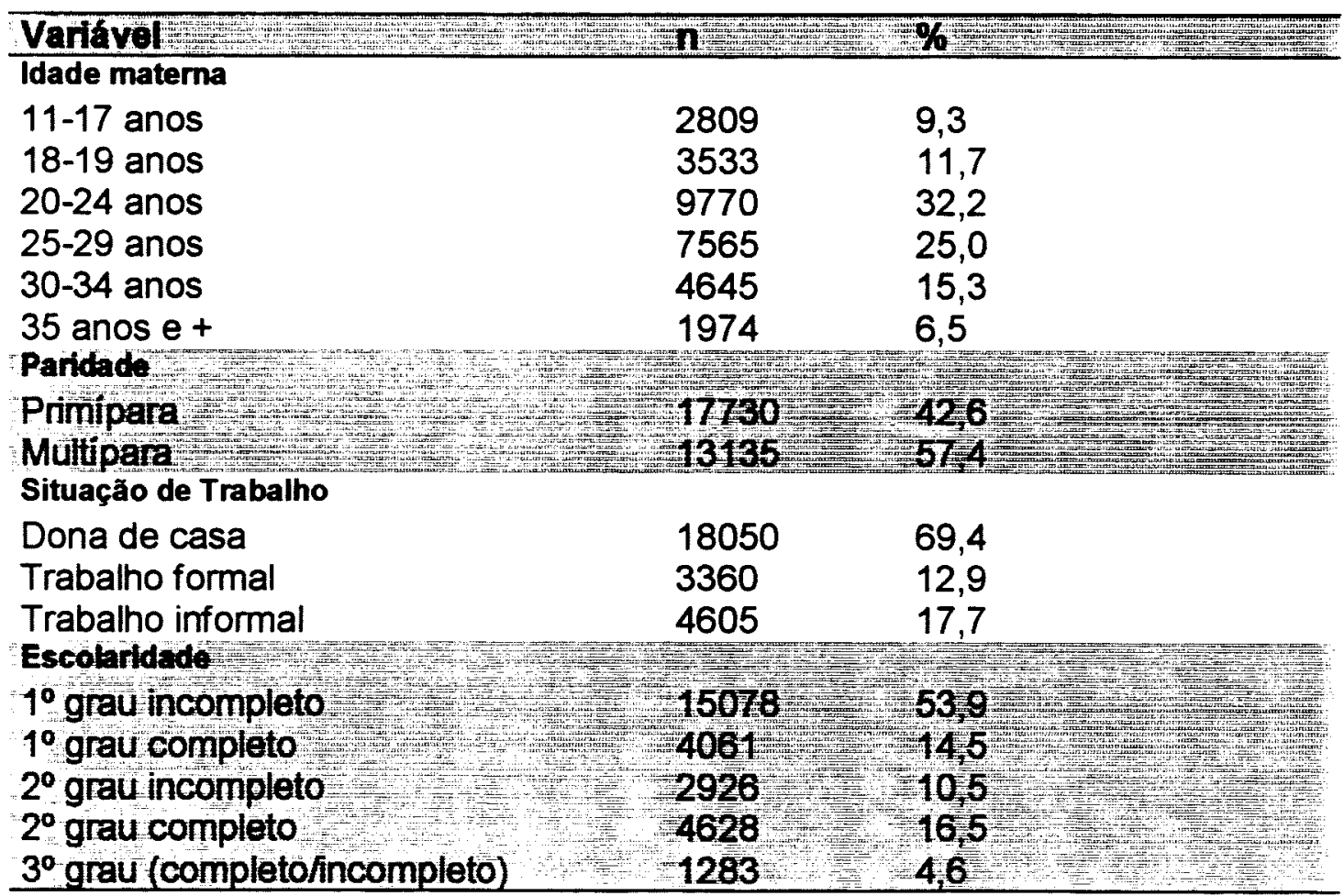


Observa-se que a maioria das mães têm entre 20 e29 anos, há ligeiro predomínio de multíparas sobre primíparas, pouco mais de $30 \%$ trabalham fora de casa e pouco mais de $50 \%$ não chegaram a completar o primeiro grau.

\subsection{Curvas de AME e AMEP em função da idade da criança}

No conjunto das 34.435 crianças estudadas nos 111 municípios paulistas verificou-se que $71 \%$ das crianças menores de seis meses haviam recebido leite materno nas 24 horas anteriores à pesquisa.

Estimativas para a freqüência de AME e AMEP em idades selecionadas, obtidas por modelos de regressão logística são apresentadas na Tabela 5.

Tabela 5 - Estimativas sobre a freqüência de aleitamento materno exclusivo (AME) e aleitamento materno exclusivo ou predominante (AMEP) e respectivos intervalos de confiança (IC ${ }_{95 \%}$ ) em idades selecionadas. Crianças residentes em 111 municípios do ESP, 1999.

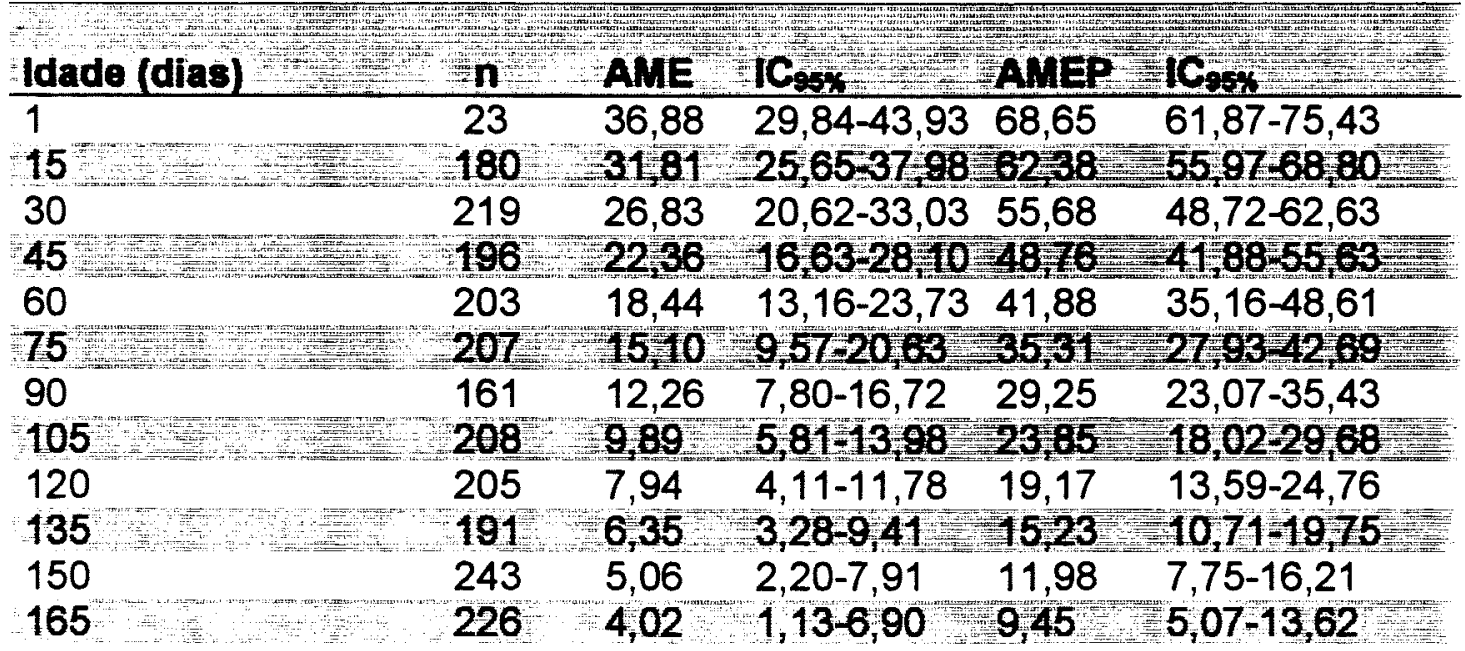


A freqüência de $A M E$ já é baixa no final da prímeira quinzena de vida (37\%), declina mais ainda aos 90 dias (15\%) e é diminuta próxima dos seis meses de idade (4-5\%). Se somarmos ao AME a prática da amamentação acompanhada de líquidos não nutritivos (AMEP), as freqüências praticamente duplicam: $69 \%$ aos 15 dias, $35 \%$ aos 90 dias e $10-12 \%$ aos seis meses de idade.

O comportamento dessas diferentes modalidades do aleitamento materno conforme a idade da criança pode ser melhor visualizado na Figura 4.

Figura 4 - Freqüências de Aleitamento Materno Exclusivo (AME) e Aleitamento Materno Exclusivo/Predominante (AMEP) segundo a idade da criança. Crianças menores de seis meses residentes em 111 municípios do Estado de São Paulo, 1999.

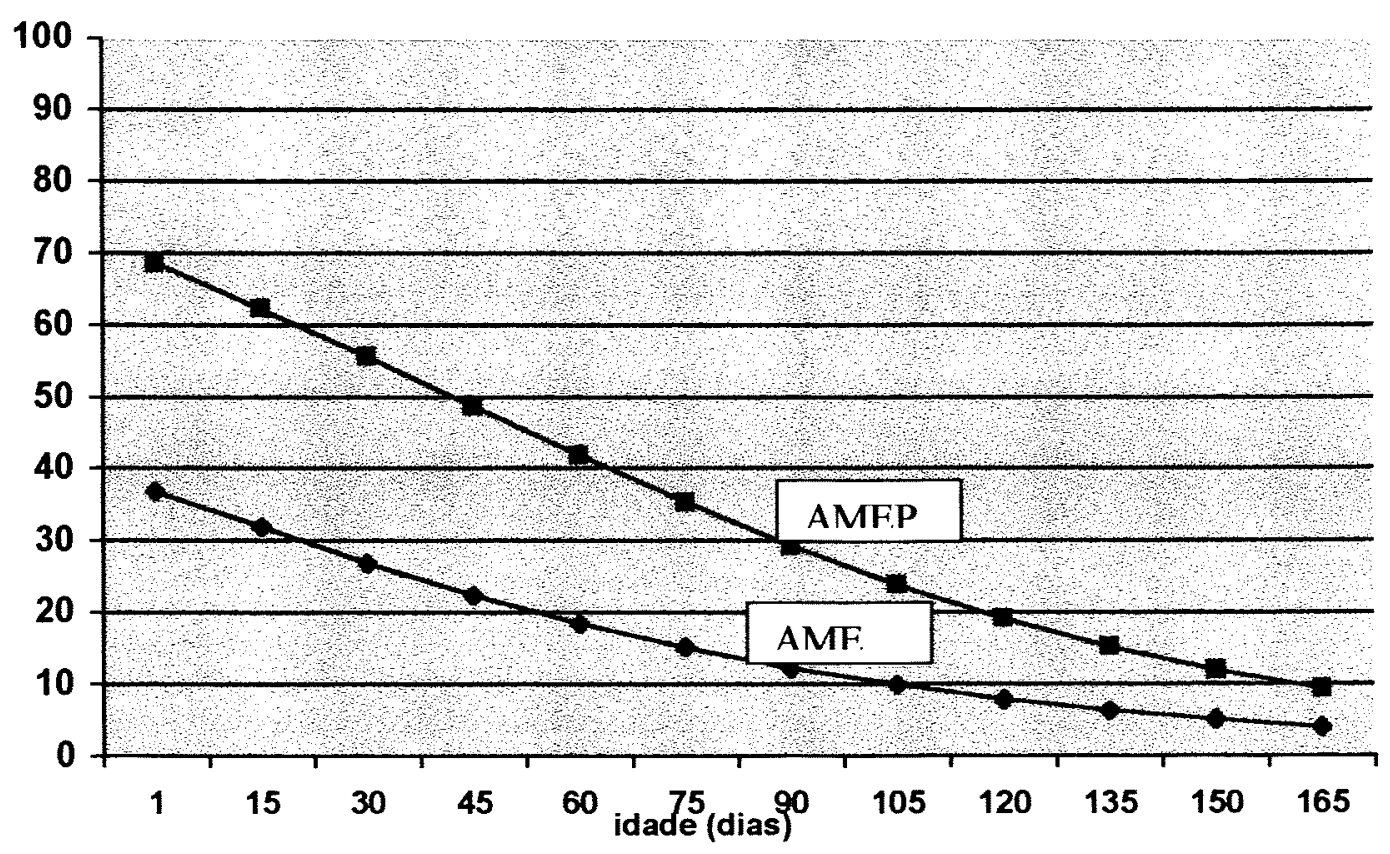


Verifica-se uma freqüência pequena de $A M E$ ao longo dos primeiros seis meses de vida. Apenas $36,9 \%$ das crianças aos 15 dias encontram-se em AME havendo um declínio acentuado até os dois meses e meio (com uma queda de aproximadamente 5 pontos percentuais a cada quinzena), chegando a $4 \%$ aos 6 meses. A baixa freqüência do AME impede que se possa estimar qual seria sua duração mediana na população, podendo-se dizer que ela não chega a 15 dias.

A freqüência de AMEP, aos 15 dias de vida, é cerca de $70 \%$, sendo verificado rápido declínio dessa prática no primeiro trimestre (em torno de 6 pontos percentuais a cada quinzena). Estima-se que a duração mediana do AMEP seja de aproximadamente dois meses.

\subsection{A influência de atributos individuais (das crianças e suas mães) sobre a freqüência do AME}

A Tabela 6 sumariza a influência de atributos das crianças e de suas mães sobre o AME, apresentando razões de chance ajustadas para a idade da criança, no programa MLwiN. 
Tabela 6. Freqüência (\%) do aleitamento matemo exclusivo segundo atributos individuais (das crianças e suas mães). 34.435 crianças menores de 6 meses de idade residentes em de 111 municípios do ESP, 1999.

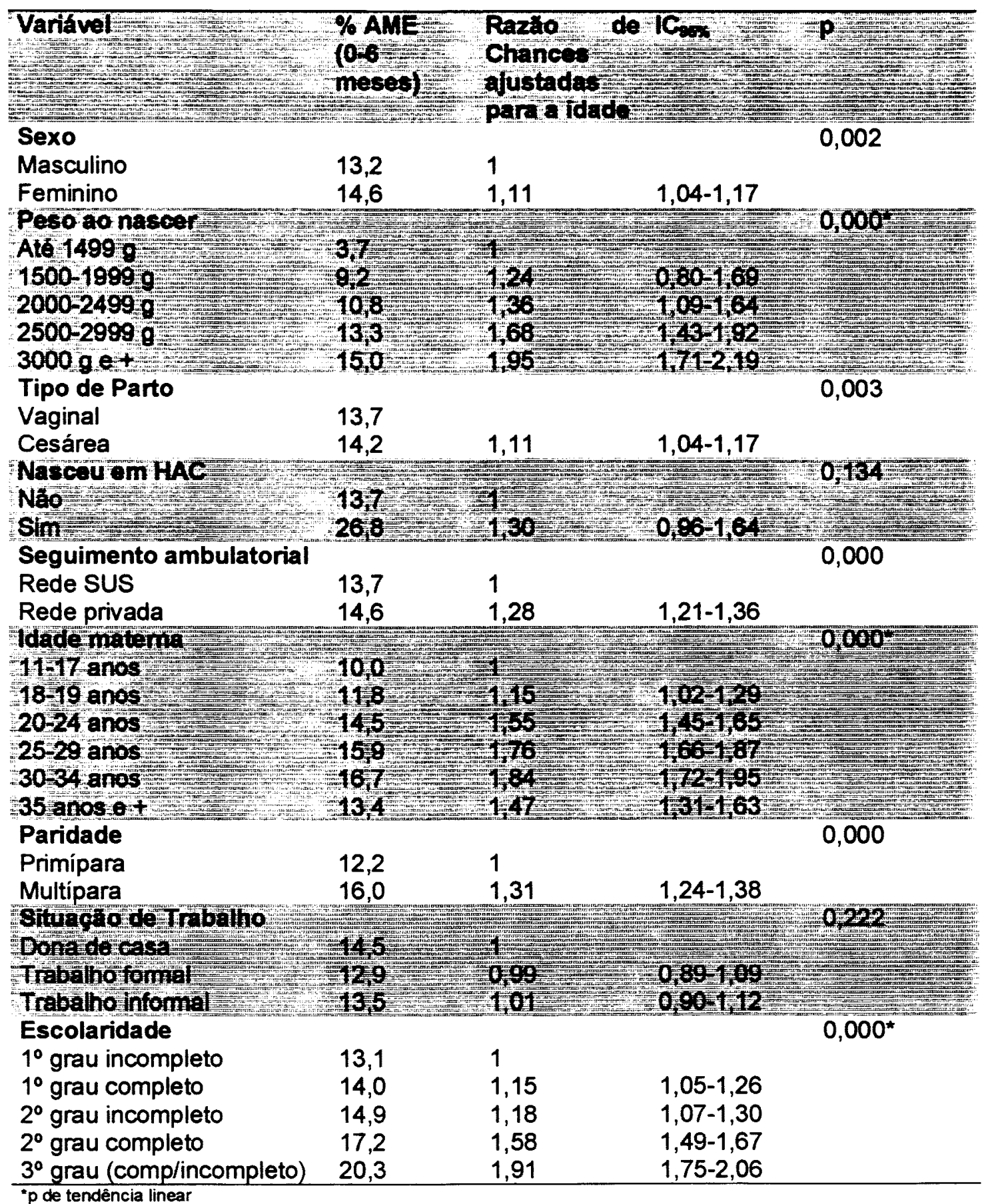


Verifica-se, inicialmente, que após o ajuste para a idade, apresentam-se significativamente associadas ao AME as seguintes variáveis: sexo e peso de nascimento da criança, tipo de parto, serviço de seguimento ambulatorial da criança e idade, paridade e escolaridade das mães. Aumentos pouco expressivos da freqüência do $A M E$ (RC entre 1,11 e 1,31) encontram-se associados ao sexo feminino, ao parto cesárea, ao seguimento ambulatorial na rede privada e a mães multiparas. Aumentos de maior intensidade ocorrem com o aumento do peso ao nascer (RC de 1,95 para nascidos com $3.000 \mathrm{~g}$ ou mais quando comparados aos nascidos com menos de $1.500 \mathrm{~g}$ ), com o aumento da idade materna até 30-34 anos (RC de 1,84 para filhos de mães entre $30-34$ anos comparadas a filhos de mães com menos de 18 anos de idade) e com o aumento da escolaridade materna ( $R C$ de 1,91 para filhos de mães com terceiro grau quando comparados a filhos de mães com menos do que o primeiro grau).

A situação de trabalho da mãe não se mostrou associada à freqüência do AME. O nascimento em HAC embora tenha mostrado uma razão de chances positiva $(R C=1,30)$ não alcançou significância estatística $(p=0,134)$, provavelmente em função da pequeníssima freqüência do evento e de sua concentração em apenas dois municipios.

Apresenta-se, a seguir, a situação do AME nos municípios que realizaram a pesquisa, bem como suas características (variáveis contextuais). 
4.4. Características sociodemográficas e relativas ao incentivo à amamentação dos municípios estudados

A Figura 5 mostra a distribuição dos 111 municípios segundo a prevalência do AME na população de crianças entre 0 e 6 meses de idade.

Figura 5 - Percentual de municípios segundo intervalos de prevalência do AME em crianças menores de seis meses de vida. 111 municípios do ESP, 1999.

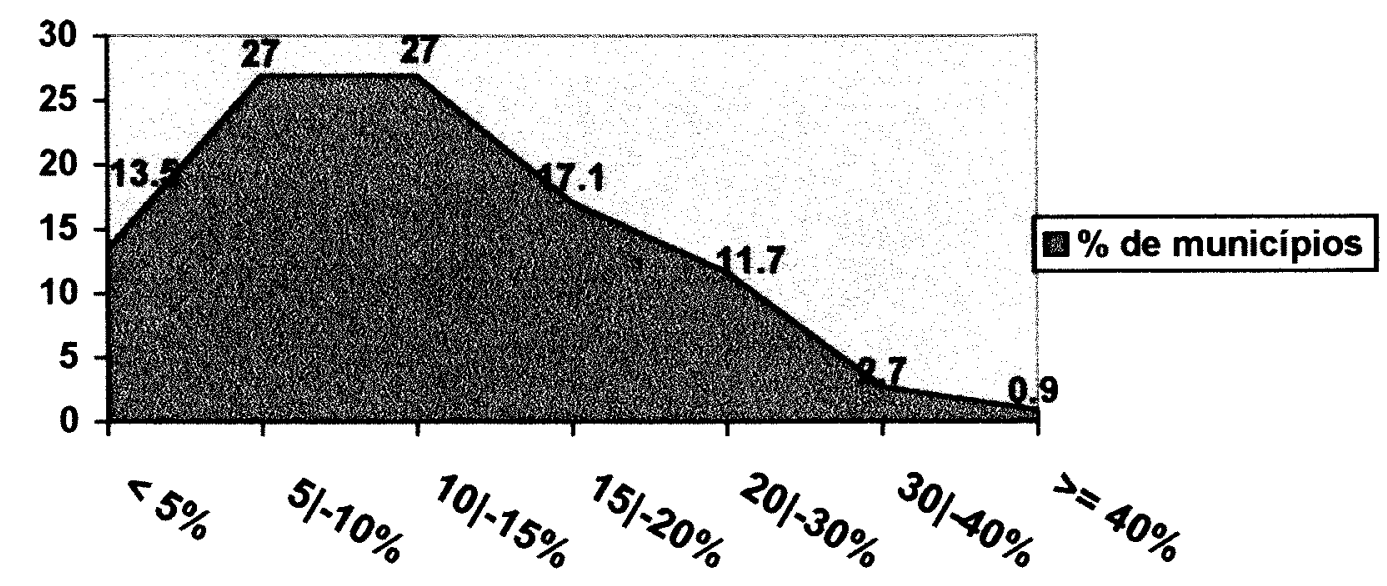

Vale notar que a situação nos municipios do Estado é muito heterogênea quanto à prática do $\mathrm{AME}$, havendo proporções consideráveis de municípios onde menos de $15 \%$ dos menores de seis meses encontram-se em AME e municipios onde mais de $30 \%$ das crianças são amamentadas exclusivamente. A média das prevalências do AME entre 0 e 6 meses encontrada nos 111 
municípios foi de $13,9 \%$ (IC $95 \% 13,6 \%-14,3 \%$ ). O Anexo 8 mostra a prevalência de AME de 0-4 meses e 0-6 meses em cada um dos 111 municípios estudados.

A Figura 6 descreve a distribuição espacial dos 111 municipios estudados conforme intervalos de prevalência do AME em menores de seis meses.

Figura 6 - Distribuição dos 111 municípios que realizaram a pesquisa "Avaliação das práticas alimentares no primeiro ano de vida em dias nacionais de vacinação" no ano de 1999, segundo a prevalência de AME em crianças de 0-6 meses. São Paulo, 1999.

Limite superior

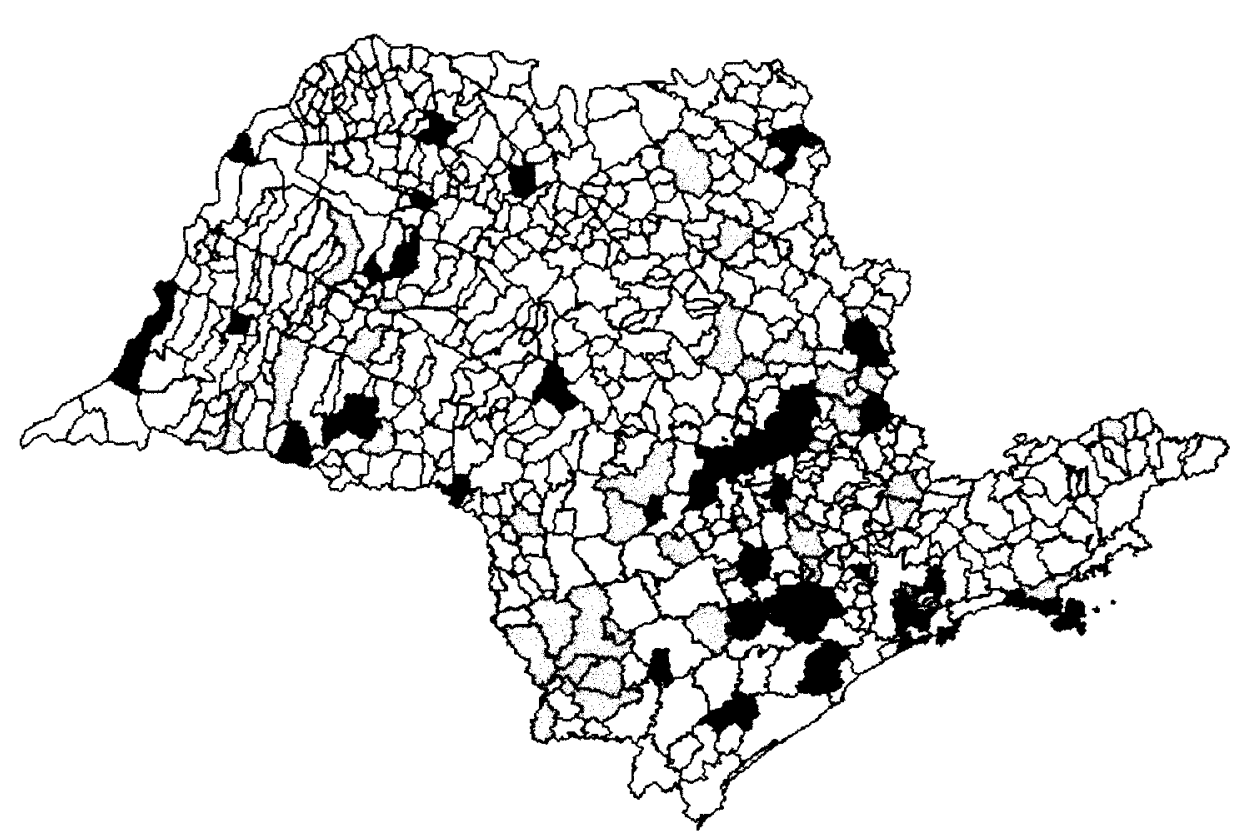

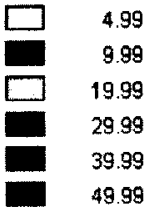


Verifica-se que em diferentes pontos do Estado municipios vizinhos apresentam perfis distintos quanto à prática do AME em menores de 6 meses.

A Tabela 7 apresenta algumas características sociodemográficas dos 111 municípios estudados.

Tabela 7. Distribuição (\%) de 111 municípios do ESP segundo região, porte populacional e índice Paulista de Responsabilidade Social (IPRS), 1999.

\begin{tabular}{|c|c|c|}
\hline$\frac{\text { Característica }}{\text { Região }}$ & $\mathbf{n}$ & $\%$ \\
\hline $\begin{array}{l}\text { Interior } \\
\text { Metropolitana } \\
\quad \text { Porte Populacional }\end{array}$ & $\begin{array}{l}98 \\
13\end{array}$ & $\begin{array}{l}88,3 \\
11,7\end{array}$ \\
\hline $\begin{array}{l}\text { Até } 10.000 \text { habitantes } \\
10.000 \mid 50.000 \text { habitantes } \\
50.000 \text { - } 100.000 \text { habitantes } \\
\text { Mais de } 100.000 \text { habitantes } \\
\text { IPRS }\end{array}$ & $\begin{array}{l}29 \\
38 \\
18 \\
26\end{array}$ & $\begin{array}{l}26,1 \\
34,2 \\
16,2 \\
23,4\end{array}$ \\
\hline $\begin{array}{l}1 \\
2 \\
3 \\
4 \\
5\end{array}$ & $\begin{array}{l}20 \\
17 \\
32 \\
23 \\
19\end{array}$ & $\begin{array}{l}18,0 \\
15,3 \\
28,8 \\
20,7 \\
17,1\end{array}$ \\
\hline
\end{tabular}

Pertencem ao interior do Estado de São Paulo cerca de $88 \%$ dos municípios estudados contra $12 \%$ da grande São Paulo. Esse perfil difere daquele do ESP, onde $94 \%$ dos municípios localizam-se no interior e apenas $6 \%$ na região metropolitana. Os municipios estudados concentram-se na faixa de 10 a 50.000 mil habitantes, sendo que no ESP cerca de metade dos municipios têm até 10.000 habitantes. Quanto ao IPRS, identificam-se $18 \%$ dos 
municípios no grupo 1 (municípios pólo, ricos, com longevidade e escolaridade médias ou altas); $15 \%$ no grupo 2 (municipios economicamente dinâmicos, com baixo desenvolvimento social); cerca de $30 \%$ do municipios são classificados no grupo 3 (municípios saudáveis com baixo desenvolvimento social); $21 \%$ no grupo 4 (municípios com baixo desenvolvimento econômico e em transição social) e $17 \%$ no último grupo (baixo desenvolvimento econômico e social). Distribuição semelhante é encontrada para o total de municípios do ESP (13\% no grupo $1,7,7 \%$ no grupo $2,39,4 \%$ no grupo $3,25,3 \%$ no grupo 4 e $14,6 \%$ no grupo 5).

Em relação às ações de incentivo ao aleitamento materno, verifica-se que aquelas desenvolvidas com maior freqüência pelos municipios correspondem à existência de política municipal formal pró-amamentação (53\%), à promoção da Semana Mundial da Amamentação $(45,1 \%)$, à formação de equipes multiprofissionais para apoio às mães lactantes $(47,3 \%)$ e ao desenvolvimento de cursos para capacitação de profissionais de saúde $(34,4 \%)$. Chama a atenção que cerca de um quinto dos municípios estudados havia realizado levantamentos sobre a situação da amamentação nos dois anos anteriores a 1999, sendo que a maioria desses levantamentos foi feito em 1998 como parte do projeto Amamentação e Municípios. O monitoramento da Norma Brasileira para Comercialização de Alimentos para Lactentes $(4,9 \%)$ e a existência de Bancos de Leite Humano $(5,4 \%)$ e de $\operatorname{HAC}(1,8 \%)$ foram registrados em uma minoria dos 111 municípios estudados (Figura 7). 
Figura 7 - Freqüência de ações de proteção, promoção e apoio ao aleitamento materno em 111 municipios do ESP, 1999.

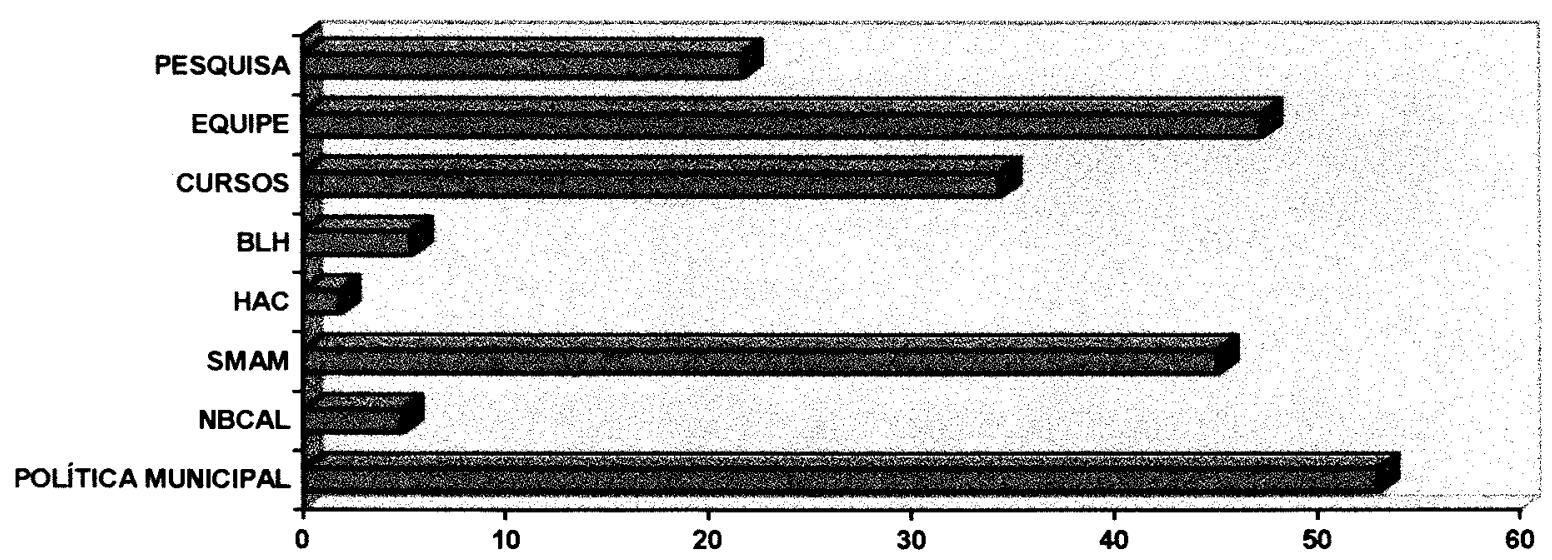

4.5. A influência do contexto (características municipais sociodemográficas e relativas ao desenvolvimento das ações de incentivo à amamentação) sobre a freqüência do AME

A Tabela 8 apresenta a influência de caracteristicas municipais sobre a freqüência do $A M E$. 
Tabela 8. Média das prevalências (\%) de AME em menores de 6 meses segundo características sociodemográficas dos municípios 111 municípios do ESP, 1999.

\begin{tabular}{|c|c|}
\hline Caracterfstica municipal $=3=3=3=\mathrm{n}=\mathrm{n}$ & 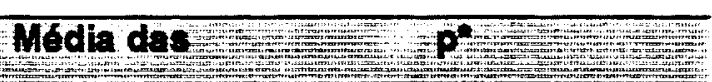 \\
\hline 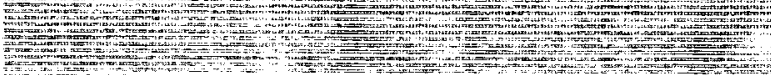 & Prevalencias de AME \\
\hline Regiăo & 0,409 \\
\hline Interior & 13,06 \\
\hline Metropolitana & 11,05 \\
\hline Porte Populacional & $0,181=$ \\
\hline Ate 10.000 habitantes & 11,49 \\
\hline 10.000 F 50.000 habitantes $n=1,=$ & 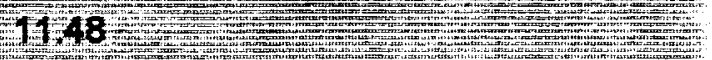 \\
\hline 50.000 F 100.000 habitantes $:=3=3$ & $16,30=3=3=3=3=3=3=3=3=3$ \\
\hline Mais de 100,000 habitantes $=3=0$ & 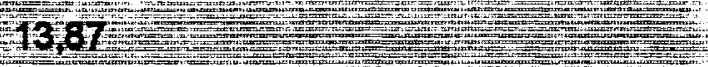 \\
\hline IPRS & 0,219 \\
\hline 1 & 12,11 \\
\hline 2 & 17,00 \\
\hline 3 & 11,85 \\
\hline 4 & 11,07 \\
\hline 5 & 13,60 \\
\hline
\end{tabular}

"p para a hipótese de não diferença entre as médias com ajuste para a média da idade das crianças em cada município

Embora se observe que as prevalências do AME tenham sido superiores nos municípios do interior (quando comparados aos municípios da região metropolitana) e nos municípios entre 50 e 100 mil habitantes (quando comparadas a municípios menores e maiores), as diferenças encontradas não 
alcançaram significado estatístico. Tampouco houve significado estatistico na associação entre o nivel de IPRS municipal e AME.

A influência de ações de incentivo à amamentação sobre a prevalência do AME é analisada na Tabela 9.

Tabela 9. Média das prevalências (\%) de AME em menores de 6 meses segundo a existência de ações de incentivo à amamentação nos municípios. 111 municipios do ESP, 1999.

\begin{tabular}{|c|c|c|}
\hline Açăo & $\begin{array}{l}\text { Prevaléncia } \\
\text { média de AME } \\
\text { (0-6 meses) }\end{array}$ & $\mathbf{p}^{\boldsymbol{*}}$ \\
\hline Política municipal & & 0,022 \\
\hline $\begin{array}{l}\text { Sim } \\
\text { Não }\end{array}$ & $\begin{array}{l}16,61 \\
11,41\end{array}$ & \\
\hline $\begin{array}{l}\text { Monitorizaçào da Norma Brasileira } \\
\text { de Comercializaçăo de Alimentos } \\
\text { para lactentes }\end{array}$ & & 0,571 \\
\hline $\operatorname{Sim}_{\text {Não }}$ & $\begin{array}{r}11,33 \\
13,93\end{array}$ & 3 \\
\hline Semana Mundial da Amamentação & & 0,01 \\
\hline $\begin{array}{l}\text { Sim } \\
\text { Não }\end{array}$ & $\begin{array}{l}17,57 \\
10,18\end{array}$ & \\
\hline Hospital Amigo da Criança & & 0,162 \\
\hline $\operatorname{Sim}_{\text {Não }}$ & $\begin{array}{l}21,20 \\
12,67\end{array}$ & \\
\hline Banco de Leite Humano & & 0,638 \\
\hline $\begin{array}{l}\text { Sim } \\
\text { Não }\end{array}$ & $\begin{array}{l}15,35 \\
13,12\end{array}$ & \\
\hline Cursos & & 0,092 \\
\hline $\operatorname{Sim}_{\text {Não }}$ & $\begin{array}{l}16,29 \\
12,03\end{array}$ & $3=$ \\
\hline Equipe multiprofissional & & 0,002 \\
\hline $\begin{array}{l}\text { Sim } \\
\text { Não }\end{array}$ & $\begin{array}{l}16,9 \\
10,59\end{array}$ & \\
\hline Pesquisa sobre AM & & 0,081 \\
\hline $\begin{array}{l}\text { Sim } \\
\text { Năo }\end{array}$ & $\begin{array}{l}17,38 \\
12,55\end{array}$ & \\
\hline
\end{tabular}


Diferentemente do encontrado com relação às características sociodemográficas dos municípios, a existência de ações de incentivo à amamentação parece influenciar a freqüência do AME. Três ações se associaram positivamente ao AME (existência formal de política municipal próamamentação, realização da Semana Mundial da Amamentação no município e ter uma equipe multiprofissional dedicada à amamentação no município) e para duas ações a associação ficou próxima da significância estatística (realização de cursos e realização levantamentos de prevalência do AM: p entre 0,05 e $0,10)$

Conforme esperado, notou-se que as variáveis que mostraram associação positiva com o AME (significativas ou não, sob o ponto de vista estatístico) apresentaram-se positivamente correlacionadas entre si (Tabela 10). Em vista dessa constatação, e para evitar o fenômeno da autocolinearidade no estudo da influência de ações pró-amamentação na freqüência do $A M E$, optou-se por construir uma variável que expressasse, de alguma forma, a "intensidade" do trabalho pró-amamentação desenvolvido em cada município, o que se fez pela simples somatória (sem qualquer ponderação) da presença de cada uma das sete ações de incentivo à amamentação que se mostraram positivamente associadas ao AME. 
Tabela 10. Coeficientes de correlação $(r)$ entre variáveis que expressam diferentes ações pró-amamentação. 111 municípios do ESP São Paulo, 1999.

\begin{tabular}{llllllll}
\hline AÇÕES & PM & SMAM & HAC & BLH & CURSOS & EQUIPE & PESQUISA \\
\hline PM & 1 & 0,43 & 0,12 & 0,07 & 0,52 & 0,33 & 0,34 \\
SMAM & 0,43 & 1 & 0,13 & 0,10 & 0,35 & 0,43 & 0,11 \\
HAC & 0,12 & 0,13 & 1 & 0,49 & 0,25 & 0,01 & 0,12 \\
BLH & 0,07 & 0,10 & 0,49 & 1 & 0,32 & 0,14 & 0,02 \\
CURSOS & 0,52 & 0,35 & 0,25 & 0,32 & 1 & 0,17 & 0,09 \\
EQUIPE & 0,33 & 0,43 & 0,01 & 0,14 & 0,17 & 1 & 0,18 \\
PESQUISA & 0,34 & 0,11 & 0,12 & 0,02 & 0,09 & 0,18 & 1 \\
\hline
\end{tabular}

A distribuição dos municípios segundo o número de ações desenvolvidas é apresentada na Figura 8.

Figura 8 - Distribuição (\%) dos municípios segundo total apurado de ações pró-amamentação. 111 municípios do ESP, 1999.

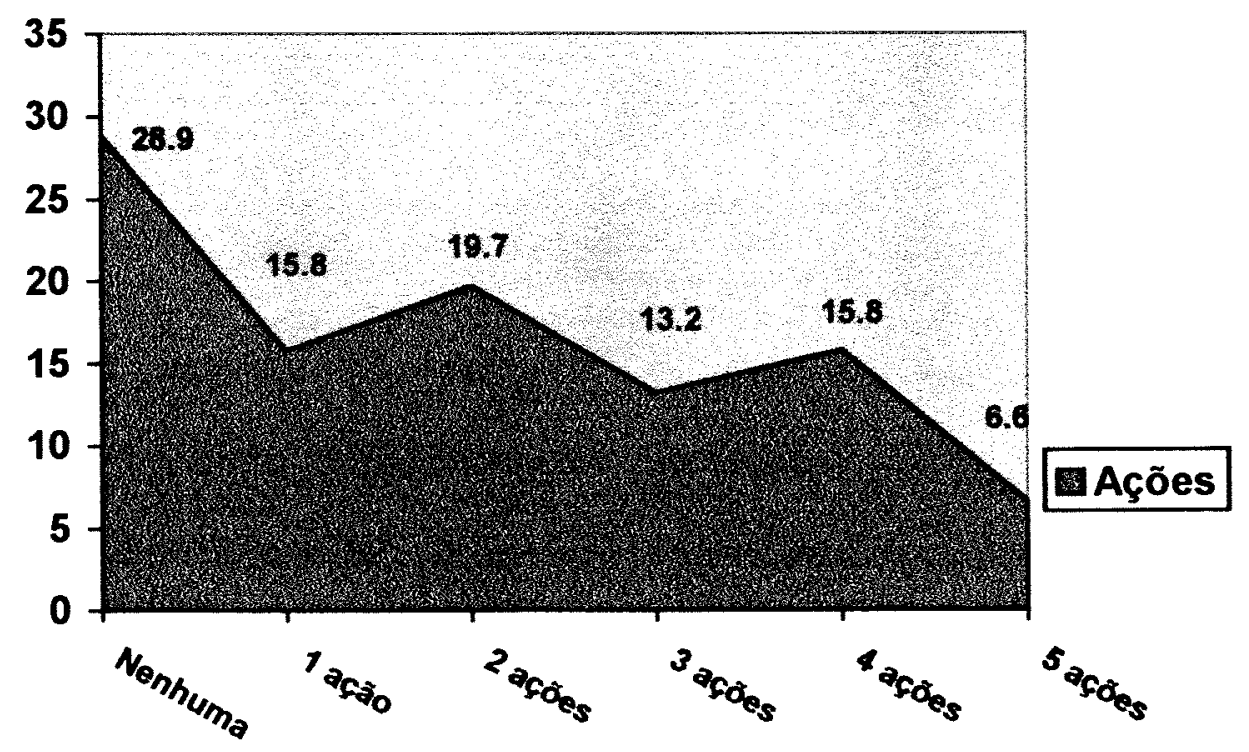


Uma clara tendência de aumento na média das prevalências de AME à medida que aumenta o número de ações pró-amamentação é vista na Figura 9. A análise estatística revela correlação estatisticamente significativa $(p=0,001)$ entre essas duas variáveis, mesmo após o ajuste para a média de idade das crianças em cada município.

Figura 9 -Prevaléncia média de AME em menores de 6 meses segundo número de ações de proteção, promoção e apoio ao AM. 111 municípios do ESP, 1999

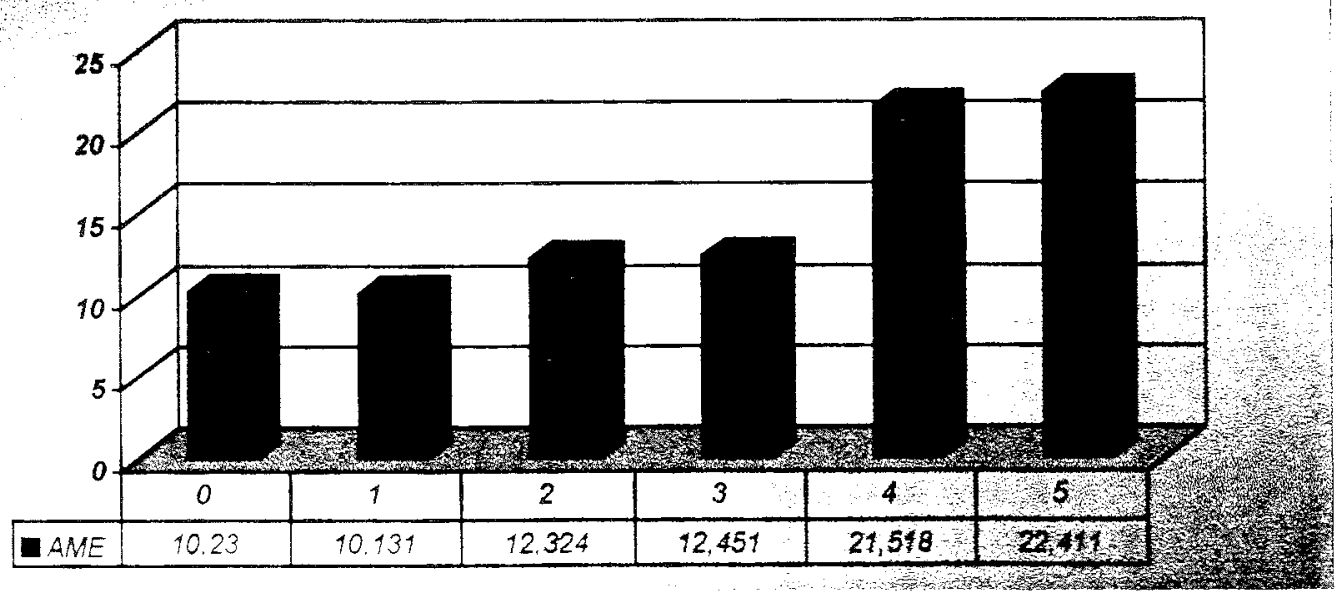

Tendo em vista que são pequenas as diferenças nas médias das prevalências do AME entre os municipios que não desenvolvem ações e os que desenvolvem apenas uma ação, optou-se pelo agrupamento dos mesmos em uma única categoria. O mesmo procedimento foi feito para os municípios com 2 
ou 3 ações e para os municípios com 4 ou 5 ações, chegando-se assim a apenas três categorias: 0-1 ação ;2-3 açōes e 4-5 ações.

Os resultados da análise da correlação entre a variável "AME em menores de 6 meses" e a variável "somatória de ações municipais próamamentação" (em seis e em três categorias), obtida por regressão linear, são apresentados na Tabela 11.

Tabela 11 - Média das prevalências de AME em menores de 6 meses segundo somatória das ações pró-amamentação no município. 111 municípios do ESP, 1999.

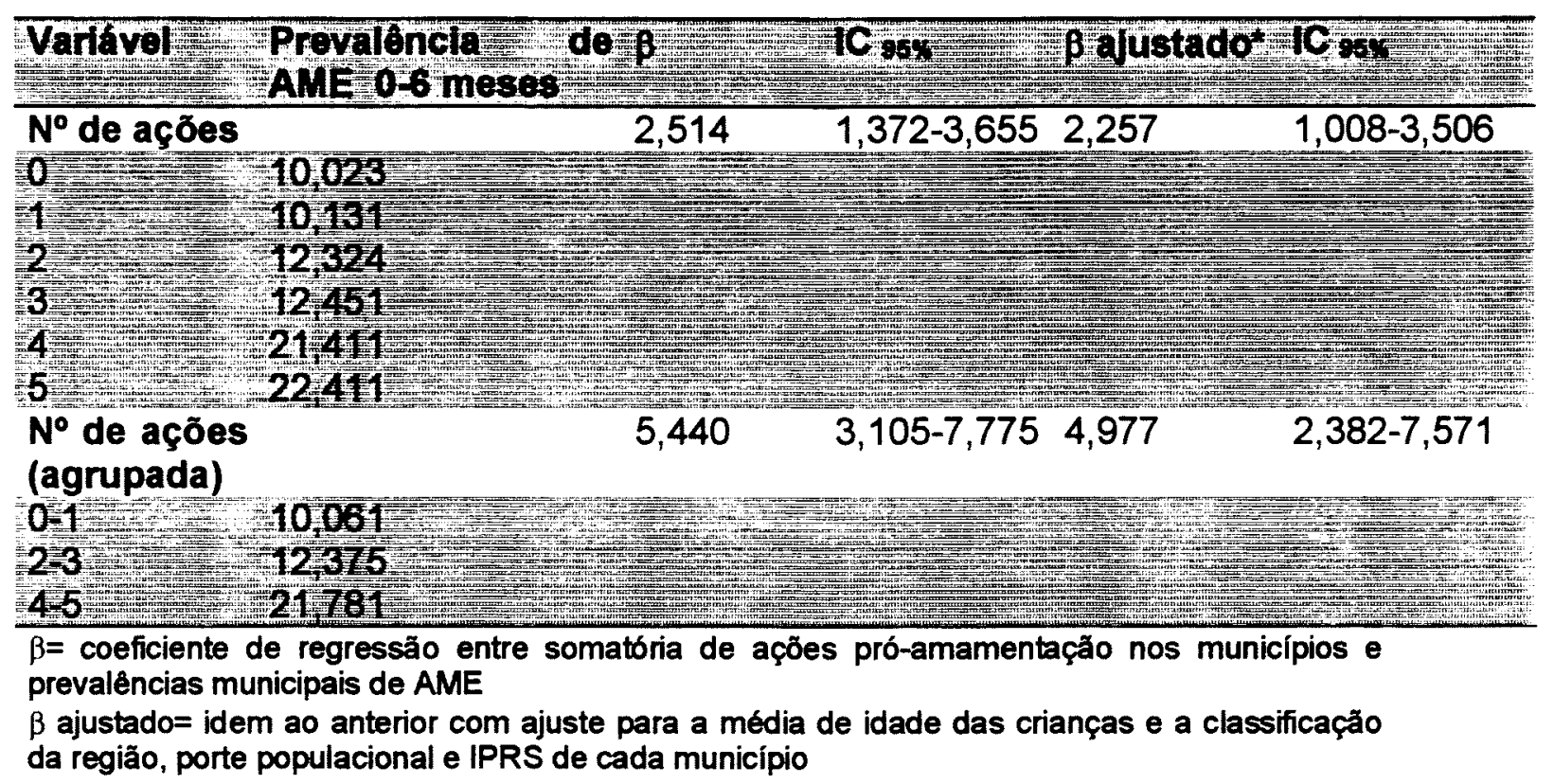


Observa-se que a somatória do $n^{0}$ de ações pró-amamentação apresenta correlação positiva e estatisticamente significativa com a prevalência do AME em menores de 6 meses, mesmo após o controle para a média da idade das crianças e características sociodemográficas dos municípios.

4.6. Análise simultânea da influência de atributos individuais e do contexto sobre a freqüência do AME

A variável individual situação de trabalho das mães e as variáveis contextuais região, porte populacional dos municípios e IPRS foram excluídas da modelagem multinivel por não terem apresentado associação significativa com o AME nas análises anteriores a cada nível. 
RESULTADOS

82

$1^{\text {a }}$ etapa - inclusão da variável faixa etária

$$
\begin{aligned}
& \left.\begin{array}{l}
\text { ame }_{i j} \sim \operatorname{Binomial}\left(\operatorname{denom}_{i j,}, \pi_{i j}\right) \\
\text { ame }_{i j}=\pi_{\pi_{j}}+e_{0 i j} \text { bcons }^{*}
\end{array}\right\} \\
& \operatorname{logit}\left(\pi_{i j}\right)=\beta_{1 j} \text { cons }+-0,496(0,047) 1 \text { mês }_{i j}+-0,774(0,050) 2 \text { meses }_{i j}+ \\
& -1,184(0,053) 3 \text { meses }_{i j}+-1,828(0,063) 4 \text { meses }_{i j}+ \\
& -2,697(0,085) 5 \text { meses }_{i j} \\
& \beta_{1 j}=-0,909(0,081)+u_{1 j} \\
& {\left[\mathcal{W}_{1 v}\right] \sim \mathrm{N}\left(0, \Omega_{u}\right): \Omega_{u}=[0,542(0,083)]} \\
& \text { bcons }{ }^{*}=\text { bcons }\left[\pi_{i j}\left(1-\pi_{i j}\right) / \text { denom }_{i j}\right]^{0.5} \\
& {\left[e_{0 i j}\right] \sim\left(0, \Omega_{e}\right): \Omega_{e}=[1,000(0,000)]}
\end{aligned}
$$


$2^{a}$ etapa - inclusão da variável do nível 1/bloco hierárquico 1: escolaridade materna

$$
\begin{aligned}
& \left.\begin{array}{l}
\text { ame }_{i j} \sim \operatorname{Binomial}\left(\text { denom }_{i j}, \pi_{i j}\right) \\
\text { ame }_{i j}=\pi_{i j}+e_{0 i j} \text { bcons }^{*}
\end{array}\right\} \\
& \operatorname{logit}\left(\pi_{i j}\right)=\beta_{1 j} \text { cons }+-0,518(0,047) 1 \text { mês }_{i j}+-0,794(0,050) 2 \text { meses }_{i j}+ \\
& -1,211(0,053) 3 \text { meses }_{i j}+-1,854(0,063) 4 \text { meses }_{i j}+ \\
& -2,724(0,085) 5 \text { meses }_{i j}+0,143(0,053) 1 \text { grau comp }_{i j}+ \\
& 0,168(0,060) 2 \text { grau inc }_{i j}+0,457(0,047) 2 \text { grau comp }_{i j}+ \\
& 0,646(0,079) 3 \operatorname{grau}_{i j} \\
& \beta_{1 j}=-1,008(0,082)+u_{1 j} \\
& {\left[u_{1 j}\right] \sim \mathrm{N}\left(0, \Omega_{u}\right): \Omega_{u}=[0,547(0,084)]} \\
& \text { bcons }{ }^{*}=\text { bcons }\left[\pi_{i j}\left(1-\pi_{i j}\right) / \text { denom }_{i j}\right]^{0.5} \\
& {\left[e_{0 i j}\right] \sim\left(0, \Omega_{e}\right): \Omega_{e}=[1,000(0,000)]}
\end{aligned}
$$


3a etapa - inclusão das variáveis do nível 1/bloco hierárquico 2: idade materna e paridade

$$
\begin{aligned}
& \left.\begin{array}{l}
\text { ame }_{i j} \sim \operatorname{Binomial}\left(\text { denom }_{i p} \pi_{i j}\right) \\
\text { ame }_{i j}=\pi_{\pi_{j j}}+e_{0 i j} \text { bcons }^{*}
\end{array}\right\} \\
& \operatorname{logit}\left(\pi_{i j}\right)=\beta_{1 j} \text { cons }+-0,531(0,047) 1 \text { mês }_{i j}+-0,810(0,050) 2 \text { meses }_{i j}+-1,227(0,053) 3 \text { meses }_{i j}+ \\
& -1,870(0,063) 4 \text { meses }_{i j}+-2,745(0,085) 5 \text { meses }_{i j}+0,163(0,054) 1 \text { grau comp }_{i j}+ \\
& 0,252(0,061) 2 \text { grau inc }_{i j}+0,484(0,050) 2 \text { grau comp }_{i j}+0,666(0,081) 3 \operatorname{grau}_{i j}+ \\
& 0,159(0,071) 18-19_{i j}+0,359(0,053) 20-24_{i j}+0,417(0,055) 25-29_{i j}+ \\
& 0,420(0,061) 30-34_{i j}+0,201(0,083) 35 \text { e }+_{i j}+0,344(0,039) \text { multipara }_{j j} \\
& \beta_{1 j}=-1,519(0,093)+u_{1 j} \\
& {\left[u_{1 j}\right] \sim \mathrm{N}\left(0, \Omega_{u}\right): \Omega_{\mathcal{L}}=[0,553(0,085)]} \\
& \text { bcons }^{*}=\text { bcons }\left[\pi_{i j}\left(1-\pi_{i j}\right) / \text { denom }_{i j} j^{0 s}\right. \\
& {\left[e_{0 \mathrm{aj}}\right] \sim\left(0, \Omega_{e}\right): \Omega_{e}=[1,000(0,000)]}
\end{aligned}
$$


$4^{a}$ etapa - inclusão das variáveis do nível 1/bloco hierárquico 3: sexo da criança, peso de nascimento, tipo de parto, tipo de maternidade, seguimento ambulatorial

$$
\begin{aligned}
& \left.\begin{array}{l}
\text { ame }_{i j} \sim \operatorname{Binomial}\left(\text { denom }_{j,}, \pi_{i j}\right) \\
\text { ame }_{i j}=\pi_{i j}+e_{0 j j} \text { bcons }^{*}
\end{array}\right\} \\
& \operatorname{logit}\left(\pi_{i j}\right)=\beta_{1 j} \text { cons }+-0,533(0,047) 1 \text { mês }_{i j}+-0,810(0,050) 2 \text { meses }_{i j}+-1,225(0,053) 3 \text { meses }_{i j}+ \\
& -1,869(0,063) 4 \text { meses }_{i j}+-2,746(0,085) 5 \text { meses }_{i j}+0,142(0,054) 1 \text { grau comp }_{i j}+ \\
& 0,231(0,061) 2 \text { grau inc }_{j j}+0,444(0,051) 2 \text { grau comp }_{i j}+0,608(0,084) 3 \text { grau }_{j j}+ \\
& 0,146(0,071) 18-19_{i j}+0,338(0,053) 20-24_{i j}+0,386(0,055) 25-29_{i j}+ \\
& 0,387(0,061) 30-34_{i j}+0,183(0,083) 35 \text { e }+_{i j}+0,346(0,039) \text { multipara }_{i j}+ \\
& 0,109(0,033) \text { menina }_{i j}+0,140(0,226) 1500-1999 \mathrm{~g}_{i j}+0,247(0,142) 2000-2499 \mathrm{~g}_{i j}+ \\
& 0,413(0,126) 2500-2999 \mathrm{~g}_{i j}+0,542(0,123) 3000 \mathrm{~g} \mathrm{e}_{i j}+0,008(0,035) \text { parto }_{i j}+ \\
& 0,096(0,043) \text { redepriv }_{i j}+0,309(0,172) \text { nasceuha }_{j j} \\
& \beta_{1 j}=-2,036(0,148)+u_{1 j} \\
& {\left[u_{1 j}\right] \sim N\left(0, \Omega_{2}\right): \Omega_{u}=[0,548(0,084)]} \\
& \text { bcons }{ }^{*}=b \operatorname{cons}\left[\pi_{i j}\left(1-\pi_{i j}\right) / \text { denom }_{i j}\right]^{05} \\
& {\left[e_{0, j}\right] \sim\left(0, \Omega_{\varepsilon}\right): \Omega_{\varepsilon}=[1,000(0,000)]}
\end{aligned}
$$


RESULTADOS

86

$5^{a}$ etapa - exclusão das variáveis sem significância estatística: tipo de maternidade e tipo de parto

$$
\left.\begin{array}{l}
\operatorname{ame}_{i j} \sim \operatorname{Binomial}\left(\text { denom }_{i j}, \pi_{j j}\right) \\
\text { ame }_{i j}=\pi_{\pi_{j}}+e_{0 j} \text { bcons }^{*}
\end{array}\right\}
$$

$\operatorname{logit}\left(\pi_{i j}\right)=\beta_{1 j}$ cons $+-0,531(0,047) 1$ mês $_{i j}+-0,807(0,050) 2$ meses $_{i j}+-1,222(0,053) 3$ meses $_{i j}+$

$-1,867(0,063) 4$ meses $_{i j}+-2,743(0,085) 5$ meses $_{i j}+0,144(0,054) 1$ grau comp $_{i j}+$

$0,231(0,061) 2$ grau inc $_{i j}+0,441(0,051) 2$ grau comp $_{i j}+0,606(0,084) 3$ grau $_{i j}+$

$0,147(0,071) 18-19_{i j}+0,339(0,053) 20-24_{i j}+0,387(0,055) 25-29_{i j}+$

$0,386(0,061) 30-34_{i j}+0,184(0,083) 35 \mathrm{e}+_{i j}+0,346(0,039)$ multipara $_{i j}+$

$0,109(0,033)$ menina $_{i j}+0,138(0,226) 1500-1999 \mathrm{~g}_{i j}+0,254(0,142) 2000-2499 \mathrm{~g}_{i j}+$

$0,419(0,126) 2500-2999 \mathrm{~g}_{i j}+0,547(0,123) 3000 \mathrm{~g} \mathrm{e}+_{i j}+0,094(0,042)$ redepriv $_{i j}$

$\beta_{1 j}=-2,032(0,148)+u_{1 j}$

$\left[u_{1 j}\right] \sim \mathrm{N}\left(0, \Omega_{u}\right): \Omega_{u}=[0,560(0,086)]$

bcons ${ }^{*}=$ bcons $\left[\pi_{4 j}\left(1-\pi_{k_{j}}\right) / \text { denom }_{1 j}\right]^{05}$

$\left[e_{0 i j}\right] \sim\left(0, \Omega_{e}\right): \Omega_{e}=[1,000(0,000)]$ 
6ª etapa - inclusão da variável do nível 2: somatória do $n^{\circ}$ ações

$$
\begin{aligned}
& \left.\begin{array}{l}
\operatorname{ame}_{i j} \sim \operatorname{Binomial}\left(\text { denom }_{i j}, \pi_{j j}\right) \\
\operatorname{ame}_{i j}=\pi_{i j}+e_{0 i j} b \text { ccons }^{*}
\end{array}\right\} \\
& \operatorname{logit}\left(\pi_{i j}\right)=\beta_{1 j} \text { cons }+-0,541(0,047) 1 \text { mês }_{i j}+-0,820(0,049) 2 \text { meses }_{i j}+-1,240(0,052) 3 \text { meses }_{i j}+ \\
& -1,895(0,062) 4 \text { meses }_{i j}+-2,773(0,081) 5 \text { meses }_{j j}+0,142(0,053) 1 \text { grau comp }_{i j}+ \\
& 0,230(0,060) 2 \text { grau inc }_{i j}+0,443(0,050) 2 \text { grau comp }_{i j}+0,605(0,082) 3 \text { grau }_{j}+ \\
& 0,149(0,069) 18-19_{i j}+0,346(0,052) 20-24_{i j}+0,394(0,054) 25-29_{i j}+ \\
& 0,393(0,060) 30-34_{i j}+0,188(0,081) 35 \text { e }+_{i j}+0,349(0,038) \text { multipara }_{j j}+ \\
& 0,111(0,033) \text { menina }_{i j}+0,109(0,218) 1500-1999 \mathrm{~g}_{i j}+0,221(0,136) 2000-2499 \mathrm{~g}_{j \mathrm{j}}+ \\
& 0,385(0,120) 2500-2999 \mathrm{~g}_{\mathrm{ij}}+0,517(0,117) 3000 \mathrm{ge}_{i j}+0,094(0,041) \mathrm{redepriv}_{i j}+ \\
& 0,166(0,157) 2-3 \text { ações }_{j}+0,930(0,176) 4-5 \text { ações }_{j} \\
& \beta_{1 j}=-2,227(0,147)+u_{1 j} \\
& {\left[u_{1 j}\right] \sim \mathrm{N}\left(0, \Omega_{u}\right): \Omega_{u}=[0,374(0,061)]} \\
& \text { bcons }{ }^{*}=b \operatorname{cons}\left[\pi_{i j}\left(1-\pi_{i j}\right) / \text { denom }_{i j}\right]^{0.5} \\
& {\left[e_{0 \mathrm{ajj}}\right] \sim\left(0, \Omega_{e}\right): \Omega_{e}=[1,000(0,000)]}
\end{aligned}
$$

A Tabela 12 mostra os determinantes individuais e contextuais do AME e correspondentes razões de chance. 
Tabela 12 - Determinantes individuais e contextuais do AME e correspondentes razões de chance obtidas por modelo multinivel hierárquico. Crianças menores de 6 meses de 111 municipios do ESP, 1999.

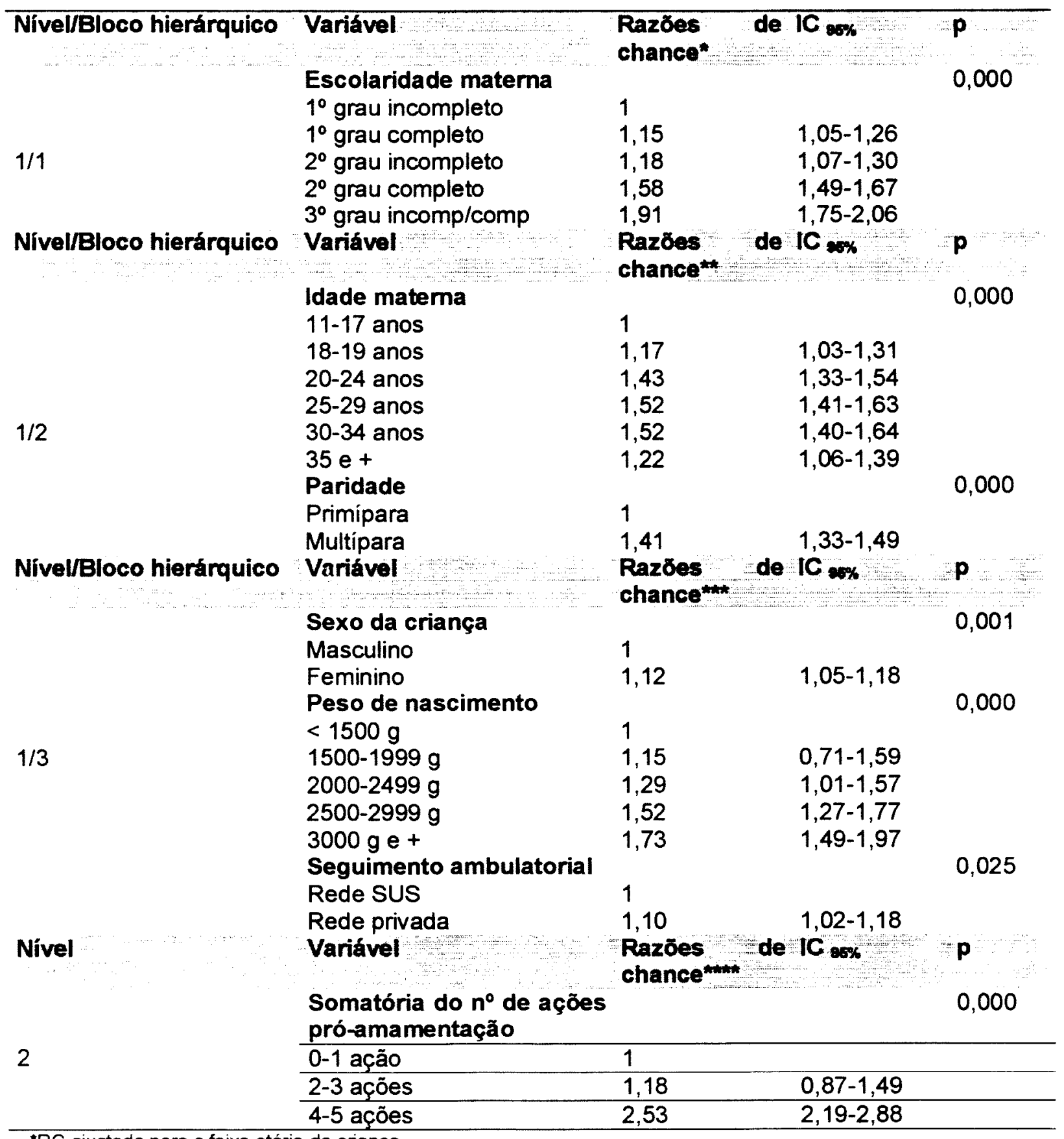

*RC ajustada para a faixa etária da criança

* RC ajustadas para a faixa etária da criança e para as variáveis dos blocos hierárquicos 1 e 2

* RC ajustadas para a faixa etária da criança e para as variáveis dos blocos hierárquicos 1,2 e 3

* RC ajustada para a faixa etária da criança e para as variáveis dos blocos hierárquicos 1,2 e 3 
Como já havia sido mostrado, a variável escolaridade materna, ajustada para a idade da criança, apresenta efeito tipo "dose-resposta", ou seja, quanto maior a escolaridade, maior a chance de AME. Os filhos de mulheres com $3^{\circ}$ grau (completo ou incompleto) apresentam quase duas vezes mais chance de AME quando comparadas àquelas que não completaram $01^{\circ} \mathrm{grau}$.

Em relação às variáveis do bloco hierárquico 2, de atributos maternos, verifica-se que a idade da mãe apresenta-se estatisticamente associada ao $\operatorname{AME}(p=0,000)$. $\dot{E}$ interessante observar que ocorre um aumento da chance de AME com o aumento da idade matema até a categoria 25-29 anos, sendo que a partir dai a RC estabiliza e diminui ligeiramente na categoria 35 anos e mais. Verificou-se também que a multiparidade esteve significativamente associada ao $A M E(R C=1,42)$ após o ajuste das variáveis do bloco 1 e da idade matema.

Verifica-se associação estatisticamente significativa entre o AME e crianças do sexo feminino $(R C=1,12)$. A associação entre $A M E$ e peso ao nascer é significativa, tendo sido evidenciado um efeito dose-resposta. As crianças que fazem acompanhamento na rede privada de serviços de saúde apresentam maior chance de $A M E(R C=1,10)$ quando comparadas às que freqüentam o SUS. O tipo de parto e o tipo de maternidade em que a criança nasceu (HAC ou não) não atingiram significância estatistica com o ajuste para as variáveis dos blocos 1 e 2 e para as demais variáveis do bloco 3 , sendo retirados do modelo final. 
É interessante observar que, independente do efeito das variáveis individuais, a variável contextual "somatória do n de ações pró-amamentação" mostra associação significativa com o AME, sendo as crianças residentes nos municipios em melhor condição (4-5 ações) têm 2,5 vezes mais chance de AME quando comparadas às crianças que residem nos municípios em pior condição.

\subsection{Efeito das interações entre as variáveis individuais e contextuais sobre o AME.}

Cabe lembrar que, para a análise das interações, as variáveis que compõem o modelo final acima descrito foram re-categorizadas. O desfecho passa a ser o desmame e as variáveis explanatórias que serão incluídas nos modelos das interações são todas dicotômicas, de modo que a categoria de base foi sempre a categoria associada à menor prevalência de desmame (ausência do AME). 
A hipótese estatística que buscamos testar, com a introdução dos termos de interação no modelo, foi a de que a condição contextual de residência da criança em um município com bom desempenho quanto à implementação de ações pró-amamentação (4-5 ações) poderia minorar a influência de determinados atributos individuais (das crianças ou de suas mães) sobre o risco de desmame (ausência de AME).

Inicialmente testou-se a interação entre "4-5 ações" e baixa escolaridade materna. Após a introdução do termo de interação, é interessante notar que o termo relativo à baixa escolaridade continua com coeficiente positivo $(R C>1)$ e estatisticamente significativo, assim como o termo "0-3 ações", isoladamente, permanece com coeficiente positivo e significativo sob o ponto de vista estatístico. Porém, o termo de interação "4-5 ações" e baixa escolaridade tem coeficiente negativo e estatisticamente significativo, ou seja, o efeito negativo da baixa escolaridade é minorado na presença de "4-5 ações" próamamentação. 


$$
\begin{aligned}
& \left.\begin{array}{l}
\text { desmame }_{i j} \sim \operatorname{Binomial}(\operatorname{denom} \\
\text { desmame } \left._{i j}, \pi_{i j}\right) \\
\pi_{i j}+e_{0 i j} \text { bcons }^{*}
\end{array}\right\} \\
& \operatorname{logit}\left(\pi_{i j}\right)=\beta_{1 j} \text { cons }+0,479(0,011) \text { faixaet }_{i j}+0,422(0,046) \text { escolaridade }_{i j}+
\end{aligned}
$$

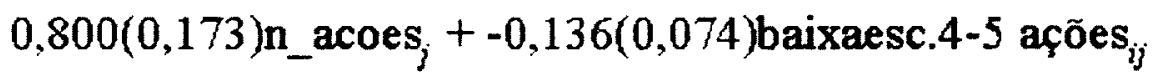

$$
\begin{aligned}
& \beta_{1 j}=-0,084(0,157)+u_{1 j} \\
& {\left[u_{1 j}\right] \sim N\left(0, \Omega_{u}\right): \Omega_{u}=[0,355(0,058)]} \\
& \text { bcons }^{*}=\text { bcons }\left[\pi_{i j}\left(1-\pi_{i j}\right) / \text { denom }_{i j}\right]^{0.5} \\
& {\left[e_{0 i j}\right] \sim\left(0, \Omega_{e}\right): \Omega_{e}=[1,000(0,000)]}
\end{aligned}
$$

A seguir, tomando-se o modelo com as variáveis do bloco hierárquico 2 (dos atributos maternos), foi incluido o termo de interação "4-5 ações $X$ mãe adolescente" , o qual não mostrou significado estatístico, tendo sido portanto desconsiderado. 
RESULTADOS

93

$$
\begin{aligned}
& \left.\begin{array}{l}
\text { desmame }_{i j} \sim \operatorname{Binomial}\left(\text { denom }_{i j}, \pi_{i j}\right) \\
\text { desmame }_{i j}=\pi_{\pi_{j j}}+e_{0 i j} \text { bcons }^{*}
\end{array}\right\} \\
& \operatorname{logit}\left(\pi_{i j}\right)=\beta_{1 j} \text { cons }+0,483(0,011) \text { faixaet }_{i j}+0,409(0,038) \text { escolaridade }_{i j}+ \\
& 0,884(0,167) n_{-} \text {acoes }_{j}+0,386(0,047) \text { adole }_{i j}+ \\
& 0,296(0,037) \text { primipara }_{i j}+-0,070(0,075) \text { adole }_{4} 4-5 \text { ações }_{j j} \\
& \beta_{1 j}=-0,391(0,156)+u_{1 j} \\
& {\left[u_{1 j}\right] \sim \mathrm{N}\left(0, \Omega_{u}\right): \Omega_{u}=[0,356(0,058)]} \\
& \text { bcons }^{*}=\text { bcons }\left[\pi_{i j}\left(1-\pi_{h j}\right) / \text { denom }_{i j}\right]^{0.5} \\
& {\left[e_{0 i j}\right] \sim\left(0, \Omega_{e}\right): \Omega_{e}=[1,000(0,000)]}
\end{aligned}
$$


RESULTADOS

94

O mesmo ocorreu com a introdução do termo de interação "4-5 ações $X$ primipara". Verifica-se, portanto, que o efeito de 4-5 ações municipais próamamentação não se mostrou capaz de modificar o efeito dos atributos maternos "primiparidade" e "mãe adolescente", ou seja, a presença de 4-5 ações pró-amamentação, nesse caso, não atenuou o risco de desmame relacionado a esses atributos materno.

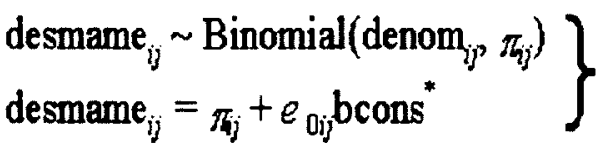

$$
\begin{aligned}
& \operatorname{logit}\left(\pi_{i j}\right)=\beta_{1 j} \text { cons }+0,484(0,011) \text { faixaet }_{i j}+0,409(0,038) \text { escolaridade }_{i j}+0,922(0,168) \mathbf{n}_{-} \text {acoes }_{j}+ \\
& 0,362(0,038) \text { adole }_{i j}+0,278(0,045) \text { primipara }_{i j}+0,051(0,071) \text { primipara } 4-5 \text { ações }_{i j} \\
& \beta_{1 j}=-0,417(0,156)+u_{1 j} \\
& {\left[u_{1 j}\right] \sim \mathrm{N}\left(0, \Omega_{u}\right): \Omega_{u}=[0,356(0,058)]} \\
& \text { bcons }{ }^{*}=b \operatorname{cons}\left[\pi_{i j}\left(1-\pi_{i j}\right) / \text { denom }_{i j}\right]^{0.5} \\
& {\left[e_{0 \text { aid }}\right] \sim\left(0, \Omega_{e}\right): \Omega_{\varepsilon}=[1,000(0,000)]}
\end{aligned}
$$


O próximo passo foi a inclusão das interações entre "4-5 ações" e as variáveis do bloco hierárquico 3 , relativas aos atributos das crianças.

A primeira interação testada foi com a variável sexo, tendo sido verificado que o efeito de 4-5 ações municipais pró-amamentação não se mostrou capaz de modificar o efeito desse atributo individual, descartando-se, portanto, a interação.

$$
\begin{aligned}
& \left.\begin{array}{l}
\text { desmame } \left._{i j} \sim \operatorname{Binomial}_{\left(\text {denom }_{i j}, \pi_{i j}\right)}\right) \\
\text { desmame }_{i j}=\pi_{\pi_{j j}}+e_{0 i j} \text { bcons }^{*}
\end{array}\right\} \\
& \operatorname{logit}\left(\pi_{i j}\right)=\beta_{1 j} \text { coils }+0,483(0,011) \text { faixaet }_{i j}+0,371(0,039) \text { escolaridade }_{i j}+ \\
& 0,885(0,171) \text { n_acoes }_{j}+0,340(0,038) \text { adole }_{i j}+ \\
& 0,303(0,037) \text { primipara }_{i j}+0,108(0,041) \text { sexo }_{i j}+ \\
& 0,357(0,062) \text { baixo_ } \mathbf{p}_{i j}+0,118(0,040) \text { sus }_{i j}+ \\
& -0,010(0,068) \text { menino.4-5 } \text { ações }_{i j} \\
& \beta_{1 j}=-0,545(0,161)+u_{1 j} \\
& {\left[u_{1 j}\right] \sim \mathrm{N}\left(0, \Omega_{u}\right): \Omega_{u}=[0,365(0,059)]} \\
& \text { bcons }{ }^{*}=\operatorname{bcons}\left[\pi_{i j}\left(1-\pi_{j j}\right) / \text { denom }_{i j}\right]^{0.5} \\
& {\left[e_{0 i j}\right] \sim\left(0, \Omega_{e}\right): \Omega_{e}=[1,000(0,000)]}
\end{aligned}
$$


Com a introdução do termo de interação baixo peso ao nascer e "4-5 ações" verificou-se que, isoladamente, os termos relativos ao baixo peso e às ações permanecem com coeficientes positivos $(R C>1)$ e estatisticamente significativos, porém, assim como o que ocorreu em relação à baixa escolaridade, a presença de 4-5 ações tem o efeito de minimizar o risco de desmame conferido pelo baixo peso ao nascer.

$$
\begin{aligned}
& \left.\begin{array}{l}
\text { desmame } \left._{i j} \sim \operatorname{Binomial}_{(\text {denom }}, \pi_{i j}\right) \\
\text { desmame }_{i j}={ }_{\pi_{j j}}+e_{0 i j} \text { bcons }^{*}
\end{array}\right\} \\
& \operatorname{logit}\left(\pi_{i j}\right)=\beta_{1 j} \text { cons }+0,482(0,011) \text { faixaet }_{i j}+0,371(0,039) \text { escolaridade }_{i j}+ \\
& 0,861(0,169) \text { n_acoes }_{j}+0,340(0,038) \text { adole }_{i j}+ \\
& 0,302(0,037) \text { primipara }_{i j}+0,104(0,033) \text { sexo }_{i j}+ \\
& 0,475(0,082) \text { baixo_ } \mathbf{p}_{i j}+0,119(0,040) \text { sus }_{i j}+ \\
& -0,310(0,125) b p .4-5 \text { ações }_{i j} \\
& \beta_{1 j}=-0,533(0,161)+u_{1 j} \\
& {\left[u_{1 j}\right] \sim \mathrm{N}\left(0, \Omega_{u}\right): \Omega_{u}=[0,369(0,060)]} \\
& \text { bcons }{ }^{*}=\text { bcons }\left[\pi_{i j}\left(1-\pi_{i j}\right) / \text { denom }_{i j}\right]^{0.5} \\
& {\left[e_{0 i j}\right] \sim\left(0, \Omega_{e}\right): \Omega_{e}=[1,000(0,000)]}
\end{aligned}
$$


Interação estatisticamente significativa também foi verificada entre as ações pró-amamentação e as crianças que freqüentam a rede SUS. Novamente o coeficiente do termo de interação é negativo ( $R C$ menor que um), ou seja, embora freqüentar a rede SUS e residir em municípios com 0-3 ações permaneçam como "fatores de risco" para o desmame, a presença de 4-5 ações pró-amamentação é capaz de reduzir o impacto negativo que a rede SUS teria sobre o AME.

$$
\begin{aligned}
& \left.\begin{array}{l}
\text { desmame }_{i j} \sim \operatorname{Binomial}\left(\text { denom }_{i j}, \pi_{i j}\right) \\
\text { desmame }_{i j}=\pi_{\pi_{j j}}+e_{0 i j} \text { bcons }^{*}
\end{array}\right\} \\
& \operatorname{logit}\left(\pi_{i j}\right)=\beta_{1 j} \text { cons }+0,484(0,011) \text { faixaet }_{i j}+0,377(0,039) \text { escolaridade }_{i j}+ \\
& 0,606(0,180) \text { n_acoes }_{j}+0,342(0,038) \text { adole }_{i j}+ \\
& 0,304(0,037) \text { primipara }_{i j}+0,105(0,033) \mathbf{s e x o}_{i j}+ \\
& 0,361(0,062) \text { baixo_} \mathbf{p}_{i j}+0,237(0,049) \text { sus }_{i j}+ \\
& -0,357(0,080) \text { SUS.4-5 ações }{ }_{i j} \\
& \beta_{1 j}=-0,366(0,165)+u_{1 j} \\
& {\left[u_{1 j}\right] \sim \mathrm{N}\left(0, \Omega_{u}\right): \Omega_{u}=[0,366(0,059)]} \\
& \text { bcons }^{*}=\operatorname{bcons}\left[\pi_{i j}\left(1-\pi_{i j}\right) / \text { denom }_{i j}\right]^{0.5} \\
& {\left[e_{0 i j}\right] \sim\left(0, \Omega_{e}\right): \Omega_{e}=[1,000(0,000)]}
\end{aligned}
$$


O passo seguinte consistiu da introdução simultânea, no modelo, dos dois termos de interação do bloco hierárquico 3 que se mostraram estatisticamente significativos. Verifica-se que os dois termos permanecem significativos, mesmo após o ajuste para todas as variáveis dos blocos hierárquicos 1,2 , e 3 e para a faixa etária da criança.

$$
\begin{aligned}
& \left.\begin{array}{l}
\text { desmame }_{i j} \sim \text { Binomial }_{\left(\text {denom }_{i j}, \pi_{i j}\right)} \\
\text { desmame }_{i j}=\pi_{\pi_{j}}+e_{0 i j} \text { bcons }^{*}
\end{array}\right\} \\
& \operatorname{logit}\left(\pi_{i j}\right)=\beta_{1 j} \text { cons }+0,484(0,011) \text { faixaet }_{i j}+0,377(0,039) \text { escolaridade }_{i j}+ \\
& 0,586(0,180) \mathbf{n}_{\text {acoes }}+0,342(0,038) \text { adole }_{i j}+ \\
& 0,304(0,037) \text { primipara }_{i j}+0,104(0,033) \text { sexo }_{i j}+ \\
& 0,469(0,081) \text { baixo } p_{i j}+0,235(0,049) \text { sus }_{i j}+
\end{aligned}
$$

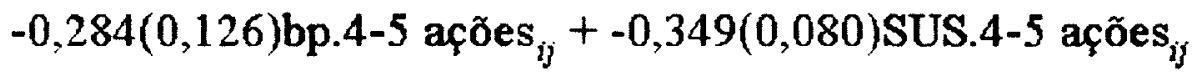

$$
\begin{aligned}
& \beta_{1 j}=-0,356(0,166)+u_{1 j} \\
& {\left[u_{1 j}\right] \sim N\left(0, \Omega_{u}\right): \Omega_{u}=[0,370(0,060)]} \\
& \text { bcons }^{*}=\text { bcons }\left[\pi_{i j}\left(1-\pi_{i j}\right) / \text { denom }_{i j}\right]^{0.5} \\
& {\left[e_{0 i j}\right] \sim\left(0, \Omega_{e}\right): \Omega_{e}=[1,000(0,000)]}
\end{aligned}
$$


O modelo final com interações permite calcular as razões de chance para o desmame associadas a cada um dos atributos individuais (das crianças e das mães) e na condição contextual de residência em municípios com pior (0-3 ações) ou melhor (4-5 ações) desempenho quanto à implementação de ações pró-amamentação. (Tabela 13)

Tabela 13. Fatores de risco para o desmame, com e sem o efeito da interação com a variável "somatória do $\mathrm{n}^{\circ}$ de açōes pró-amamentação". Crianças menores de seis meses de 111 municipios do ESP, 1999.

\section{RC para o desmame}

Bloco Fator de risco Com 0-3 ações Com 4-5 ações

hierárquico

\begin{tabular}{|c|c|c|c|}
\hline \multirow[t]{2}{*}{$\overline{1}$} & Escolaridade ( $<8$ anos) & $1,53^{*}$ & $1,33^{*}$ \\
\hline & Idade materna (< 18 anos) & $1,44^{\star \star}$ & $1,44^{\star \star}$ \\
\hline \multirow[t]{2}{*}{2} & Paridade (primipara) & $1,34^{\star \star}$ & $1,34^{\star \star}$ \\
\hline & Sexo da criança (masculino) & $1,11^{* * *}$ & $1,11 * *$ \\
\hline \multirow[t]{2}{*}{3} & Peso ao nascer (baixo peso) & $1,60^{m+*}$ & $1,20^{* \star *}$ \\
\hline & $\begin{array}{l}\text { Seguimento } \\
\text { ambulatorial(SUS) }\end{array}$ & $1,26^{* * \pi}$ & $0,89^{* * n}$ \\
\hline
\end{tabular}

\footnotetext{
${ }^{*} R C$ ajustada para a idade da criança e somatória do $n^{\circ}$ de ações municipais pró-amamentação

** $R C$ ajustadas para a idade da criança, variáveis dos blocos hierárquicos 1 e 2 e somatória do

$n^{\circ}$ de ações municipais pró-amamentação

*** RC ajustadas para a idade da criança, variáveis dos blocos hierárquicos 1,2 e 3 e somatória do $n^{\circ}$ de ações municipais pró-amamentação
} 
Verifica-se que a condição contextual de residência em municípios com melhor desempenho quanto a ações pró-amamentação reduz o impacto negativo da baixa escolaridade matema sobre o AME e o efeito do baixo peso ao nascer. Além disso, o fator de risco para o desmame "freqüentar a rede SUS" tem seu efeito modificado de tal forma nos municipios com melhor desempenho das políticas de amamentação, que acaba por transformar-se, nesses municipios, em um fator de proteção para o AME. 


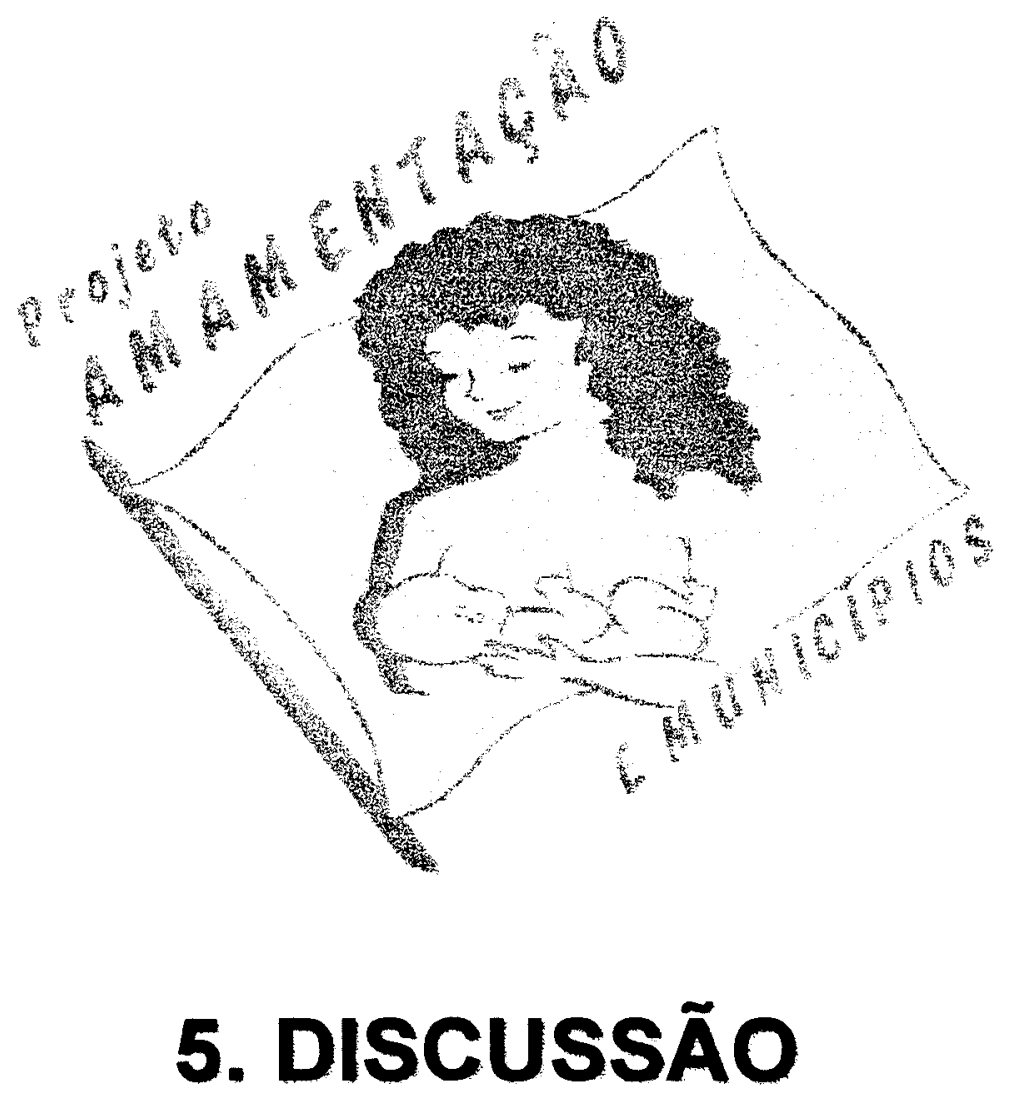

Um galo nāo tece uma manhā, ele precisará sempre de outros galos.

De um que apanhe esse grito e que o lance a outro;

De um outro galo que apanhe o grito de um galo antes e o lance a outro;

E de outros galos que, com muitos outros galos,

Cruzem os fios do sol de seus gritos de galo,

Para que a manhā, desde uma tênue teia, se vá tecendo, entre todos os galos.

(Joāo Cabral de Melo Neto) 
Verificou-se que, no conjunto das 34.435 crianças residentes nos 111 municipios do ESP, é baixa a prevalência do AME em menores de seis meses, sendo bastante heterogênea a distribuição do AME nos municipios

A utilização da análise multinivel permitiu a identificação de determinantes individuais e contextuais do AME. O modelo final mostrou que $\mathrm{O}$ aleitamento materno exclusivo, na amostra estudada, sofre a influência da condição socioeconômica (expressa pela escolaridade materna), de atributos maternos (idade e paridade) e de caracteristicas das crianças (sexo, peso de nascimento e acompanhamento na rede pública ou privada de serviços de saúde). Verificou-se ainda que, controlados os efeitos das variáveis individuais, a somatória do número de ações de proteção, promoção e apoio ao aleitamento materno desenvolvidas pelos municípios exerce um impacto positivo sobre o AME, havendo indicação de que a implementação dessas ações atenua 0 impacto negativo sobre o AME de condições socioeconômicas desfavoráveis (indicada pela baixa escolaridade materna), do baixo peso de nascimento e inverte o sentido da associação entre o acompanhamento ambulatorial da criança em serviço público de saúde e $O A M E$, tornando aquele acompanhamento fator de proteção e não mais fator de risco para o desmame.

A discussão dos resultados deste trabalho está estruturada em três tópicos, nos quais se discorre sobre: 1) limitações do estudo; 2) comparações com a literatura e 3) implicações. 


\subsection{Limitações do estudo}

Nos últimos anos tem-se verificado no Brasil uma tendência crescente de estudos que investigam a situação municipal do aleitamento matemo a partir de inquéritos realizados junto à população de crianças imunizadas nos Dias Nacionais de Vacinação (CARVALHAES et al, 1997; MONEGO et al, 1998; VIEIRA et al, 1998; ARCOVERDE et al, 1997; MENDES-GOMES et al, 1998; SENA et al, 1999).

São vantagens dessa estratégia, evidentemente, o baixo custo para a sua realização, a relativa facilidade para o seu planejamento, a rapidez na coleta de dados e o alto grau de adesão da população (KITOKO et al, 2000).

Destacam-se a seguir algumas limitações dos inquéritos baseados na população de crianças imunizadas nos Dias Nacionais de Vacinação as quais poderiam interferir na validade intema e externa do presente estudo.

\subsubsection{Validade interna}

\section{-Viés de informação:}

A impossibilidade de refazer as entrevistas, caso sejam identificadas inconsistências de preenchimento ou ausência de informação nos questionários, é uma evidente limitação dos inquéritos realizados nos Dias Nacionais de Vacinação. Visando minorar os efeitos decorrentes da 
impossibilidade de re-entrevistar as mães das crianças estudadas pelo Projeto Amamentação e Municípios, enfatizou-se no treinamento oferecido a todas as coordenações municipais a necessidade do rigoroso treinamento de todos os supervisores e entrevistadores, bem como a necessidade de que todos recebessem os manuais de procedimentos em campo preparados pela coordenação geral do projeto

Além disso, vale notar que a participação dos 111 municipios no projeto foi absolutamente voluntária, garantindo-se com isso o interesse e o entusiasmo das coordenações municipais pelo projeto

Outra providência tomada pelo projeto Amamentação e Municípios, visando garantir a qualidade das informações obtidas, foi a restrição do questionário de modo que toda entrevista não ultrapassasse, em média, 4 minutos.

Como já foi mencionado, as questões relacionadas às características maternas foram aplicadas somente quando as crianças eram acompanhadas de suas mães. Esse procedimento levou a perdas em $10 \%$ dos casos mas, por outro lado, garantiu a obtenção de informações fidedignas sobre os atributos maternos.

Uma limitação adicional merece ser apontada em relação aos municípios pequenos. Apesar da maior facilidade em realizar inquéritos nesses municipios, - pequeno número de crianças estudadas, mesmo representando toda a população de menores de um ano, determina flutuações aleatórias das estimativas de ano para ano, seja quanto à freqüência do aleitamento matemo, 
seja quanto à associação entre atributos individuais e contextuais e aleitamento materno. Nessa situação, estimativas mais confiáveis requereriam o acúmulo de inquéritos anuais. De qualquer sorte, os erros introduzidos por flutuações aleatórias tenderiam a subestimar (e não superestimar) as associações encontradas entre determinantes e freqüência do aleitamento materno.

\section{-Viés de seleção}

O fato de os inquéritos municipais sobre a situação da amamentação realizados em Dias Nacionais de Vacinação não se apoiarem em amostras probabilísticas da população infantil residente nos municipios acarreta a possibilidade de que os resultados desses inquéritos não possam ser generalizados para o conjunto da população infantil dos municípios estudados, o que, em tese, prejudicaria a validade externa dos resultados do presente estudo. Em face dos argumentos relacionados a seguir, acredita-se que a validade dos resultados do presente estudo se aproxima da validade que se observaria caso os inquéritos sobre a situação municipal do aleitamento materno fossem domiciliares. 
1) A cobertura das campanhas de vacinação na maioria dos 111 municipios estudados é elevada

A validade extema dos resultados do presente estudo poderia ser questionada se a cobertura das campanhas de vacinação (proporção de crianças vacinadas sobre o total estimado de crianças no municipio) fosse baixa nos municípios estudados.

Do total de 111 municipios que realizaram a pesquisa, 90 optaram por coletar os dados na primeira fase da campanha de vacinação (agosto de 1999) e 21 o fizeram na segunda fase (outubro de 1999).

Analisando-se os dados de cobertura da campanha de vacinação de 1999 de todos os municipios, nas respectivas fases em que realizaram a pesquisa, verifica-se que, em média, essa cobertura foi de $91 \%$ sendo que a maioria dos municipios estudados atingiu coberturas vacinais acima de $90 \%$ (Figura 10). 
Figura 10. Distribuição dos 111 municipios paulistas que participaram do projeto Amamentação e Municipios segundo intervalos de cobertura da campanha de vacinação na qual realizou-se a pesquisa, 1999.

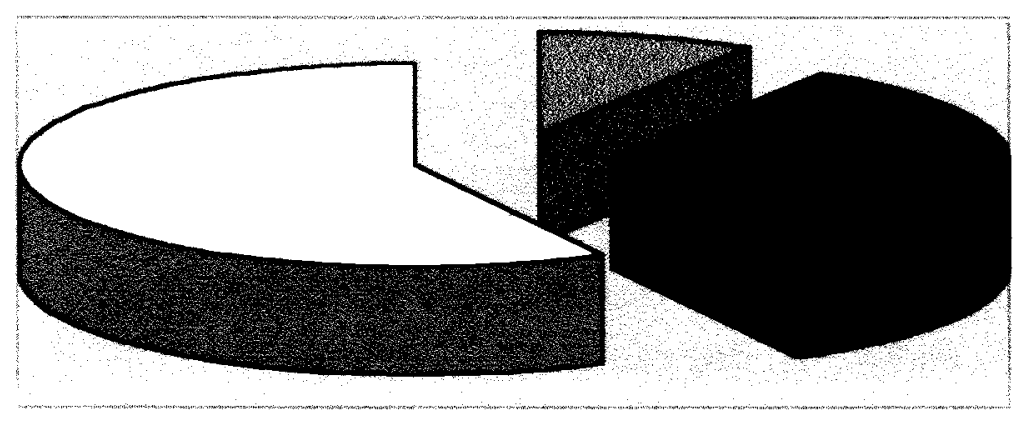

70-80\% - $81-90 \%$ $\square 91-100 \%$

2) $O$ percentual de perdas de crianças menores de um ano é baixo

Outro ponto que deve ser levado em consideração, quando se analisa a validade interna do presente estudo, diz respeito ao percentual de perdas de crianças ou à "cobertura da pesquisa".

Os coordenadores da pesquisa nos municipios são orientados a adotar diferentes estratégias para evitar perdas na fila, como, por exemplo, a formação de filas somente para as crianças menores de um ano e a identificação das crianças alvo da pesquisa com fitas ou adesivos.

Para os municípios pequenos, foi possível calcular o percentual de perdas de crianças (proporção de crianças incluídas no estudo sobre o total de 
crianças vacinadas no município). A Figura 11 mostra que, dos 91 municipios que realizaram a pesquisa em caráter universal (sem utilizar amostras), a maioria incluiu mais de $80 \%$ das crianças menores de um ano que freqüentaram a campanha de vacinação, sendo que a cobertura da pesquisa nesses municípios atingiu, em média, 81,9\%.

Figura 11. Distribuição dos 91 municípios paulistas que participaram do projeto Amamentação e Municípios sem utilizar amostras segundo intervalos de perda de crianças menores de um ano que deveriam ser incluídas na pesquisa, 1999.

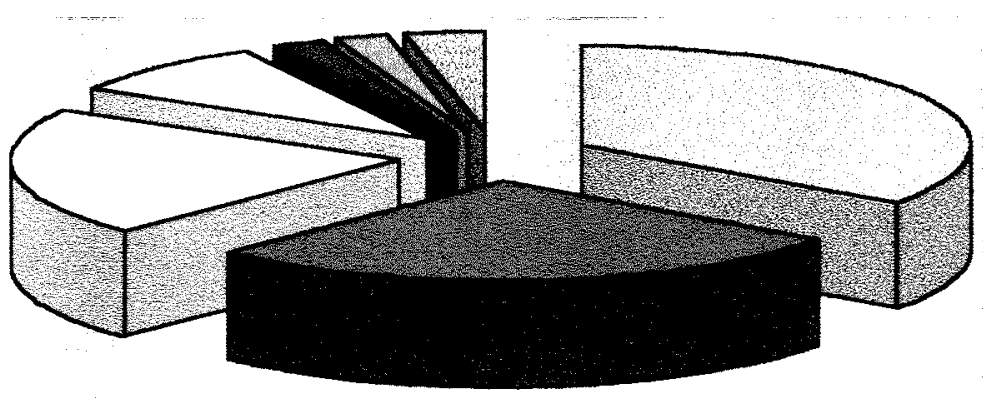


3) Nos municípios que utilizaram amostras, a distribuição das crianças segundo variáveis que podem influenciar o aleitamento materno se aproxima daquela estimada para a população infantil dos municípios

A existência do Sistema de Informação de Nascidos Vivos (SINASC) possibilitou a comparação entre as crianças menores de um ano incluidas no estudo (a partir do processo de amostragem) com o total de nascidos vivos em cada um dos municípios, segundo a situação de escolaridade matema, idade materna, tipo de parto e baixo peso ao nascer (ANEXO 8 ). Utilizou-se para tais comparações os dados do SINASC de 1998.

Verifica-se que em $1 / 4$ dos municípios que utilizaram amostras, 0 percentual de baixa escolaridade materna pode ser considerado equivalente segundo as duas fontes (SINASC e projeto Amamentação e Municípios). Nos demais municipios, prevalências pouco menores de baixa escolaridade foram verificadas nas amostras estudadas, quando comparadas ao total de nascidos vivos de 1998 em cada município. O percentual de mães adolescentes e o percentual de partos vaginais foram similares segundo as duas fontes na maioria dos municípios, e em relação ao baixo peso ao nascer os indicadores foram equivalentes em todos os municipios analisados. 


\subsubsection{Validade externa}

Sobre a validade extema do presente estudo, é importante lembrar que os resultados de prevalência global de AME não são representatvos do Estado de São Paulo, uma vez que a amostra foi composta de forma intencional, a partir do interesse dos municipios na realização da pesquisa sobre aleitamento materno. Porém, acredita-se que as associações entre o AME e as variáveis explanatórias analisadas possam ser generalizáveis para outros municípios do Estado de São Paulo e outros estados que tenham características semelhantes às dos municípios estudados

\subsection{Comparações com a literatura}

\subsubsection{A freqüência do aleitamento materno nos 111 municipios estudados}

Chama a atenção, nesse estudo, a baixa freqüência do aleitamento materno exclusivo em menores de seis meses e a grande variação desse indicador nos 111 municípios estudados.

Inquéritos sobre amamentação em dias nacionais de vacinação foram realizados sob a coordenação do Ministério da Saúde em 1999, em todas as capitais brasileiras, exceto o Rio de Janeiro, empregando metodologia semelhante à do projeto Amamentação e Municipios (amostragem por conglomerados, questionário semi-estruturado com questões sobre alimentação das crianças menores de um ano nas 24 horas anteriores à pesquisa e indicadores de aleitamento materno propostos pela OMS). Essa pesquisa 
mostra que é baixa a média das prevalências de aleitamento materno exclusivo em menores de quatro meses $(35,6 \%)$ nas capitais estudadas e, à semelhança do que se verificou no presente estudo, detectou ampla variação da situação da amamentação exclusiva no País. Porém, verifica-se no ESP maior concentração de municípios em intervalos de prevalência entre 0 e $20 \%$, enquanto que nas capitais brasileiras a maior freqüência de $A M E$ em menores de quatro meses está entre 20 e $30 \%$, sendo considerável o número de capitais que têm prevalências acima de $40 \%$ (Figura 12)

Figura 12 -Distribuição percentual de 111 municípios do ESP e de capitais brasileiras segundo intervalos de prevalência do AME em menores de quatro meses, 1999.

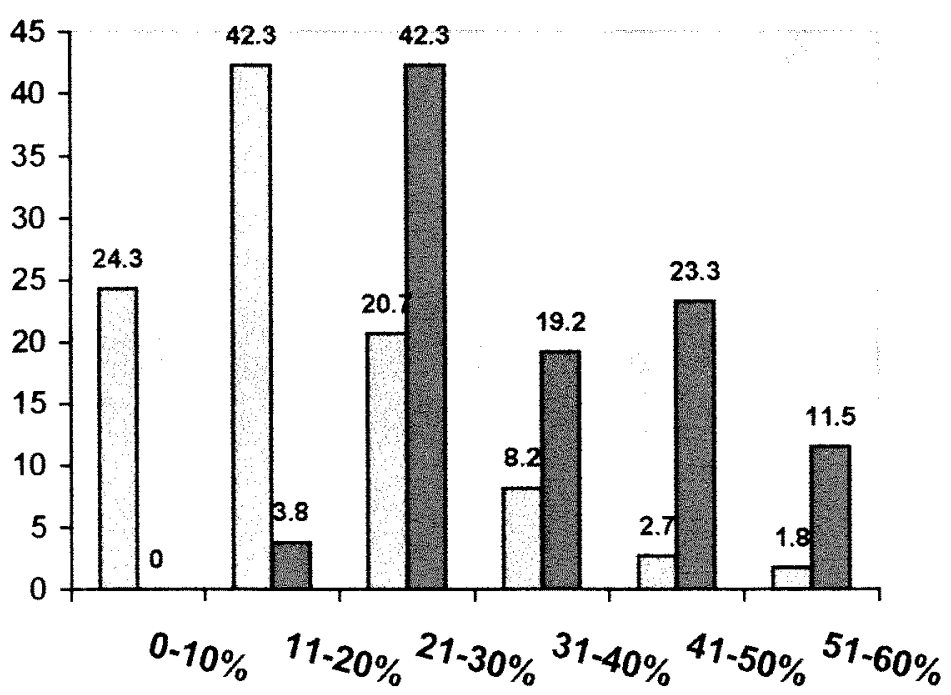


O presente estudo identificou ainda alto percentual de crianças em aleitamento matemo predominante. A introdução de líquidos não nutritivos é precoce, especialmente o chá. O questionário aplicado pelos municípios em 1999 permite verificar que um terço das crianças teriam recebido chá no primeiro dia em casa, após a alta da matemidade. Este fato sugere que a orientação dos profissionais de saúde não tem sido eficiente para evitar a introdução precoce dos líquidos não nutritivos. Sabe-se até mesmo que muitos profissionais de saúde prescrevem rotineiramente o uso de água e chás. Estudo realizado no município de Pelotas (RS) mostrou que $44 \%$ dos médicos que prestavam atendimento pediátrico no serviço público ou privado prescreviam o uso de chás para crianças menores de seis meses, para o tratamento de cólicas ou suplementação à dieta (CESAR et al, 1996).

\subsubsection{Os determinantes individuais e contextuais do aleitamento materno exclusivo}

Identificam-se, na literatura, poucos estudos sobre determinantes do aleitamento materno exclusivo, sendo que os mesmos têm privilegiado a investigação de características individuais (atributos das mães e das crianças) associadas a essa prática. O fato de não terem sido detectados estudos que analisam o papel de variáveis contextuais na determinação do AME limitará, de alguma forma, a discussão dos achados do presente estudo. A seguir, discute- 
se a influência de atributos individuais sobre o $A M E$, à luz de alguns trabalhos recentemente publicados.

\section{A influência de atributos individuais sobre o AME}

Analisando-se inicialmente o papel da condição socioeconômica na determinação do $A M E$, inserida no primeiro bloco hierárquico do marco conceitual apresentado, e sintetizada nesse estudo pela variável escolaridade materna, verifica-se que a melhor condição socioeconômica favorece o AME. Pôde-se observar um efeito do tipo "dose-resposta", ou seja, a chance de AME aumenta à medida que aumenta o nivel de escolaridade da mãe, de tal forma que mulheres que têm o $3^{\circ}$ grau incompleto/completo têm o dobro de chance de amamentarem exclusivamente seus filhos nos primeiros seis meses de vida quando comparadas às mulheres que não completaram o $1^{\circ} \mathrm{grau}$.

Sabe-se que em muitos paises industrializados existe uma associação positiva entre nivel socioeconômico da família e aleitamento materno (TRUSSEL,1992) e que o mesmo não ocorre em paises em desenvolvimento, onde a amamentação tende a declinar com a melhoria do nível socioeconômico (SIMOPOULOS E GRAVE, 1984; WILLIANSON, 1989).

Estudos realizados no Brasil identificam um padrão de amamentação semelhante àquele encontrado nos países desenvolvidos, no que se refere ao papel do nível socioeconômico. Podemos citar como exemplos os estudos realizados nos municípios de São Paulo (MONTEIRO et al, 1988) e Pelotas 
(BARROS et al 1986), nos quais descrevem-se associações positivas entre freqüência de amamentação e escolaridade do chefe da familia e renda familiar.

Embora a influência da condição socioecônomica sobre o aleitamento materno seja conhecida, pouco se sabe até o momento sobre a influência daquela condição sobre a freqüência do aleitamento matemo exclusivo.

O último estudo populacional realizado no Brasil mostrou que a duração mediana da amamentação exclusiva era inferior a um mês entre mulheres com menos de três anos de escolaridade e de cerca de dois meses entre mulheres com 12 ou mais anos de escolaridade (BEMFAM, 1997). Porém, considerando os problemas metodológicos que envolveram a definição do $A M E$, já discutidos anteriormente, não parece adequado considerar esses dados para a análise da associação entre situação socioeconômica e AME no Brasil.

Estudo prospectivo realizado por PÉREZ-ESCAMILLA et al (1995), em municípios de diferentes países (Santos/Brasil, Cidade do México/México e San Pedro Sula e Tegucigalpa/Honduras), mostrou que a amamentação exclusiva era mais freqüente entre mulheres de alto nivel socioeconômico no municipio de Santos, São Paulo, sendo que em municípios do México e Honduras, o oposto ocorria.

Na cidade de Benin, Nigéria (EREGIE, 1998) e em Istambul e na Turquia (NEYSI et al, 1991), nenhuma associação foi encontrada entre a situação socioeconômica das mulheres e a duração da amamentação exclusiva. 
Esses achados indicam a necessidade de realização de mais estudos, em diferentes culturas, para melhor investigar a associação entre a prática da amamentação exclusiva e variáveis socioeconômicas.

Em relação aos atributos maternos, inseridos no segundo bloco hierárquico do marco conceitual utilizado no presente estudo, pôde-se identificar associação estatisticamente significativa entre idade materna e AME. Esse dado corrobora o resultado de estudo colaborativo realizado no Brasil, México e Honduras, no qual somente na amostra de mulheres brasileiras foi identificada uma tendência maior de amamentação exclusiva entre as maiores de 18 anos. Os autores do estudo consideram que é provável que as adolescentes amamentem menos pelo fato de terem menos suporte social (PERÉZ-ESCAMILLA, 1995).

No tocante à paridade, este estudo identificou maior chance de amamentação exclusiva entre as multíparas. Não existe consenso na literatura sobre o efeito da paridade sobre o aleitamento matemo, e pouco se sabe sobre a influência desse atributo sobre o AME. SIMOPOULOS E GRAVE (1984), revisando a literatura sobre determinantes do aleitamento materno, verificaram que a amamentação era mais freqüente entre os primogênitos e discutem que a experiência prévia de amamentação de um filho poderia influenciar a opção por amamentar ou não os outros filhos. FORMAN (1984) em ampla revisão da literatura sobre determinantes do AM em países em desenvolvimento, identificou situação oposta à descrita por SIMOPOULOS e GRAVE (1984), e 
descreve que a chance de aleitamento materno aumenta com o aumento do número de filhos.

Quanto à situação de trabalho, identificou-se que mulheres que não trabalhavam fora de casa tenderam a praticar mais a amamentação exclusiva, porém a associação entre essa variável e o AME não alcançou significado estatístico nas análises preliminares, sendo a variável excluida da análise multivariada.

PERÉZ-ESCAMILLA et al (1995) verificaram, no Brasil e em Honduras, que mulheres que haviam retornado ao trabalho tiveram menor chance de AME quando comparadas às que não haviam retomado. Porém, não foi possivel identificar, nesse estudo, se o trabalho havia causado a interrupção do AME ou se as mulheres haviam introduzido suplementos antes mesmo de retomarem ao trabalho.

HIGHT-LAURAKAN et al (1996), utilizando dados disponiveis das Pesquisas em Demografia e Saúde (DHS) de 15 países, calcularam o risco atribuivel populacional do uso de substitutos do leite materno entre mulheres cujo emprego as mantinham afastadas de seus filhos. Os autores verificaram que o emprego era responsável por somente $5 \%$ ou menos do uso de substitutos do leite materno e, portanto, concluem que outros fatores estariam determinando o desmame precoce.

No Sri Lanka, um inquérito populacional foi realizado entre mulheres trabalhadoras rurais, sendo que o retorno ao trabalho e a percepção de ter leite 
insuficiente mostraram-se negativamente associados com a prática da amamentação exclusiva (SORENSEN et al, 1998).

Embora não se verifique consenso na literatura acerca do impacto do trabalho sobre o AME, é generalizado o consenso sobre a necessidade do reforço da legislação de proteção à mulher que trabalha e amamenta e do apoio especial às mulheres que permanecem afastadas de seus filhos em função do trabalho.

No tocante à influência dos atributos das crianças, inseridos no último bloco hierárquico, verificou-se maior chance de amamentação exclusiva entre as crianças do sexo feminino. Esse dado coincide com os achados do estudo de PÉREZ-ESCAMILLA et al (1995) no Brasil e em Honduras. Os autores discutem a possibilidade de os profissionais de saúde e/ou mães acreditarem que os meninos têm maiores necessidades nutricionais, e, portanto, necessitarem mais cedo de complementos alimentares. Esse mesmo achado foi descrito em estudo realizado nas Filipinas, sugerindo que essa associação pode ser comum em diferentes regiōes do mundo (ADAIR, 1993).

O peso de nascimento mostrou forte associação com AME no presente estudo. HORTA et al. (1996) já haviam descrito que bebês de baixo peso tendem a ser amamentados por periodos mais curtos. EREGIE (1998), em estudo realizado na Nigéria, analisando a associação do AME com as variáveis idade matema, educação materna e peso de nascimento identificou que somente o peso de nascimento apresentou associação estatisticamente significativa com a amamentação exclusiva, após o controle das demais 
variáveis. Estudo realizado no Brasil e em Honduras identificou maior duração da amamentação exclusiva em crianças nascidas com peso maior ou igual a $3.100 \mathrm{~g}$ (PÉREZ-ESCAMILLA et al 1995). Esse achado é consistente com a hipótese de que os bebês de menor peso de nascimento, por apresentarem uma sucção mais fraca, não estimulariam o estabelecimento de uma produção adequada de leite materno (PERÉZ-ESCAMILLA, 1995b).

No presente estudo verificou-se, ainda, que as crianças que realizavam seguimento ambulatorial na rede privada de serviços de saúde tiveram mais chance de AME quando comparadas às que freqüentavam a rede pública (SUS), mesmo após o controle para a condição socioeconômica e outras possiveis variáveis de confusão. Entretanto, como se comentará a seguir, os modelos multivariados que estudaram a interação entre variáveis contextuais e atributos individuais com a freqüência de AME indicaram que o "efeito negativo" do seguimento na rede pública é restrito aos municípios com mau desempenho quanto à implementação de ações pró-amamentação

No presente estudo, as crianças que nasceram de cesárea tenderam a apresentar maior freqüência de AME, porém a variável perdeu significância estatística quando analisada no modelo multivariado. Estudo realizado por MAZUR e MIKIEL-KOSTYRA (2000) sobre a associação entre práticas hospitalares e AME identificou associação significativa entre o tipo de parto e AME, sendo que as crianças nascidas de parto cesárea tiveram 5,2 vezes mais chance de introduzir suplementos quando comparadas às nascidas de parto vaginal. 


\section{A influência das variáveis contextuais sociodemográficas}

A partir de uma análise ecológica, verificou-se que a localização do municipio em região metropolitana ou interior do Estado, seu porte populacional e seu nível de desenvolvimento socioeconômico, medido pelo IPRS municipal, não influíram significativamente sobre a freqüência do AME. Esses achados sugerem que o AME é um fenômeno que, diferentemente de outros desfechos como mortalidade infantil e desnutrição, não têm nas características "macro-contextuais" seus principais determinantes. O quadro se modifica quando analisamos a influência do contexto no que se refere à existência nos municípios de ações de incentivo à amamentação, o que se comenta a seguir.

A influência das variáveis contextuais relativas às ações próamamentação sobre o AME

É importante lembrar que as ações municipais de incentivo à amamentação escolhidas para essa análise refletem em grande parte as proposições de organismos intemacionais para a construção de uma política abrangente de incentivo à amamentação (OMS, 1989).

A análise de cada uma das ações isoladamente revelou alguns aspectos importantes, que serão discutidos a seguir. 
Os municipios que relataram possuir politicas formais de incentivo ao aleitamento materno instituídas, apresentaram média de prevalências de aleitamento matemo exclusivo superiores à observada entre os municipios sem políticas formais. O fato de possuir politicas formais de incentivo ao aleitamento materno foi entendido como indicação do investimento político feito em prol da amamentação no município. Os municípios que não contavam com uma política local de aleitamento materno foram aqueles que, em treinamentos e reuniões, referiam claramente que o incentivo à amamentação era praticado por um profissional de saúde determinado, ou por um pequeno grupo de profissionais interessados no assunto, sem que isso tivesse reflexo na definição das prioridades da agenda municipal.

Outra ação de proteção ao aleitamento materno analisada foi o monitoramento da NBCAL - Norma Brasileira de Comercialização de Alimentos para Lactentes. $E$ interessante verificar, antes de mais nada, a baixa freqüência com que essa ação é relatada pelos municipios. Esse fato é preocupante, pois é reconhecido que, entre as diversas causas do desmame precoce, especialmente em regiões industrializadas, está a influência negativa da presença e da propaganda de alimentos artificiais (REA e TOMA 2000).

Apesar do potencial efeito negativo da propaganda e da existência no Brasil de uma legislação específica que regulamenta a promoção comercial dos alimentos infantis, poucos municipios se dedicam à atividade de monitoramento de cumprimento dessa legislação, à exceção dos locais que contam com a 
existência de grupos da Rede IBFAN (International Baby Food Action Network), que somam cerca de 30 cidades no país.

De qualquer sorte, observou-se que a média das prevalências de AME nos três municipios que referiram atuar em relação ao cumprimento da legislação foi ligeiramente inferior à média encontrada nos demais municípios, admitindo-se que esse resultado se deva ao acaso. Por essa razão, a variável monitoramento da NBCAL não foi incluída na construção da variável que expressa a somatória das ações pró-amamentação no município.

A principal estratégia de promoção do aleitamento matemo no Brasil tem sido a realização de atividades durante a Semana Mundial de Amamentação SMAM. Promovida pela Waba, uma rede intemacional de pessoas físicas e organizações não-governamentais (ONGs) e, no Brasil, em parceria com a Coordenação de aleitamento materno do Ministério da Saúde, a Semana Mundial foi instituída para reforçar a necessidade de fazer cumprir as propostas da Declaração de Innocenti (www.saude.gov.br)

Vale notar que os esforços do Ministério da Saúde para a divulgação e elaboração de material de apoio à Semana (cartazes, panfletos, manuais) e o apoio conseguido através de convênios firmados com o serviço postal em várias regiões têm sido importantes para a adesão de muitos municípios brasileiros a essa iniciativa.

Muitos municípios têm instituído equipes multiprofissionais para oferecer suporte às mulheres que amamentam. Sabe-se que essa é uma estratégia bem sucedida, a exemplo do que foi relatado por BARROS et al 
(1995) no municipio do Guarujá, São Paulo. No presente estudo, a existência no municipio de um grupo multiprofissional dedicado à amamentação teve influência significativa sobre a prevalência da amamentação exclusiva.

A implementação de Bancos de Leite Humano - BLH, segundo ALMEIDA (1999), foi nas duas últimas décadas um dos mais importantes elementos estratégicos da política brasileira em favor da amamentação. Mais do que locais destinados ao processamento e amazenamento de leite matemo, os BLH têm desempenhado um papel fundamental no apoio à amamentação. Entretanto, no presente estudo, poucos municípios implantaram BLH. Embora a média das prevalências do AME tenha sido ligeiramente superior nos poucos municipios que contaram com BLH, a associação entre essa condição e o AME não foi estatisticamente significativa. O fato de poucos municipios contarem com essa condição reduziu o poder da análise estatistica em identificar o impacto da existência dos BLH nos municipios.

O mesmo ocorreu quando foi analisada a influência da IHAC - Iniciativa Hospital Amigo da criança sobre o AME. Apenas dois municípios dos cento e onze estudados contavam com um HAC. A média das prevalências de AME foi superior nesses municípios, porém não de forma significativa do ponto de vista estatístico. $\dot{E}$ interessante notar que, tomando-se somente as crianças estudadas nos dois municípios que possuiam HAC, a prevalência de AME foi de $24,5 \%$ para as que nasceram nesses hospitais e $16,3 \%$ para as que nasceram em outros hospitais. Ainda considerando apenas as crianças que nasceram nesses dois municípios, verificou-se que a freqüência de $A M E$ foi 
superior entre as crianças que nasceram nos HAC até o quarto mês de vida (FIGURA 13). De fato espera-se que a influência positiva sobre o AME das ações desenvolvidas nos HAC seja maior nos primeiros meses de vida da criança, sendo que a manutenção da amamentação do quarto ao sexto mês depende de outros mecanismos de apoio, inclusive os relacionados à garantia dos direitos da mulher trabalhadora.

Figura 13 - Freqüência de crianças em AME em diferentes idades segundo hospital de nascimento (Hospitais Amigos da Criança HAC ou outros hospitais). São Paulo, 1999.

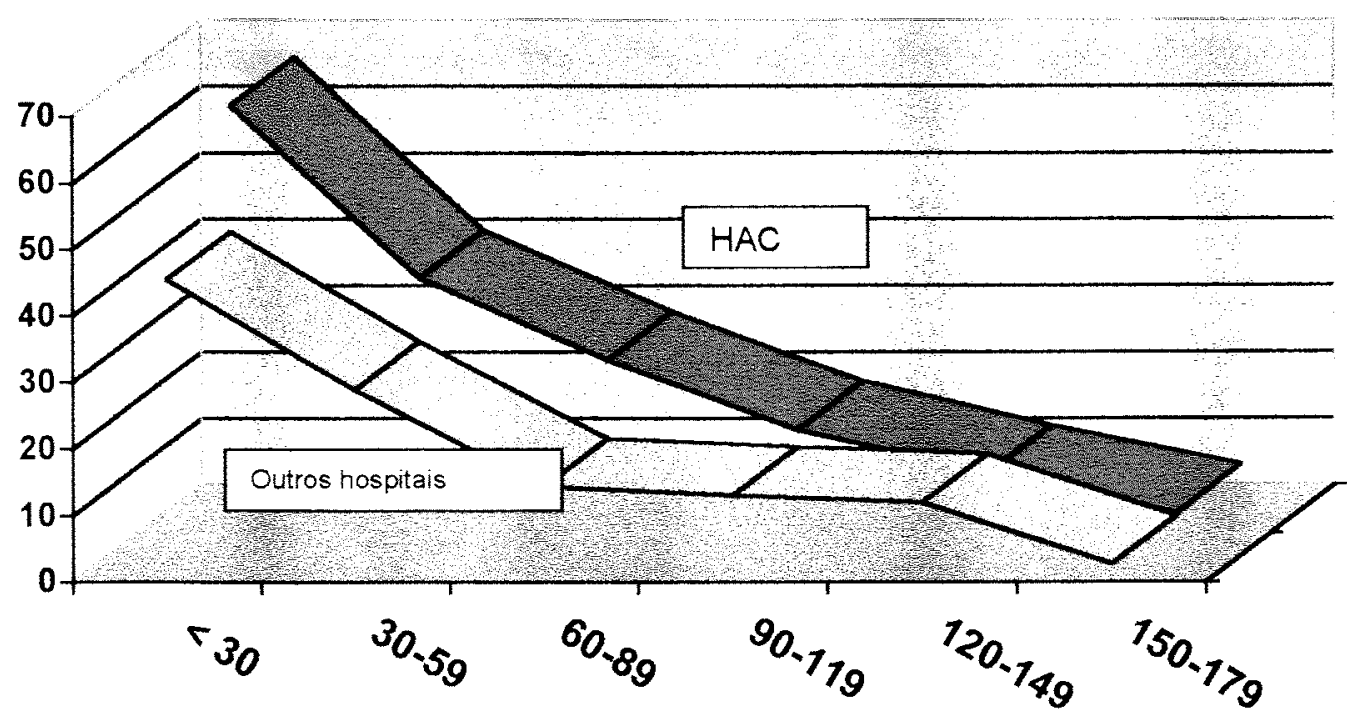

faixa etárìa (dias) 
$\mathrm{Na}$ literatura existem alguns relatos que demonstram a influência de determinadas rotinas hospitalares sobre o AME. Por exemplo, em Santos, São Paulo, uma pesquisa mostrou que a implementação de alguns dos passos da IHAC (alojamento conjunto, início precoce da amamentação e apoio à amamentação durante o período de hospitalização) aumentou em dois meses (de 22 para 75 dias) a duração mediana da amamentação exclusiva (LUTTER et al 1997). Os resultados de outro estudo realizado em Porto Alegre, comparando a freqüência de AME entre crianças nascidas em um hospital antes e dois anos depois da implantação da IHAC mostram que a prevalência de AME dobrou com a implementação dos Dez Passos (aumentou de $28 \%$ para $53 \%$ aos 30 dias de vida e de $16 \%$ para $36 \%$ aos dois meses) (GIUGLIANI 2001). Porém mais estudos precisam ser desenvolvidos para avaliar o impacto do cumprimento dos Dez passos para o sucesso do aleitamento matemo, que constituem as bases da IHAC.

Um passo fundamental para garantir a implementação do apoio às mães diz respeito à capacitação de profissionais de saúde. Segundo NAYLOR (1994) a maioria dos profissionais considera o leite matemo o alimento de escolha para as crianças, mas nem todos estão preparados para o manejo clínico da lactação.

O impacto positivo de um curso de manejo da lactação sobre o AME, promovido pelo Centro de Lactação de Santos, São Paulo, foi relatado por TADDEl et al. (2000). 
REA e VENANCIO (1999) avaliaram o impacto do Curso de Aconselhamento em Amamentação, mostrando que o mesmo é capaz de aumentar conhecimentos, melhorar as habilidades no manejo clínico e o desempenho dos participantes na utilização de técnicas de aconselhamento em amamentação.

O presente estudo considerou como evidência da capacitação de profissionais de saúde a realização de dois treinamentos: o curso Manejo Clínico e Promoção do Aleitamento Materno, também conhecido por "Curso de 18 horas" (UNICEF), elaborado para o cumprimento do passo 2 da IHAC e o curso de Aconselhamento em Amamentação (OMSMellstart). Os municípios que desenvolveram esses cursos apresentaram médias das prevalências de AME, superiores aos demais, porém a associação entre essa ação e o AME não chegou a ser significativa $(p=0,09)$.

Por fim, os municipios que relataram a realização anterior de pesquisa sobre aleitamento materno tiveram maiores prevalências de AME quando comparados aos que não relataram tal ação $(p=0,08)$. Essa questão foi incluída na análise por dois motivos: considerou-se, por um lado, que a existência de interesse por parte do municipio na realização de pesquisas sobre AM poderia ser um marcador do investimento feito nessa área; por outro lado, a existência de dados sobre a situação do AM pode subsidiar o planejamento de ações adequadas à realidade local.

Vale notar a constatação de correlações positivas entre as freqüências nos municípios das diferentes ações de incentivo ao aleitamento matemo. 
Coeficientes de correlação mais elevados foram observados quanto à politica municipal pró-amamentação e a realização de cursos e a Semana da Amamentação; quanto à realização da SMAM e a presença de equipe multiprofissional no municipio e quanto à existência de $\mathrm{HAC}$ e BLH.

Esses resultados podem levar a elaboração de várias hipóteses no tocante às formas de organização municipal para o incentivo à amamentação. Por exemplo, as baixas correlações entre a existência de política municipal próamamentação e a implementação da IHAC e de BLH poderia ser interpretada como decorrente da pequena influência exercida pelo poder municipal sobre a definição de prioridades para a gestão das matemidades (em sua maioria filantrópicas ou estaduais). A alta correlação entre HAC e BLH poderia ser explicada pelo fato de serem ações definidas no nivel hospitalar. A existência de uma equipe profissional dedicada à amamentação poderia favorecer o desenvolvimento de atividades na Semana Mundial de Amamentação.

Quando o efeito das ações de incentivo ao aleitamento materno sobre o AME foi analisado empregando-se a variável sintética "somatória de ações próamamentação", constatou-se, na "abordagem ecológica" que a correlação entre a freqüência de AME nos municípios e a "somatória de ações" foi significativa mesmo após o controle de possiveis variáveis de confusão: idade média das crianças, região, porte populacional e IPRS.

Empregando-se modelos multinivel verificou-se que, controlados os efeitos das variáveis individuais, a "somatória de ações" exerce um impacto 
positivo sobre o $A M E$, sendo essa variável a que apresentou a maior $R C$ no modelo final.

É interessante também observar que o efeito da somatória de ações municipais pró-amamentação indicou a existência de um limite crítico (4 ações), a partir do qual há um substancial aumento na prevalência do AME. Esse achado é consistente com argumentações de GIUGLIANI (2001). A autora, a partir de ampla revisão da literatura sobre estratégias para aumentar a prevalência do $\mathrm{AME}$, concluiu que para um aumento substancial das taxas de amamentação exclusiva, várias ações necessitam ser implementadas conjuntamente, incluindo a ampliação das atividades educativas, apoio da comunidade, legislação trabalhista e cumprimento da Norma Brasileira de Comercialização de Alimentos para Lactentes. É razoável conjeturar que os municipios que desenvolvem 4 ou mais ações pró-amamentação seriam capazes de remover alguns dos principais obstáculos para a prática da amamentação exclusiva, apontados pela mesma autora: a falta generalizada de conhecimento sobre o valor da amamentação exclusiva (por parte da comunidade, profissionais de saúde e gestores); as práticas dos serviços de saúde que desestimulam o AME, como por exemplo a separação de mães e bebês após o parto, a oferta na maternidade de outros líquidos, como soro glicosado e fórmulas e o uso de mamadeiras; as práticas culturais e crenças disseminadas sobre a necessidade do uso de água, chá, outros alimentos e chupetas nos primeiros meses de vida da criança; a falta de confiança das 
mulheres para a amamentação; o não cumprimento de legislação de proteção à mulher trabalhadora e a promoção comercial dos substitutos do leite materno.

A Figura 14 apresenta um esquema de como as ações municipais poderiam atuar sobre os principais obstáculos, mencionados por GIUGLIANI (2001), para a prática da amamentação exclusiva. 
Figura 14. Impacto das ações municipais de incentivo ao aleitamento materno sobre os principais obstáculos para a prática da amamentação exclusiva. São Paulo, 2002.

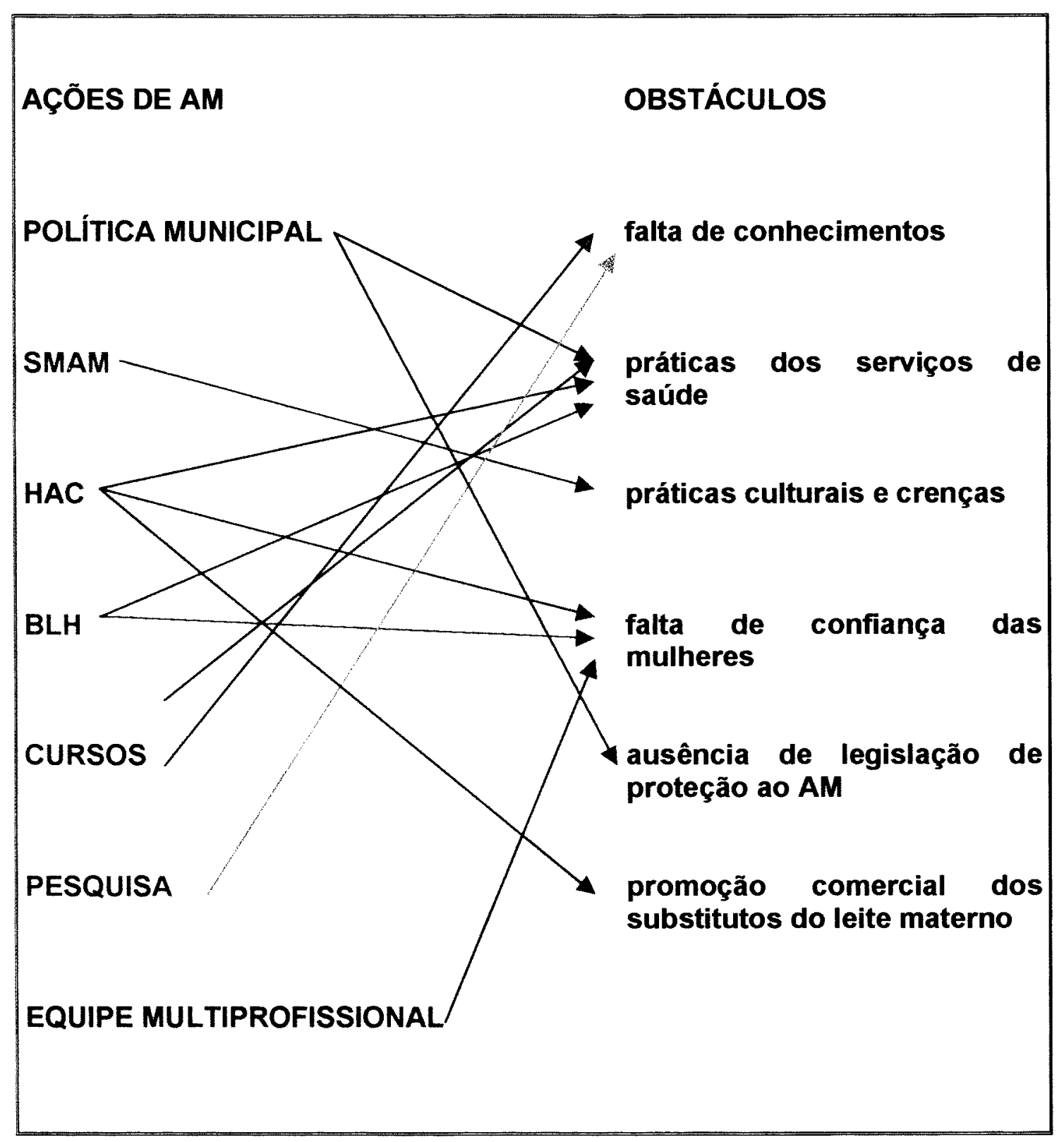




\section{O Efeito das interações entre as variáveis individuais e contextuais}

Uma das vantagens dos modelos multinivel, apontada por HOX (1995), é a possibilidade de análise das interações entre as variáveis que descrevem os individuos e as variáveis que descrevem os grupos sociais.

Dessa forma, foi possivel testar a hipótese de que a variável sintética contextual "somatória de ações pró-amamentação" modifica o efeito de variáveis individuais, tendo sido identificadas três interações estatisticamente significativas no modelo final. Essas três interações evidenciam que a implementação pelos municípios de no mínimo 4 ações pró-amamentação é capaz de modificar o efeito de três fatores de risco para o desmame precoce: a "baixa escolaridade matema", o "baixo peso de nascimento" e o "seguimento ambulatorial na rede SUS". A implementação de pelo menos quatro ações próamamentação atenua em $13 \%$ o risco relativo de desmame precoce associado à "baixa escolaridade materna". No segundo caso, a implementação de pelo menos quatro ações reduz em $25 \%$ o risco relativo de desmame associado ao "baixo peso de nascimento". No terceiro caso, a mesma implementação de pelo menos quatro ações inverte a associação entre "seguimento ambulatorial na rede SUS" e freqüência do AME, transformando o seguimento na rede SUS em fator de proteção (e não mais de risco) para o desmame precoce. Nos três casos, as evidências falam a favor do potencial que tem a implementação concomitante de várias ações para reduzir desigualdades sociais com relação à prática do AME. 


\subsection{Implicações do estudo}

A identificação do declínio abrupto da amamentação exclusiva na primeira quinzena de vida na amostra estudada tem uma implicação prática a ser considerada no planejamento de intervenções. Os achados mostram que é necessário pensar em estratégias de atuação que tenham impacto nos primeiros dias de vida da criança. Nesse sentido, há ainda muito o que fazer para ampliar o número de hospitais amigos da criança no ESP (que atualmente somam 14), uma vez que a IHAC é apontada como uma das estratégias mais adequadas para melhorar o apoio dado às mulheres no período perinatal.

Tendo em vista a alta freqüência de aleitamento materno predominante em nosso meio e o uso abusivo, especialmente do chá, nos primeiros dias de vida da criança, é fundamental melhorar a orientação dada às mães sobre os riscos da introdução precoce de líquidos não nutritivos na dieta do lactente.

O presente estudo identificou alguns "grupos de risco" para a interrupção do $A M E$ antes do $6^{\circ}$ mês de vida, o que poderá ser útil para o planejamento de ações de incentivo à amamentação voltadas especificamente a esses grupos. Porém, é importante ter em vista que intervenções para reduzir a prevalência desses "fatores de risco" são em geral complexas e, de modo geral, com efeitos a médio ou longo prazo.

Ao contrário do que ocorre em relação às variáveis individuais, cujo efeito pode extrapolar o poder de atuação dos municípios, a implementação das ações pró-amamentação, consideradas pelo presente estudo, está no âmbito 
municipal. Esse fato, somado à constatação do impacto positivo das ações próamamentação e também às evidências de que a implementação de um número de ações pró-amamentação pode atenuar ou mesmo anular o efeito negativo de "fatores de risco" individuais para o desmame precoce, deveriam ser um estímulo a mais para o trabalho das equipes municipais.

É importante que os municípios, ao realizarem o planejamento de suas ações, levem em consideração que é necessário trabalhar um mínimo de ações para que ocorra um impacto positivo sobre a freqüência do $A M E$, provavelmente porque é necessário remover simultaneamente vários dos obstáculos para a prática do AME.

É de fundamental importância que os municipios, após a realização do diagnóstico da situação da amamentação, definam qual a estratégia mais adequada para sua realidade.

Espera-se que o Projeto Amamentação e Municipios (que transcende a finalização desse trabalho) e os resultados desse estudo possam contribuir para a expansão da prática da amamentação no Estado de São Paulo. 


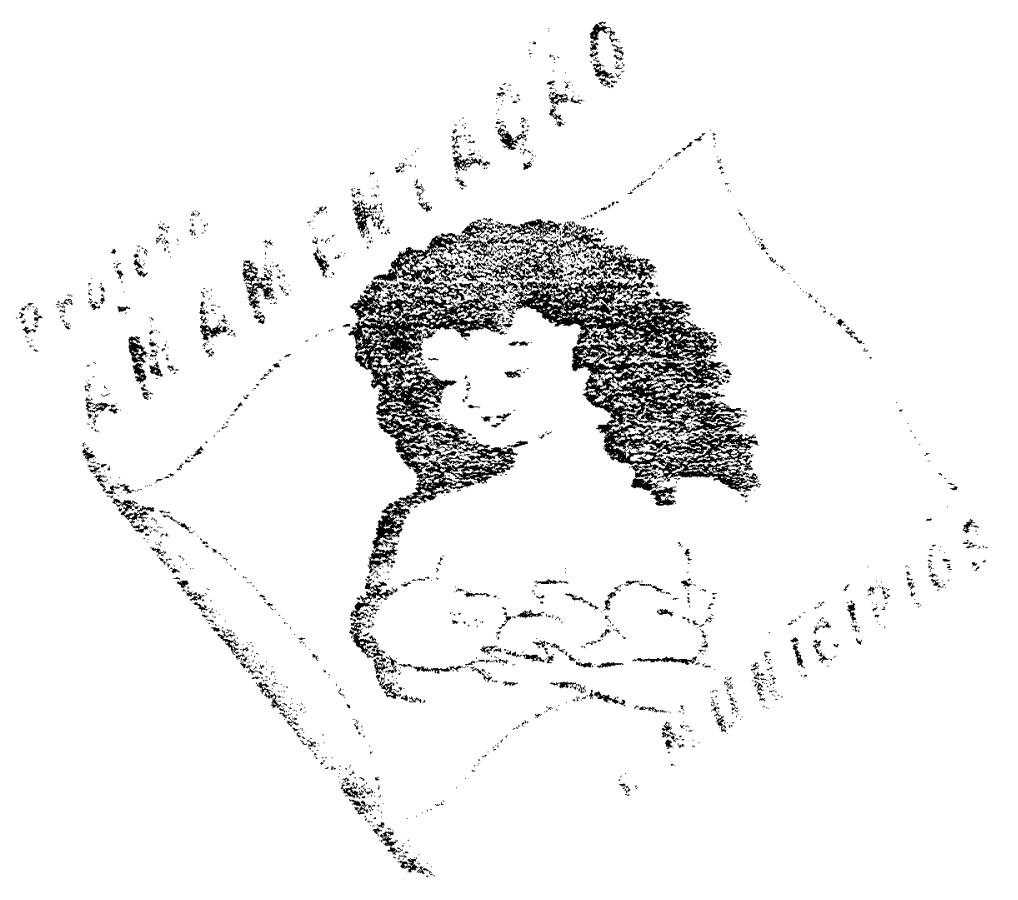

\section{CONCLUSÕES}

Folha, mas viva na árvore,

Fazendo parte do verde.

Nāo a folha solta,

Bailando no vento

A cançāo da agonia

Grāo de areia, quase nada, Inútil quando sozinho.

Mas que é terra, A terra,

Quando é grão

Fazendo parte do chão,

Esta coisa firme

Por onde o homem caminha.

(Thiago de Mello) 


\section{CONCLUSÕES}

- É reduzida a prevalência do AME nos primeiros seis meses de vida nos 111 municipios analisados e a freqüência de $A M E$ declina rapidamente nos primeiros dias de vida da criança;

- A situação do AME no ESP é bastante heterogênea, tendo sido verificada ampla variação do indicador "AME em menores de seis meses" nos 111 municípios estudados;

- Levando em conta atributos das crianças e de suas mães, foram identificadas como condições individuais de risco para a não prática do AME: "baixa escolaridade materna", "primiparidade" "idade materna inferior a vinte anos", "crianças do sexo masculino", "baixo peso ao nascer" e "acompanhamento na rede pública de serviços de saúde";

- Os municípios que desenvolvem pelo menos quatro das ações próamamentação consideradas pelo estudo (ter uma política de AM; ter uma equipe multiprofissional dedicada ao AM; realizar o curso de 18 horas do UNICEF ou o curso de Aconselhamento em Amamentação OMSMellstart; promover a SMAM; ter HAC; ter BLH; realizar pesquisa 
sobre AM) aumentam em média duas vezes a chance de sua população infantil estar em AME nos primeiros seis meses de vida, controlados os efeitos de diferenças na composição dessa população quanto a atributos das crianças e de suas mães, que poderiam influenciar a freqüência do $\mathrm{AME}$

- A implementação de pelo menos quatro ações pró-amamentação atenua o risco relativo de desmame precoce associado à "baixa escolaridade materna", ao "baixo peso de nascimento" e inverte a associação entre "seguimento ambulatorial na rede SUS" e freqüência do AME, transformando o seguimento na rede SUS em fator de proteção (e não mais de risco) para o desmame precoce. 


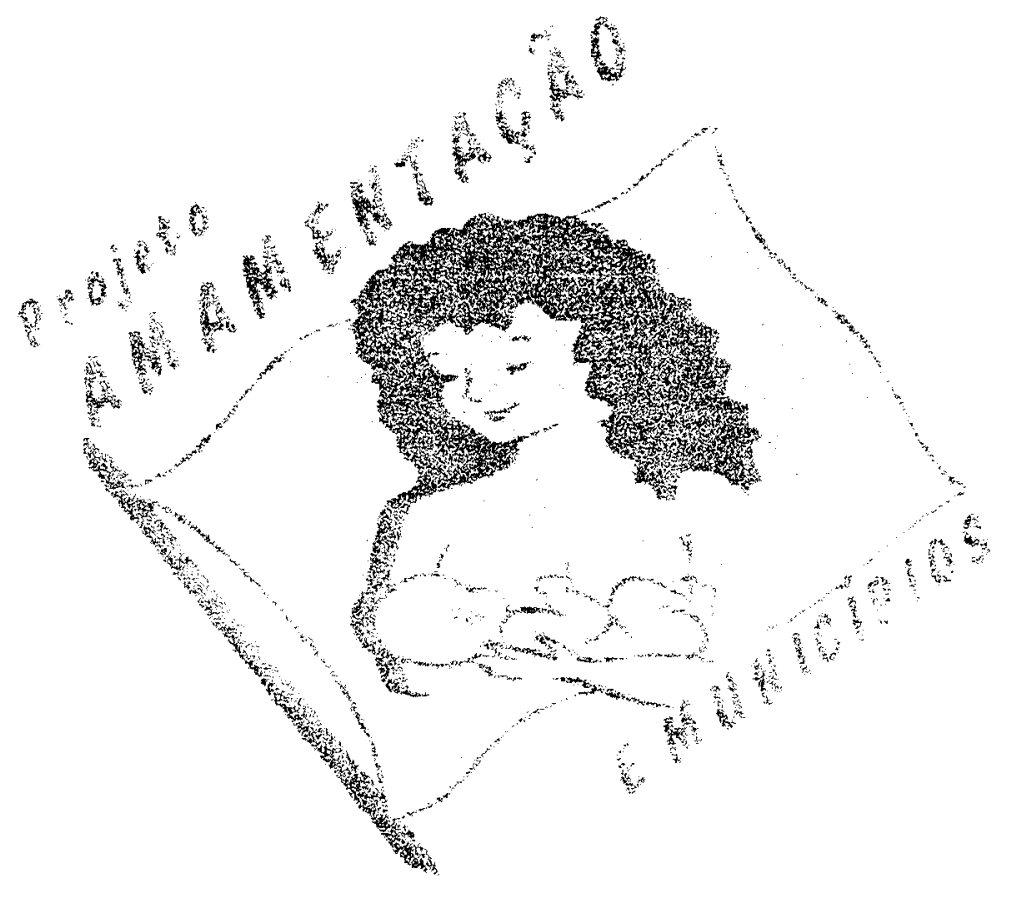

\section{REFERÊNCIAS}

Mas é preciso ter força

É preciso ter raça, é preciso ter sonho, Sempre

Quem traz na pele essa marca

Possui a estranha mania de ter fé na vida...

(Milton Nascimento) 
Adair LS, Popkin BM, Guikey DK. The duration of breastfeeding: how it is affected by biological, socio-economic, demographic, health sector and food industry factors? Demography 1993; 30: 63-80.

Akré J (Ed.). Alimentação Infantil - Bases Fisiológicas. Instituto de Saúde, São Paulo, 1994.

Almeida JAG. Amamentação: um híbrido natureza-cultura. Rio de Janeiro: Ed. Fiocruz, 1999; p. 91-113.

Almeida MF. O uso de informações em saúde na gestão de serviços. Saúde e Sociedade $1995 ; 4(1): 39-42$

Almroth SG. Water requirements of breast-fed infants in a hor climate. Am J Clin Nutr 1978; 31: 1154-57.

Aniansson $G$, Alm B, Andersson B, Hakansson A. A prospective coherent study on breast-feeding and otitis media in Swedish infants. Pediat Infect Dis $1994 ; 13: 183-8$

Araújo LDS. Querer/poder amamentar. Uma questão de representação? Londrina: Ed da UEL, 1997. 
Arcoverde TL, Correa DJ, Martins JT. Perfil do aleitamento materno em uma unidade de saúde do município de Blumenau. In: V Encontro Nacional de aleitamento materno. Anais, p. 67. Londrina: Centro de Referência em Amamentação de Londrina/Comitê de Estímulo ao Aleitamento Matemo de Londrina/Associação Médica de Londrina/IBFAN Brasil; 1997

Ashraf RN, Jahil F, Zaman S, Kartberg J, Khan SR, Lindblad BS, Hanson LA. Breastfeeding and protection against neonatal sepsis in a high risk population. Arch. Dis. Child. 1991; 66: 488-90.

Barros AJD. Modelos Multi-nivel - Uma introdução à teoria e à prática. Departamento de Medicina Social, Faculdade de Medicina da Universidade Federal de Pelotas, 2001. [mimeo].

Barros FC, Temer TC, Toniolo Filho S, Tomasi E, Victora CG. The impact of lactation centres on breastfeeding patterns, morbidity and growth: a birth cohort study. Acta Paediatr 1995; 84: 1221-6.

Barros FC, Victora CG, Vaughan JP. Breastfeeding and socioeconomic status in Southem Brazil. Acta Paediatr Scand 1986; 75: 558-62, 1986

BEMFAM. Pesquisa Nacional sobre Demografia e Saúde. Rio de Janeiro, 1997. [Relatório de Pesquisa] 
Bener UM, Denic S, Galadari S. Longer breastfeeding and protection against childhhod leukaemia and lymphomas. Eur J Cancer 2001; 37: 234-8.

Betrán AP, Onis M, Lauer J, Villar J. Ecological study of effect of breastfeeding on infant mortality in Latin America. BMJ 2001; 323: 303-6.

Bitoun P. The economic value of breastfeeding in France. Les Dossiers de $L$ Obstetrique $1994 ; 216: 10-13$.

Blaww R, Alberse EC, Beneke T, Lombard CJ, Laubscher R, Hough FS. Risk factors for the development of osteoporosis in South Africa population. South Afr Med J 1994; 84: 328-32.

Brasil. Ministério da Saúde. DATASUS. Tab Win - tab para Windows versão 2.0; 2001. http:// www.datasus.gov.br [2001 JUN 03]

Brasil. Ministério da Saúde. Descentralização das ações de saúde. A ousadia de cumprir e fazer cumprir a lei. Brasília, 1993.

Brasil. Ministério da Saúde. Prevalência de aleitamento materno nas capitais brasileiras e no distrito federal. Brasilia, 2001. 
Brown $\mathrm{KH}$, Black R, Romana GL et al. Infant feeding practices and their relationship with diarrhoea and other diseases in Huascar (Lima), Peru. Pediatrics $1989 ; 83: 31-40$.

Brown $\mathrm{KH}$, de Kanashiro HC, Del Aguilla R, Guillermo LR, Black RE. Milk Consumption and hydratation status of exclusively breast-fed infants in a warm climate. J Pediatr 1986; 108:677-80.

Carvalhaes MABL, Parada CMGL, Manoel CM, Venancio SI. Diagnóstico da situação do aleitamento materno em área urbana do Sudeste do Brasil: utilização de metodologia simplificada. Rev. Saúde Pública 1998; 32(5):430-6.

Cesar JA, Kuhn D, Devens ES, Martins Jr E, Aguiar MRC, Holthausen RS, Teixeira AMB, Horta BL. Prescrição de chás para crianças menores de seis meses: a opinião dos médicos de uma cidade de porte médio no sul do Brasil. J. Pediatr 1996; 72(1): 27-31.

Cesar JA, Victora CG, Barros FC, Santos IS, Flores JA. Impact of breast feeding on admission for pneumonia during posneonatal period in Brazil: nested case control-study. Br Med J 1999; 318:1316-20. 
Chang-Claude J, Eby $N$, Kiechle $M$, Bastert $G$, Becher $H$. breastfeeding and breast cancer risk by age 50 among women in Germany. Cancer Causes Control 2000; 11: 687-95.

Chua S, Arulkumanan S, Lim I, Selamat N, Ratnam SS. Influence of breastfeeding and nipple stimulation on pospartum uterine activity. Br J Obstet Gynaecol 1994; 101: 804-5.

Colton, T. Statistics in Medicine. Boston, Mass., Little Grown, 1974.

Coutsoudis A, Kubendran P, Spooner E, Kuhn L, Coovadia HM. Influence of infant-feeding patterns on early mother-to-child transmission of HIV-1 in Durban, south Africa: a prospective cohort study. Lancet 1999; 354: 471-6.

Cummings RG, Klineberg RJ. Breastfeeding and other reprodutive factors and the risk of hip fracture in eldrly women. Int J Epidemiol 1993; 2: 684-91.

Cunningham AS, Jelliffe DB, Jeliffe EFP. Breastfeeding and health in the 1980s: a global epidemiological review. J. Pediatr 1991; 118: 659-66.

Davies-Adetugbo AA. Sociocultural factors and the promotion of exclusive breastfeeding in rural Yoruba communities of Osun Satate, Nigeria. Soc Sci Med 1997;45:113-25. 
Davis MK, Stavitz DA, Graubard BI. Infant feeding and childhood câncer. Lancet $1998 ; 2: 365-8$.

De Zoysa I, Rea MF, Martines J. Why promote breastfeeding in diarrhoeal disease control programmes? Health Policy Plan. 1991; 6: 371-9.

Dean AG, Dean JA, Coulombier D, Brendel KA, Smith DC, Burton AH. Epi Info, Version 6.0: a word processing database and statistics program for epidemilogy on microcomputers. Center of Disease Control and Prevention, Atlanta, Georgia, USA, 1994.

Diex-Roux AV. Bringing Context Back into Epidemiology: Variables and Fallacies in Multilevel Analysis. Am J Public Health 1998; 88:216-22.

Duncan B, Ey J, Holberg CJ, Wrigth AL, Martinez FD, Taussig LM. Exclusive breastfeeding for at least 4 months protects against otitis media. Pediatrics 1993; $91: 867-72$.

Ellis TM, Atkinson MA. Earlu infant diets and insulin dependent diabetes. Lancet 1996; 347:1464-5. 
Eregie $\mathrm{CO}$. Studies on exclusive breastfeeding: a report on associated factors in an African population. J Trop Pediatr 1998;44:172-3.

Feachem RG, Koblinsky MA. Interventions for the control of diarmoeal diseases among young children: promotion of breastfeeding. Bull. WHO 1984; 62(2):271-91.

Ferreira MU, Cardoso MA, Santos ALS, Ferreira CS, Szarfac SC. Rapid epidemiologig assessment of breastfeeding practices: probit analyisis of current status data. J. Trop. Pediatr 1995; 41: 5-8.

Ford RPK, Taylor BJ, Mitchell EA, Enrigth SR, Steward AW, Becrof DM et al. Breastfeeding and the risk of sudden infant death syndrome. Int $\mathbf{J}$ Epidemiol 1993; $22: 885-90$

Forman MR, Lewando-Hundt G, Graubard BI, Chang D, Sarov B, Berendes HW. Factors influencing milk insufficiency and its long-term health effects: the Bedouin Infant Feeding Study. Int J Epidemiol 1992; 21:53-8.

Forman MR. Review of research on the factors associated with choice and duration of infant feeding in less-developed countries. Pediatrics 1984; 74(suppl): 667-94. 
Fundação SEADE. http:// www.seade.sp.gov.br. [2001 jun 03]

Fuchs SC, Victora CG, Fachel J. Modelo hierarquizado: uma proposta de modelagem aplicada à investigação de fatores de risco para a diarréia grave. Rev Saúde Pública 1996; 30(2): 168-78.

Gimeno SG, Souza JMP. Amamentação ao seio com leite de vaca e o diabetes mellitus tipo 1. Rev. Bras. Epidemiol 1998; 1: 4-13.

Gillman MW, Rifas-Shiman SL, Camargo CA Jr. Risk of overweigh among adolescents who were breastfed as infants. JAMA 2001; 285:2461-67.

Giugliani E.R.J. Technical consultation on infant and young child feeding. How can we increase exclusive breastfeeding; 2001 [mimeo]

Goldberg NM, Adams E. Supplementary water for breast-fed babies in a hot and dry climate-not really a necessity. Arch Dis Child 1983; 58:73-4.

Goldemberg P. Repensando a desnutrição como questão social. $2^{a}$ ed. Campinas, Ed Unicamp, 1989.

Goldstein H. Multilevel satatistical models. $2^{a}$ ed. Londres. Edward Amold; 1995. 
Gray $\mathrm{RH}$, Campbell OM, Apelo R et al. Risk of ovulation during lactation. Lancet $1990 ; 335: 25-9$

Hardy E, Faundes A, Marussi ES, Algaba MFO, Pinotti JA. Aleitamento materno e câncer de mama. Estudo caso controle desenvolvido em Campinas - São Paulo. Rev Bras Ginec Obstetr. 1993; 5: 83-7.

Harfouche JK, Psycho-social aspect of breastfeeding including bonding. Food Nutr Bull 1980; 2: 2-6.

Hight-Laurakan V, Rutstein SO, Peterson AE, Labbok MH. The use of breast milk substitutes in developing cuntries: the impact of women's employment. Am J Public Health 1996; 86: 1235-1240.

Hobcraft JN, McDonald JW, Rutstein SO. Demographic determinants of infant and early child mortality: a comparative analysis. Pop Stud 1985; 39:363-85.

Horta BL, Barros FC, Halpern R, Victora CG. Baixo peso ao nascer em duas coortes de base populacional no Sul do Brasil. Cad Saúde Pública 1996; 12(supple. 1): $27-31$. 
Horwood LJ, Ferguson DM. Breastfeeding and later cognitive development and academic outcomes. Pediatrics 1998; 101(1): 99.

Hosmer DW Lemeshow S. Applied logistic regression. John Wiley and Sons, New York, 1989.

Howie PW. Protective effect of breastfeeding against infection among infants in a Scottish city. Br J Nutr 1989; 300: 11-6.

Hox JJ. Applied Multilevel Analysis. TT-Publikaties, Amsterdam, 1995.

Jason JM, Nieburg P, Marks JS. Mortality and infectious disease associated with infant-feeding practices in developing countries. Pediatrics $1984 ; 74: 702-27$.

Huffman SL, Panagides D, Rosenbaum J, Parlato M. Breastfeeding Promotion in Central America: High Impact at Low Cost Nutrition Communication Project, Washington DC: Academy for Educational Development; 1991.

Jelliffe DB, Jelliffe EFP. Human Milk in the modern world. Oxford: OUP, 1978.

Jones $G$, Riley $M$, Dwyer $T$. Breastfeeding in early life and bone mass in prepubertal children: a longitudinal study. Osteoporos Int 2000; 11: 146-52. 
Karjalainen J, Martin JM, KNIP M, Ilonen J, Robinson BH, Savilahti E, Akerblom HK, Dosch HM. A bovine albumin peptide as a possible trigger of insulindependent diabetes mellitus. N Engl J Med 1992; 327: 302-7.

Kitoko PM, Réa MF, Venancio SI, Vasconcelos ACCP, Santos EKA, Monteiro CA. Situação do aleitamento matemo em duas capitais brasileiras: uma análise comparada. Cad Saúde Pública 2000; 16(4):1111-1119.

Lanting $\mathrm{Cl}$ et al. Neurological differences between 9 year-old children fed breastmilk or formula as babies. Lancet $1994 ; 344: 1319-22$.

Lawrence RA, Lawrence RM. Breastfeeding: a guide for medical profession. $5^{\text {th }}$ ed. Mosby: St Louis; 1999. Psychology impact of breastfeeding; p. 197-232.

Leach A, McArdle TF. Neonatal mortality in a rural area of the Gambia. Ann Trop Pediatr 1999;19:33-43.

Leão MM, Coitinho DC, Recine E, Costa LAL, Lacerda AJ. O perfil do aleitamento matemo no Brasil. In: Fundação IBGE/UNICEF. Perfil estatístico de crianças e mães no Brasil . Rio de Janeiro, IBGE, 1989. p. 97-110. 
Lucas A, Morley R, Cole TJ, Lister G, Leeson-Payne C. Breast milk and subsequent intelligence quotient in children born premature. Lancet 1992; 339: $261-4$

Lucas A, Cole TJ. Beast milk and neonatal necrotizing enterocolitis. Lancet 1990; 336: 1519-23

Lutter CK, Perez-Escamilla R, Segall A, Sanghvi T, Teruya K, Wickham C. The effectiveness of a hospital-based program to promote exclusive breast-feeding among low-income women in Brazil. Am J Publ Health 1997;87:659-63.

Marcolini TT. Amamentação. In Noronha DT, Lopes GP, Montgomery M. Tocoginecologia psicossomática. São Paulo: Amed; 1993. cap 12, p. 83-8.

Marild S, Jodal ULF, Mangelus L. Medical histories of children with acute pyelonephritis compared with controls. Pediatr. Infect. Dis. J. 1989; 8: 511-5.

Martins Filho J, Sanged CAA. Modificação da prevalência da amamentação na região de Campinas, após oito anos de estímulo contínuo, em nível ambulatorial. J Pediatr 1987; 62: 251-6 
Mazur J, Mikiel-Kostyra K. Determinants of newborn feeding in maternity hospital care. Part II: factors associated with exclusive brestfeeding. Ginekol Pol 2000; 71(7): 604-10,

Mendes Gomes MA, Campos TP, CASTRO, IRR, BRASIL, CLP. Diagnóstico da situação do aleitamento materno em campanha de vacinação: a experiência do município do Rio de Janeiro em 1996. In: IV Congresso Brasileiro de Epidemiologia, Resumos, p. 309. Rio de Janeiro: Associação Brasileira de Pós-Graduação em Saúde Coletiva - ABRASCO; 1998.

Mitchel EA. Results from the first year of Zealand cot death. New Zealand Medical Journal, 1991; 104: 71-76.

Monego ET, Silva BHAB, Oliveira, ALI, Pinto SL, Venancio SI, Kitoko P. Prevalência de aleitamento materno no Estado de Goiás. In: IV Congresso Brasileiro de Epidemiologia, Resumos, p. 311. Rio de Janeiro: Associação Brasileira de Pós-Graduação em Saúde Coletiva - ABRASCO; 1998.

Monteiro CA, Rea MF, Victora C. Can infant mortality be reduced by promoting of breastfeeding? Evidence from São Paulo city. Health Policy Plann 1990; 5:23-9. 
Monteiro CA. Saúde e Nutrição das crianças de São Paulo: diagnóstico, contrastes sociais e tendências. São Paulo: HUCITEC: EDUSP, 1998; p 15.

Monteiro CA, Zuniga HPP, Benício MH, Rea MF, Tudisco ES, Sigulem DM. The Recent Revival of Breast-feeding in the City of São Paulo, Brazil. Am. J. Public Health $1987 ; 77: 964-6$.

Monteiro CA, Zuniga HPP, Benício MHA, Rea MF. Breastfeeding patterns and socioeconomic status in the city of Sào paulo. J Trop Pediatr 1988; 34: 186-192.

Monteiro CA. O panorama da nutrição infantil nos anos 90 . Cadernos de Politicas Sociais, UNICEF, Série Documentos para Discussão, 1. Brasília, 1997.

Muller M. The baby killer. London, War on want paphlet, 1974.

Narayanan I, Prakash K, Murthy NS, Gujral VV. Randomized conntrolled trial of effect of raw and pasteurized human milk and formula in the incidence of neonatal infection. Lancet $1884 ; 2: 1111-13$.

Naylor AJ, Creer AE, Lopez GW, Dixon S. Lactation management education for physicians. Semin Perinatol 1994; 18(6): 525-531. 
Norusis MJ, SPSS for Windows Advanced statistics, Release 6.0, Englewood Cliffs, New York, N.J.: Prentice - Hall; 1993.

Notzon F. Trends in infant feeding in developing countries. Pediatrics 1984; 74 (suppl): 648-66.

Nurture. The Economic Value of Breastfeeding: Four Perspectives for Policymakers. Center to Prevent Childhood Malnutrition Policy Series, 1(1): 1-16, September; 1990.

Organização Mundial da Saúde. Proteção, promoção e apoio ao aleitamento materno: o papel especial dos serviços de saúde. Genebra, 1989.

Palmer $\mathrm{G}$. The politics of breastfeeding $4^{\mathrm{a}}$ ed. London, Pandor press, 1993.

Pérez-Escamilla R, Cohen R, Brown KH, Landa-Rivera L, Canahuati J, Dewey KG. Maternal anthropometric status and lactation performance in a low-income honduran population; evidence for the role of infants: Am J Clin Nutr 1995b; 61 : $528-534$. 
Pérez-Escamilla R, Lutter C, Segall AM, Rivera A, Trevino-Siller S, Sanghvi T. Exclusive breast-feeding duration is associated with attitudinal, socioeconomic and biocultural determinants in three Latin American countries. J Nutr $1995 ; 125: 2972-84$

Peréz-Escamilla R; Dewey, KG. The epidemiology of breastfeeding in México: urban vs. rural areas. Bull. Pan. Am. Health Org. 1992; 26:30-36.

Pérez-Escamilla, R. Breastfeeding patterns in Latin America and the Caribbean. Bull. Pan. Am. Health Org. 1993; 27: 32-42.

Pisacane A. Breastfeeding and multiple sclerosis. Brit Med J 1994; 308: 14111412.

Pisacane A . Breastfeeding and urinary tract infection. J. Pediat., 1992; 87-9.

Popkin BM, Bilsborrow RE, Akin AS, Yamamoto ME. Breast-feeding determinants in low-income countries. Med Anthrop 1983; 7:1-31.

Popkin BM, Adair I, Akin JS, Black R. Breastfeeding and diarmeal morbidity. Pediatrics 1990; 86(6): 874-82. 
Rea MF,Venancio SI. Avaliação do curso de Aconselhamento em Amamentação - OMS/UNICEF. J. Pediatr 1999; 75(2): 112-118.

Rea MF, Toma TS. Proteção do leite materno e ética. Rev.Saúde Publica $2000 ; 34(4): 388-95$

Rea MF, Berquó E. Impact of the Brazilian national breast-feeding programme on mothers in greater São Paulo. Bull. World Health Organ. 1990; 68: 365-71.

Romieu I, Werneck G, Ruiz VS, White M, Herandez M. Breastfeeding and asthma among Brazilian children. J Asthma 2000; 37: 575-83.

Rosenblatt KA. Lactation and risk of epithelial ovarian cancer. Int J Epidemiol $1993 ; 22(2): 192-97$

Saarinen UM, Kajosaari M. Beastfeeding as prophilaxis against atopic disease: a prospective follw up estudy until 17 years old. Lancet 1995; 346: 1065-69.

Sachdev HPS, Krishna J, Puri RK, Satyanarayana L, Kumar S. Water supplementation in exclusively breasfed infants during summer in the tropics. Lancet 1991; 337: 929-33. 
Sanghvi TG. Melhora da eficácia em função dos custos da promoção do aleitamento materno em maternidades. Resumo do estudo USAID/LAC HNS na América Latina (1992-1995). UNICEF New York Nutrition Section; 1996.

Secretaria de Estado da Saúde. http://www.saude.sp.gov.br. [2001 JUN 03]

Sena MCF, Silva EF, Pereira MG. Prevalência do aleitamento matemo no Distrito Federal, Brasil. Cad. Saúde Pública 2002; 18(3).

Shu XO, Clemens J, Zheng W, Ying DM, Ji BT, Jin F. Infant breastfeeding and the risk of childhood lynphoma and leukaemia. Int. J. Epidemiol 1995; 24: 27 32.

Sigulem DM, Tudisco ES. Aleitamento natural em diferentes classes de renda no município de São Paulo. Arch Latinoam Nutr 1980; 30: 400-16.

Silva- Ayçaguer, L.C. 1995. Excursão a la regresión logística en ciencias de la salud. Madrid: Ed. Diaz de Santos.

Silva, NN. Amostragem Probabilística: um curso introdutório. EDUSP, São Paulo, 1998 
Simopoulos AP, Grave GD. Factor associated with the choice and dutation of infant-feeding pratice. Pediatrics 1984; 74 (suppl): 603-14.

Sociedade Civil Bem-Estar Familiar no Brasil. Pesquisa Nacional sobre Demografia e Saúde. BEMFAM, 1997. Amamentação e Situação Nutricional das Mães e Crianças. p.125-38, 1996.

Sorensen E, Fernando DN, Hettiarachchi I, Durongdej S, Podhipak A, Skaara BB. Exclusive breastfeeding among women on the plantations in Sri Lanka. J Trop Pediatr 1998;44:313-5.

Sousa PLR; Barros FC; Pinheiro GNM; Gazzalle RV. The decline in breatfeeding in Brazil. J. Trop. Pediatr.Environ. Child Health 1975; 21: 212-5.

Susser M. The logic in ecological: I. the logic of analysis. Am J Public Health $1994 ; 84: 825-29$.

Taddei JAAC, Westphal MF, Venancio SI, Bógus C, Souza S. Breasfeeding training for health professionals and resultant changes in breastfeeding duration São Paulo Med J/Rev Paul Med: 118(6) 185-1912000 
Temboury MC. Influence of breastfeeding on the infant's intellectual development. J Pediatr Gastroentr Nutr 1994; 18: 32-6.

Trussel J, Grummer-Strawn L, Rodriguez G, Vanlandingham M. Trends and differentials in breastfeeding behavior: evidence from the WFS and DHS. Population Stud. 1992; 46: 285-307.

UNICEF. Situação Mundial da Infância, 1998.

Venancio SI, Monteiro CA. A evolução da prática da amamentação nas décadas de 70 e 80. Rev. Bras. Epidemiologia 1998; 1 (1):40-9.

Victora CG, Smith PG, Vaughan JP, Lombardi C, Fuchs SMC, Gigante LP, Nobre LC, Teixeira AMB, Moreira LB, Barros FC. Evidence for protection by breastfeeding against infant deaths from infectious diseases in Brazil. Lancet $1987 ; 2: 317-22$

Victora, CG. Infection and disease: the impact of early weaning. Food Nut. Bull. 1996;17:390-6.

Victora CG, Huttly SR, Fuchs SC, Olinto MT. The role of conceptual frameworks in Epidemiological analysis: A Hierarchical Approach. Int J Epidemiol. 1997; 26(1): 224-227. 
Vieira GO, Glisser, M, Araújo SPT, Sales A. Indicadores do aleitamento materno na cidade de Feira de Santana, Bahia. J Pediatria, 74(1):11-6; 1998

Virtamen SM, Rasanen L, Ylonen K, Aro A, Clayton D, Langholz B, Pitkaniemi J, Savilahti E, Lounamaa R, Tuomileho J, Akerblom HK. Early introduction of dairy products associated with increase risk of IDDM in Finnish Children. Diabetes 1993; 42: 1786-90

WHO Collaborative Study Team on the Role of Breastfeeding on Prevention of Infant Mortality. Effect of breastfeeding on infant and child mortality due to infectious diseases in less developed countries: a pooled analysis. Lancet 2000; 355: 451-55

Williamson NE. Breastfeeding trends and patterns. Int J Gynecol Obstet 1989; Suppl 1:145-52.

Winikoff $B$, Castle $M$, Laukaran $V$. Feeding infants in four societies:causes and consequences of mother's choices. Westport, CT: Greenwood Press, 1989.

Woolridge MW, Phil D, Baum JD. Recent advances in breast-feeding. Acta. Paediatr. Jpn. 1993; 35:1-12. 
World Health Organization .WHA54.2, Geneva, 2001.

World Health Organization, Division of Child Health and Development. Indicators for assessing breastfeeding practices. Geneva: World Health Organization, 1991.

World Health Organization. The optimal duration of exclusive breastfeeding 2001; http://www.who.int.

World Health Organization. Breast-feeding - the technical basis and recommendations for action. Geneva, 1993.

World Health Organization. Breast-feeding and complementary feeding: a continuum. In: Complementary feeding of young children in developing countries: a review of current scientific knowledge. Geneva: World health Organization, 1998 p. 15-44.

World Health Organization. Innocenti Declaration on the protection, promotion and support of breastfeeding. Ecol Food Nutr 1991; 26: 271-3.

World Health Organization. Global data bank on breastfeeding.Geneva, 1996. 
Wright AL, Holberg CJ, Taussig LM, Martinez FD. Factors influencing the relation of infant feeding to asthma and recurrent wheezy in childhood. Thorax 2001; 56: $192-7$.

Yang M, Rasbash J, Goldstein H, Barbosa M. MLwiN Macros for advanced multilevel modelling. London, Institute of Education, 1999.

Yoon P, Black RE, Moulton LH, Becker S. Effects of not breastfeeding on risk of diarmoeal and respiratory mortality in children under 2 years of age in Metro Cebu, the Philippines. Am. J. Epidemiol 1996; 143: 1142-48.

Zeitllin MF, Asmed NU. Nutritional correlates of frequency and length of breasfeeds in rural Bangladesh. Early Hum Develop 1995; 41:97-110.

Zheng $T$, Duan $L$, Liu $Y$, Zhang $B$, Wang $Y$, Chen $Y$, Zang $Y$, Owens $P H$. Lactation reduces breast câncer risk in shandong Province, China. Am J Epidemiol 2000; 152: 1129-35.

Zuniga HPP, Monteiro CA. Uma nova hipótese para a ascensão da mortalidade infantil da cidade de São Paulo nos anos 60. In: Monteiro, C.A. Velhos e novos males da saúde no Brasil: a evolução do pais e de suas doenças. São Paulo, HUCITEC/ABRASCO/NUPENS-USP. São Paulo, 1995. p. 157-73. 
ANEXO 1 


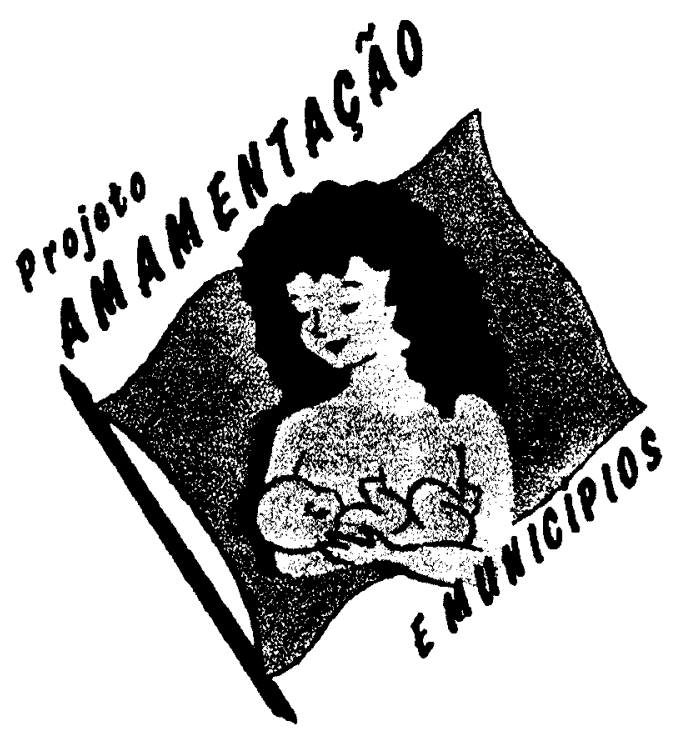

\section{AVALIAÇÃO DE PRÁTICAS ALIMENTARES NO PRIMEIRO ANO DE VIDA EM DIAS NACIONAIS DE VACINAÇÃO}

\section{MANUAL DO SUPERVISOR}

NUCLEO DE INVESTIGACĀO EM SAÚDE DA MULHER E DA CRIANCA NÚCLEO DE INVESTIGAÇÃO EM EPIDEMIOLOGIA INSTITUTO DE SAÚDE

SECRETARIA DE ESTADO DA SAÚdE DE SÃO PAULO NISMIC/NIEP/S/SES/SP
NUCLEO DE PESQUISAS EPIDEMIOLOGICAS EM NUTRIĊ̃O E SAÚdE FACULDADE DE SAUUDE PÚBLICA UNIVERSIDADE DE SÃO PAULO-NUPENSS / USP

APOIO: GATS/SES/SP - UNICEF

Rua Santo Antonio, 590 - 2.0. Andar - Bela Vista - CEP 01314-000 - São Paulo - SP Fones: 11 3105-9047/9048 ramais 211/212 Sonia/Cirlei/Lilian ou r. 233 Biba FAX. 3106-7328 E-mail: soniavaisaude.sp.gov.br 


\section{Caro(a) Supervisor(a),}

Muitos são os prejuízos da interrupção precoce do aleitamento materno para a saúde infantil, e no tocante ao estado nutricional, a situação pode ser agravada pela não adequação da dieta do desmame.

A OMS recomenda que as crianças devem ser amamentadas exclusivamente por 4-6 meses (o que diminui substancialmente os riscos de infecções e mortes infantis neste periodo), devendo continuar a receber o leite materno até os dois anos de vida ou mais.

No Brasil, apesar de estudos evidenciarem uma tendência de aumento da prática da amamentação nas três últimas décadas, não faltam indícios de que ações de proteção, promoção e apoio à amamentação devem ser intensificadas, uma vez que estamos longe de atingir as metas propostas pela OMS

Com o processo de municipalização é fundamental que os planejadores ao nivel local obtenham indicadores confiáveis da prática de alimentação infantil com vistas ao desenho e avaliação de intervenções apropriadas. Nesse sentido, levantamentos epidemiológicos realizados em campanhas de vacinação, como o que propomos neste treinamento, possibilitam um diagnóstico rápido da situação da amamentação e alimentação infantil com um baixo custo. Este manual foi elaborado para ajudar você na organização da coleta dos dados e na preparação dos mesmos para digitação e análise. No caso de dúvidas entre em contato conosco. Bom trabalho!

\section{PARTE 1 \\ Qual a metodologia utilizada na pesquisa?}

A realização da pesquisa em campanhas de vacinação traz a vantagem de se obter os dados de alimentação infantil de forma rápida, com um baixo custo, de uma amostra representativa da população de menores de um ano no município (já que é alta a cobertura vacinal das campanhas).

A OMS propôs em 1991 um conjunto de indicadores para avaliar as práticas de alimentação infantil, com o objetivo de padronizar a forma de coleta e análise destes dados e permitir a comparação entre diferentes estudos nacionais e internacionais. Nesta pesquisa optamos por adotar esta proposta e elaboramos um questionário adequado à mesma. Os indicadores propostos são simples, relativamente fáceis de medir e interpretar. A seguir descrevemos os termos e definições do aleitamento materno utilizados, as recomendações da OMS sobre alimentação no primeiro ano de vida e os indicadores a serem utilizados. 
ALEITAMENTO MATERNO: a criança recebe leite materno (diretamente do peito ou ordenhado).

ALEITAMENTO MATERNO EXCLUSIVO: a criança recebe apenas leite materno de sua mãe ou ama-de-leite, ou leite materno ordenhado, e não recebe outros líquidos ou sólidos com exceção de vitaminas, suplementos minerais ou medicamentos.

ALEITAMENTO MATERNO PREDOMINANTE: a fonte predominante de nutrição da criança é o leite materno. Porém, a criança também pode receber água e bebidas à base de água (água açucarada e com sabores, infusões, chá, etc); suco de frutas; solução de sais de hidratação oral (SRO); vitaminas, minerais e medicamentos em gotas ou xaropes, e líquidos cerimoniais (em quantidades limitadas).

ALEITAMENTO MATERNO EXCLUSIVO E ALEITAMENTO MATERNO PREDOMINANTE: juntas constituem o aleitamento materno completo.

ALIMENTACÃO COMPLEMENTAR: a criança recebe leite materno e alimentos sólidos (ou semi-sólidos).

ALIMENTACÃO COM MAMADEIRA: a criança recebe líquidos (incluindo leite materno) ou alimentos semi-sólidos em mamadeira.

${ }^{1}$ WORLD HEALTH ORGANIZATION. Indicators for assessing breastfeeding practices.

Update. Programme for Control of Diarrhoeal Diseases, (10): 1-4, 1992. 


\section{Grupos de idade para a medida de indicadores baseados nas recomendações sobre alimentação infantil. ${ }^{2}$}

Propõe-se 4 periodos de igual duração (4 meses) para o cálculo dos indicadores, levando-se em consideração as recomendações sobre alimentação infantil segundo grupos de idade.

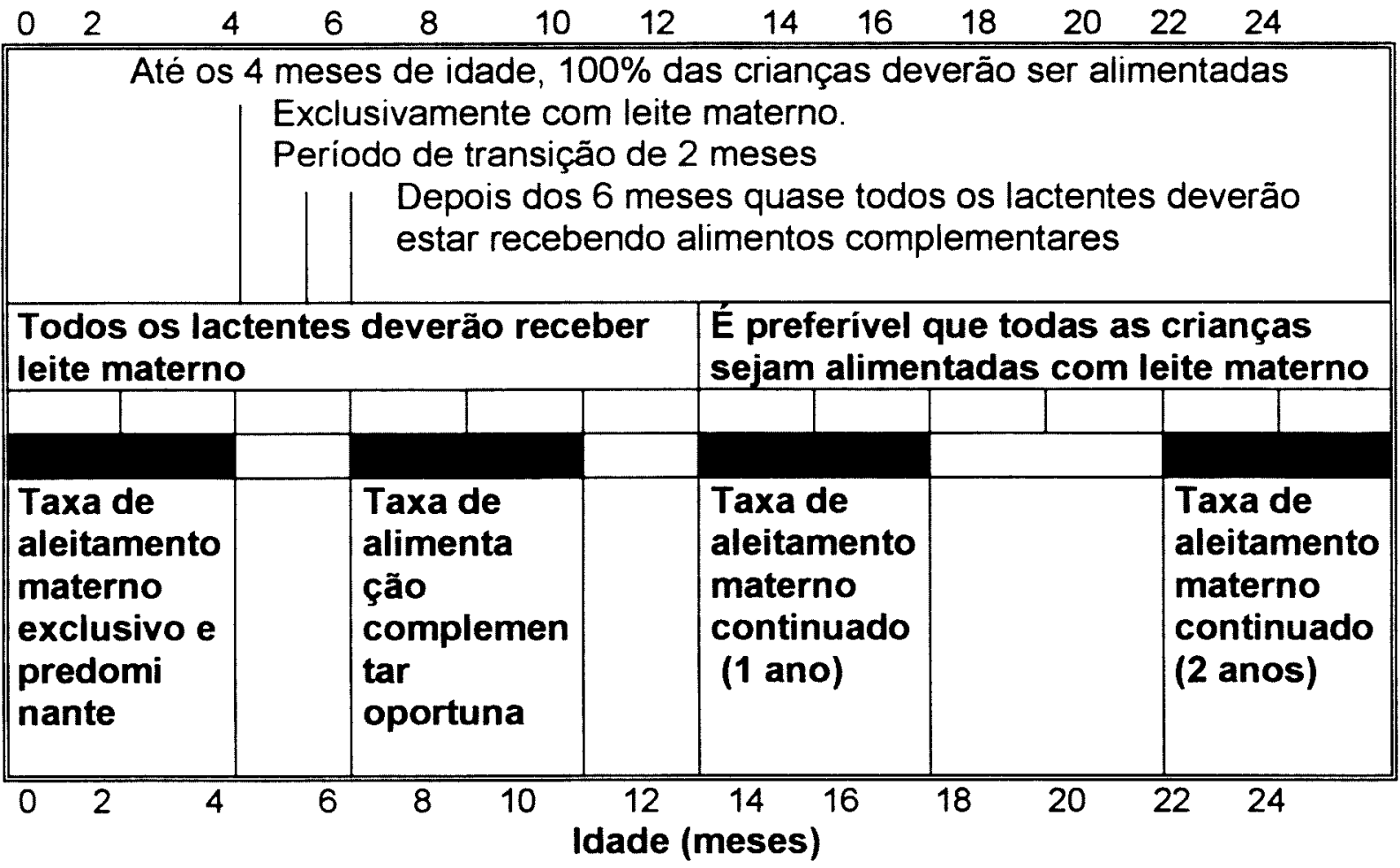

\footnotetext{
2 WORLD HEALTH ORGANIZATION. Indicators for assessing breastfeeding practices.

Update. Programme for Control of Diarrhoeal Diseases, (10): 1-4, 1992
} 
INDICADORES PARA AVALIAÇÃO DAS PRÁTICAS DE AMAMENTAÇÃO -
OMS

Propõe-se que os indicadores listados a seguir sejam obtidos utilizando-se dados atuais sobre alimentação infantil (current status), através de recordatório de 24 horas.

Taxa de aleitamento materno exclusivo (AME)

Criancas $<4$ meses ( $<120$ dias) que estavam em AME nas últimas $24 \mathrm{~h}$

Crianças menores de 4 meses ( 120 dias) de idade

AME - Cálculo Atual:

Crianças $<6$ meses ( $<180$ dias) que estavam em AME nas últimas $24 \mathrm{~h}$ Crianças menores de 6 meses ( 180 dias) de idade

Taxa de aleitamento materno predominante (AMP)

Criancas $<4$ meses ( $<120$ dias) que estavam em AMP nas últimas $24 \mathrm{~h}$ Crianças menores de 4 meses (120 dias) de idade

Taxa de alimentação complementar oportuna

Ccas 6-9 meses (180-299 dias) que receberam alimentos complementares mais leite materno nas últimas $24 \mathrm{~h}$

Crianças 6-9 meses (180-299 dias) de idade

Taxa de aleitamento materno continuado ( 1 ano)

Crianças 12-15 meses de idade que receberam LM nas últimas $24 \mathrm{~h}$ Crianças 12-15 meses de idade

Taxa de aleitamento materno continuado ( 2 anos)

Criancas 20-23 meses de idade que receberam LM nas últimas $24 \mathrm{~h}$

Crianças 20-23 meses de idade

Taxa de alimentação com mamadeira

Crianças $<12$ meses que receberam alimentos em mamadeira nas últimas $24 \mathrm{~h}$ Crianças $<12$ meses de idade 


\section{PARTE 2 \\ Quais são as atividades do supervisor de campo?}

O Supervisor de Campo é a pessoa responsável pela pesquisa no município. Sua atuação é fundamental para que a coleta de dados aconteça de forma adequada, garantindo assim a confiabilidade nos resultados. Suas atividades incluem fundamentalmente:

1) Divulgação da pesquisa junto à Coordenação da Campanha de Vacinação para que haja o devido entrosamento e a colaboração entre os entrevistadores e a mesa de vacinação.

\section{2) Recrutamento dos entrevistadores}

Os entrevistadores poderão ser recrutados nos próprios serviços de saúde, entre o professorado, entre alunos de cursos - de magistério, técnico de enfermagem, ou faculdades da área de saúde.

Uma vez que o município não terá despesas com a remuneração dos entrevistadores, a preocupação fundamental deve ser a de fornecer condições de trabalho razoáveis, como por exemplo: um lanche (como aquele oferecido ao pessoal de vacinação), passe de ônibus, uma ajuda de custo (conforme a disponibilidade de recursos), uma camiseta. No caso do funcionalismo, propomos a troca do dia de trabalho no dia da campanha, por alguma folga. Aos estudantes poderão ser oferecidos certificados de participação. Esses incentivos favorecem a melhoria na qualidade do trabalho do entrevistador, devem ser consideradas como um aspecto fundamental no sucesso da pesquisa.

Quanto ao número de entrevistadores a serem recrutados, sugerimos a presença de 1 entrevistador para cada 50 crianças menores de 1 ano a serem vacinadas. Mesmos nos postos onde a previsão é de que menos de 50 crianças sejam vacinadas o ideal é contar com a presença de 2 entrevistadores. Se isso não for possível, o entrevistador deve ficar muito atento para não deixar de entrevistar nenhuma criança menor de um ano, principalmente nos momentos em que várias crianças entram no posto ao mesmo tempo. Por questão de segurança, é sempre desejável que um número de entrevistadores a mais sejam treinados, para cobrir eventuais faltas no dia da campanha. Caso não haja faltas, essas pessoas poderão ser encaminhadas aos postos com maior movimento. 


\section{3) Treinamento dos entrevistadores}

O treinamento deverá ser aplicado a todos os entrevistadores, sendo que a ausência de um entrevistador no treinamento impossibilita sua participação na pesquisa.

Os entrevistadores deverão ser treinados para que não haja perda de criancas na fila de vacinação. Municípios pequenos irão incluir na pesquisa todos as crianças menores de um ano que comparecerem aos postos. Nestes casos a preocupação dos entrevistadores será somente a de identificar e captar todos os acompanhantes das crianças menores de um ano para a entrevista.

Municipios maiores trabalharão com amostras, sendo o procedimento para captação das crianças um pouco mais complexo. Nessa situação deverá ser realizado o sorteio sistemático de crianças menores de um ano na fila de vacina. Se no seu município for necessário trabalhar com amostragem, consulte nas Instruções para Municípios com Amostra como deve ser feita a orientação dos entrevistadores em cada posto de vacinação. forma:

A captação das crianças na fila vacina poderá ser feita da seguinte

a) Nos postos de vacinação com a presença de 2 entrevistadores o primeiro entrevistador percorrerá a fila da vacinação para identificar as crianças com menos de um ano de idade e para explicar às mães ou acompanhantes o propósito da pesquisa. O acompanhante receberá do primeiro entrevistador uma marca (um adesivo, uma fitinha) que servirá para que o segundo entrevistador, após a vacinação, identifique as crianças com marca e aplique o questionário.

b) Nos postos de vacinação com a presença de 1 entrevistador é fundamental que a mesa de vacinação colabore, pois o risco de perda de crianças é maior, especialmente se houver concentração de um grande número de crianças em um dado momento. No caso do entrevistador se ausentar por algum motivo (horário de lanche, ida ao sanitário) a mesa da vacinação deverá orientar as mães ou acompanhantes que aguardem um momento até o retorno do entrevistador.

\section{A perda de informações deve ser evitada ao máximo!}


No treinamento sugere-se a leitura completa do Manual do Entrevistador que contém orientações gerais sobre os procedimentos de campo, além de discutir todas as questões que compõem o questionário, que estão divididas em 06 blocos: local da pesquisa; identificação da criança; alimentação da criança nas últimas 24 horas; informações sobre nascimento, parto e atendimento médico; alimentação após a alta da maternidade e características das mães.

É fundamental que os entrevistadores experimentem preencher o questionário antes do dia da campanha para sentir as dificuldades e que haja oportunidade para tirar suas dúvidas.

$O$ ideal é que o treinamento seja feito em torno de 15 dias antes da pesquisa, para que os entrevistadores não esqueçam as orientações dadas no treinamento.

\section{4) Supervisão da coleta de dados}

É fundamental que, no dia da Campanha, uma pessoa (ou equipe) esteja disponivel para distribuir e recolher o material utilizado na pesquisa, para percorrer todos os postos de vacinação e verificar o andamento da pesquisa, solucionando problemas e dúvidas dos entrevistadores. Seria interessante também que os entrevistadores pudessem entrar em contato telefônico com a equipe de supervisão durante o período de coleta de dados, para esclarecimentos de dúvidas que não fossem resolvidas na consulta ao Manual do Entrevistador. É importante observar na supervisão de campo se:

- na circulação de crianças no posto de vacinação, o entrevistador consegue entrevistar todas as crianças menores de 1 ano, contando com a ajuda de outro entrevistador responsável pela identificação daquelas a serem entrevistadas ou ainda com a colaboração do próprio pessoal da campanha de vacinação, que poderão encaminhar ao entrevistador as crianças;

- na leitura das questões o entrevistador mantém uma postura de neutralidade diante das respostas, é paciente, lê com atenção as perguntas sem ler as respostas;

> no preenchimento do questionário o entrevistador transcreve com caligrafia legivel as questões abertas; assinala apenas uma alternativa nas questões fechadas; indica com clareza a alternativa escolhida mesmo no caso de rasuras. Convém ainda fazer uma leitura rápida do campo Observação no final do questionário, ou de outras anotações do entrevistador que poderão registrar alguma dúvida importante de ser esclarecida.

Durante a realização da supervisão de campo avaliar rapidamente 0 preenchimento daquelas questões que costumam trazer mais dúvidas 
verificar se o entrevistador está preenchendo questionários apenas de crianças menores de um ano;

- verificar se o entrevistador está preenchendo todas as questões do quadro da alimentação nas últimas 24 horas;

> verificar se o entrevistador está preenchendo as Q.31 a 36 apenas para crianças menores de 4 meses;

- verificar se o entrevistador está preenchendo as Q.37 a 47 apenas para as crianças acompanhadas de suas mães;

- verificar se está sendo respeitado o fluxo das questões no quadro referente as informações da mãe. Exemplos:

Q.40 resposta Sim segue para $Q .42$

Q.41 resposta Não segue para Q.44

Q.45 resposta Não e Não trabalhou segue para Q.47

5) Providenciar o material necessário para realização da pesquisa

- Cópias do Questionário

- Manual do Entrevistador

- Manual do Supervisor de Campo

- Canetas, pastas ou pranchetas

- Fitas de cetim ou etiquetas para identificação das crianças menores de 1 ano

- Lanches, ajuda de custo para os gastos com transportes, camisetas

- Crachá para identificação dos entrevistadores

\section{6) Preparação dos questionários para digitação}

- Após a coleta dos dados os questionários deverão ser numerados e revisados.

- O campo $\mathrm{N}^{\circ}$ ODD destinado ao número de cada questionário deverá ser preenchido pelo supervisor de campo, após o recolhimento de todos os questionários.

O quadro relacionado à questão “(11) QUAL A MARCA?” deverá ser preenchido durante a revisão dos questionários pelo supervisor de campo. Para tal, utilize a lista abaixo: 
FÓRMULAS INFANTIS

\begin{tabular}{|c|c|c|c|c|}
\hline NESTLÉ & $\begin{array}{l}\text { MEAD } \\
\text { JOHNSON }\end{array}$ & $\begin{array}{l}\text { SUPPORT/ } \\
\text { NUTRÍCIA }\end{array}$ & WYETH & ABBOTT \\
\hline $\begin{array}{l}\text { Pré Nan } \\
\text { Nan } 1 \\
\text { Nan } 2 \\
\text { Nan HA } \\
\text { Bio Nan } \\
\text { Nestogeno } 1 \\
\text { Nestogeno } 2 \\
\text { Nestogeno Soy } \\
\text { Pelargon } \\
\text { Al } 110 \\
\text { Alsoy } \\
\text { Alfaré }\end{array}$ & \begin{tabular}{|l} 
O-lac \\
Enfamil I \\
Enfamil II \\
Enfamil AR \\
Enfalac \\
Pregestimil \\
Pro Sobee
\end{tabular} & $\begin{array}{l}\text { Aptamil pre } \\
\text { Aptamil } 1 \\
\text { Aptamil } 2 \\
\text { Aptamil } \\
\text { Bebelac } 1 \\
\text { Bebelac } 2\end{array}$ & Nursoy & $\begin{array}{l}\text { Isomil } \\
\text { Similac Advance } 1 \\
\text { Similac Advance } 2\end{array}$ \\
\hline
\end{tabular}

Dado o grande número de marcas regionais de leite integral, seria impossivel listar todos eles. Podemos dar alguns exemplos: NINHO, NINHO CRESCIMENTO, LA SERENISSIMA, GLÓRIA, ITAMBÉ, PARMALAT, SOL, TEIXEIRA, etc.

Incluir em outro tipo de leite em pó os leites desnatados e semidesnatados; leites de cabra em pó; leites de soja em pó que não constarem do quadro acima. 
ANEXO 2 


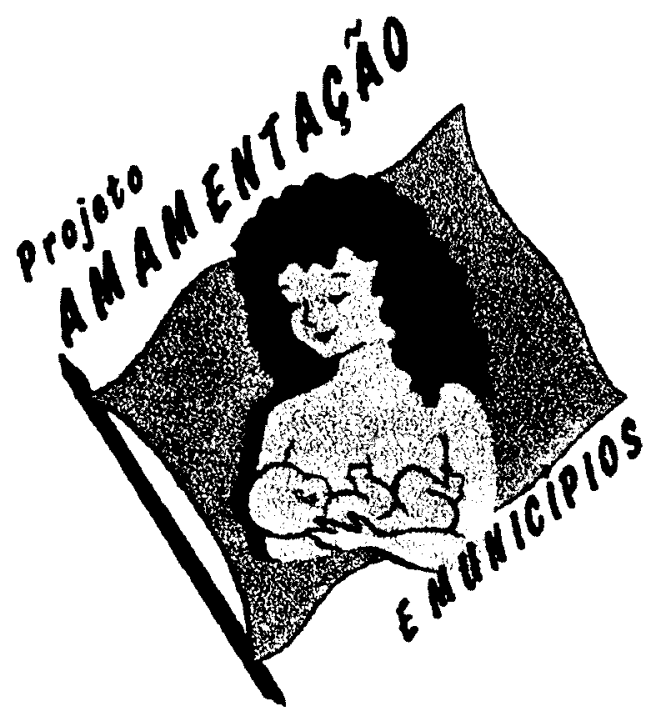

AVALIAÇÃo de PRÁtiCAS ALIMENTARES NO PRIMEIRO ANO DE VIDA EM DIAS NACIONAIS DE VACINAÇĀO

\section{MANUAL DO ENTREVISTADOR}

NÚCLEO DE INVESTIGAÇ̃̃o EM SAÚDE DA MULHER E DA CRIANÇA NÚCLEO DE INFORMÁTICA INSTITUTO DE SAÚDE

SECRETARI AE ESTADO dA SAÚdE dE SÃo PAULO

NISMIC/NIIS/IS/SES/SP
NÚCLEO DE PESQUISAS EPIDEMIOLÓGICAS EM NUTRIÇÃO E SAÚDE

FACULDADE DE SAÚDE PÚBLICA

UNIVERSIDADE DE SÃO PAULO-NUPENSS / USP

APOIO: GATS/SES/SP - UNICEF

Rua Santo Antonio, 590 - 2.o. Andar - Bela Vista - CEP $01314-000$ - São Paulo - SP Fones: 11 3105-9047/9048 ramais $211 / 212$ Sonia/Cirlei/Lilian ou 233 Biba

E-mail: soniav $\alpha$ isaude.sp.gov.br 


\section{Caro (a) Entrevistador(a),}

Sabemos que a alimentação adequada no $1^{\circ}$ ano de vida é de extrema importância. Tanto o leite materno como os demais alimentos precisam ser dados de forma, em quantidade e no momento apropriados.

Essa pesquisa ajuda a conhecer melhor os hábitos de alimentação e a situação de aleitamento das crianças menores de 1 ano. Com os resultados em mãos, os profissionais de saúde poderão organizar programas pertinentes à comunidade onde trabalham, e orientar as mães sobre as formas de alimentação mais adequadas para o crescimento saudável de suas crianças.

Sua participação é fundamental para que essa pesquisa se realize. Siga as instruções deste manual e bom trabalho!

\section{ORIENTAÇÕES GERAIS}

- É essencial que as orientações do Supervisor de Campo sobre a forma de identificação e captação das crianças no dia da campanha de vacinação sejam seguidas corretamente, para que as crianças menores de um ano sejam incluidas em número suficiente na pesquisa.

- Anote no espaço a seguir as orientações do Supervisor de Campo sobre a identificação e captação das crianças na fila da vacina.

- O correto preenchimento do questionário é fundamental no alcance dos objetivos da pesquisa. A maneira como esse preenchimento será feito pode levar a erros na digitação e na análise de dados. Por essa razão, 
recomenda-se que sejam respeitadas as instruções que constam deste manual

- Não se deve confiar na memória. O questionário deve ser preenchido na hora, evitando anotações posteriores à entrevista. Nos casos em que houver dúvida quanto à alternativa a ser assinalada, anote no canto da folha do questionário o que o entrevistado está respondendo. Consulte o manual sempre que tiver dúvidas.

- A maioria das questões são fechadas, ou seja, para respondê-las basta assinalar com ( $\mathrm{x}$ ) uma única alternativa, que corresponde a resposta dada pela mãe ou acompanhante da criança. Evite mostrar o questionário ou ler as alternativas das respostas. Leia somente a pergunta. A leitura das alternativas pode fazer com que o informante responda sempre "não sei" para terminar logo a entrevista. Nas questões abertas (nome da criança, do hospital, etc) anote com letra legível, exatamente o que for respondido pela mãe ou acompanhante da criança.

- Logo após a entrevista e antes de liberar a mãe ou acompanhante da criança, uma revisão rápida é necessária para confirmar que nenhuma pergunta foi omitida. A ordem das questões deve ser respeitada e não se deve alterar qualquer item do questionário. Caso seja necessário fazer observações, estas devem ser escritas no quadro das observações colocado no final do questionário.

- Não deixe nenhuma pergunta sem resposta.

- O entrevistador deve evitar ao máximo manifestar suas opiniões (risos, olhares de censura, etc.) para não influenciar as respostas. Ler as perguntas com simpatia, concentração e paciência ajuda bastante, principalmente naqueles casos em que o acompanhante da criança não consegue entender com facilidade as perguntas.

- A apresentação do entrevistador poderá ser com a seguinte frase:

- Bom dia! Estamos realizando uma pesquisa sobre alimentação das crianças aqui de cidade). A Sra. (Sr.) poderia me dizer a idade dessa criança? (mencionar o nome da

Nos casos em que a criança tiver mais de 1 ano, o entrevistador deverá agradecer e dirigir-se à próxima criança.

\footnotetext{
Todos os dados devem ser preenchidos com caneta esferográfica.
} 
PREENCHIMENTO DO QUESTIONÁRIO

\section{QUESTÕES 01 À 04}

$\mathbf{N}^{\circ}[][][][$ o quadro referente ao número do questionário será preenchido posteriormente pelo supervisor de campo .

As demais questões: (01) DATA, (02) ENTREVISTADOR, (03) MUNICíPIO, (04) LOCAL DE VACINAÇÃO deverão ser preenchidas antes do início da aplicação dos questionários, para diminuir o tempo de duração de cada entrevista.

\section{QUESTÕES 05 À 07}

(05) NOME DA CRIANÇA: Anotar apenas o primeiro nome.

(06) DATA DE NASCIMENTO DA CRIANÇA:

Procure anotar de preferência a data de nascimento da carteira de vacinação ou de outro documento da criança. Não havendo documento, anote a data de nascimento que informar. Se a criança já completou 1 ano de idade, ou está fazendo aniversário no dia de entrevista, agradeça a colaboração e passe para outra criança. Pretende-se estudar apenas a alimentação das crianças que ainda não completaram um ano de idade.

\section{(07) A SRA. É MÃE DA CRIANÇA?}

Consideramos também como mãe, a pessoa que assumir a responsabilidade pelo cuidado da criança na ausência prolongada da mãe biológica. Para os acompanhantes do sexo masculino não faça a pergunta, assinale "não" e continue fazendo as perguntas. Qualquer explicação importante poderá ser copiada nas OBSERVAÇÕES no final do questionário.

\section{QUESTÕES 08 À 25}

Esta é a parte central do questionário. Refere-se aos alimentos que a criança consumiu desde a manhã do dia anterior até a manhã do dia em que está sendo feita a entrevista. Cada alimento deve ser perguntado individualmente como está no questionário. Se a mãe ou o acompanhante não souber sobre um alimento, marque "não sabe" e passe para o alimento seguinte. 


\section{(08) LEITE DE PEITO?}

Se a mãe mencionar que deu leite de peito, deve-se perguntar (09) QUANTAS VEZES? da manhã do dia anterior à manhã do dia da entrevista (incluindo as mamadas durante a noite). Se a mãe responder 8 ou mais mamadas anotar o número 8 . Se a mãe não deu leite de peito ou o informante não sabe informar, registrar a resposta e passar diretamente à questão 10.

\section{(10) LEITE EM PÓ?}

Se a mãe mencionar que deu leite em pó, deve-se perguntar (11 IQUAL A MARCA? Interessa saber o nome comercial do leite (Ninho, Nestogeno, Nan, Pelargon, Glória, Itambé, La Serenissima, etc.). Se a mãe não deu leite em pó ou o informante não sabe informar assinalar a resposta e passar diretamente a questão 12.

\section{G PREENCHIMENTO EXCLUSIVO DA COORDENAÇ̃̃O:}

$\square$ FÓRMULA INFANTIL ILEITE INTEGRAL $\square$ Outro TIPO DE LEITE EM PÓ

O quadro acima deverá ser preenchido no final dos trabalhos pelo Supervisor de Campo.

\section{(12) OUTRO LEITE?}

Pergunte se a criança consumiu outro leite que não seja o leite materno nem o leite em pó. Nesse caso não interessa a marca, mas só o tipo de leite (ex. leite de soja, cabra, fresco, in natura).

\section{(13) MINGAU?}

Refere-se à refeição pastosa preparada com alguma farinha (trigo, mandioca, láctea, etc.) ou engrossante (maizena, cremogena, aveia, etc.) e misturada com leite, fruta ou mesmo só com água.

\section{(14) SOPA OU PAPA DE LEGUMES?}

Refere-se à refeição de sal líquida (sopa) ou pastosa (papa). Se recebeu sopa ou papa, deve-se perguntar (15) COM CARNE? Considerar carne de peixe, vaca, frango e vísceras (fígado, rim, coração).

\section{(16) COMIDINHA COM SAL?}

Refere-se à refeição de sal sólida que contém pedaços inteiros de alimentos, e que se assemelha à comida dos adultos. Se a criança comeu comidinha de sal deve-se perguntar (17) COM CARNE? e (18) COM FEIJÃO?

(19) ÁGUA PURA? Refere-se à água sem açúcar. 
(20) ÁGUA COM AÇÚCAR? Refere-se à água adicionada de açúcar.

(21) CHÁ? Refere-se à qualquer tipo de chá, inclusive se é oferecido como remédio.

(22) SUCO DE FRUTA? Refere-se a qualquer tipo de suco, fresco ou não.

(23) FRUTA (EM PEDAÇO OU AMASSADA)? Refere-se a todo o tipo de fruta consumida em pedaço ou amassada.

(24) ALGUNS DESSES ALIMENTOS (OU LÍQUIDOS) FOI DADO POR MAMADEIRA OU CHUQUINHA?

A questão procura averiguar se algum alimento (leite materno, outro leite, sopa ou papa, água, suco, etc.) foi dado à criança por meio de mamadeira ou chuquinha.

(25) A CRIANÇA CHUPA CHUPETA?

A questão procura verificar o uso de chupeta no dia anterior.

QUESTÕES 26 À 30

FAZER AS PERGUNTAS DO QUADRO ABAIXO PARA TODAS AS

CRIANCAAS MENORES DE 1 ANO

INFORMAÇÕES SOBRE NASCIMENTO, PARTO E ATENDIMENTO MÉDICO:

(26)

HOSPITAL

ONDE

A

CRIANÇA

NASCEU:

(Anote o nome) $\square$ Nasceu em casa

Não Sabe

Anotar o nome do hospital ou do serviço de saúde onde a criança nasceu, mesmo que não seja do município onde está se realizando a entrevista. Se a criança tiver nascido em casa ou outro lugar que não seja instituição de saúde, basta assinalar a alternativa "nasceu em casa". Se o acompanhante não souber sobre o local de nascimento, marque "não sabe" . 
(27) MUNICIPIO ONDE A CRIANÇA

NASCEU:

(Anote o nome) $\square$ Não Sabe

(28) PESO AO NASCER:

gramas (Anote da carteira de

\section{vacinação)}

Dar preferência para informação contida no cartão de vacinação. Caso não haja essa informação pergunte ao acompanhante.

(29) TIPO DE PARTO: $\square$ Normal $\square$ Fórceps $\square$ Cesárea $\square$ Não Sabe

(30) ONDE COSTUMAM LEVAR ESTA CRIANÇA PARA CONSULTA MÉDICA?

$\square$ Neste Posto de Saúde $\square$ Outro Posto da Rede Pública $\square$ Serviço Particular ou Convênio

Tratando-se de Posto Volante de Vacinação verificar se a criança freqüenta um serviço público de saúde e nesse caso anotar "outro posto da rede pública". Se o informante der duas ou mais respostas, procure saber em qual serviço a criança é levada na maioria das vezes. Se a criança é recémnascida e não iniciou acompanhamento médico, procure saber onde pretendem levar a criança para fazê-lo. E lembre-se, só é permitida uma resposta.

\section{QUESTÕES 31 À 36}

FAZER AS PERGUNTAS DO QUADRO ABAIXO APENAS PARA AS CRIANÇAS MENORES DE 4 MESES

(31) COM QUANTOS DIAS A CRIANÇA RECEBEU ALTA DA MATERNIDADE?

Anotar o número de dias que a criança permaneceu no hospital desde o dia de nascimento até a alta da maternidade. Não interessa qualquer outra internação que ocorreu após a alta da maternidade. 
As questões 32 a 36 referem-se à alimentação da criança no primeiro dia em casa após a alta da maternidade. Deve ser feita alimento por alimento, anotando-se a resposta correspondente.

(32) MAMOU NO PEITO?

(33) TOMOU OUTRO LEITE QUE NÃO O LEITE DE PEITO?

(34) TOMOU ÁGUA?

(35) TOMOU ÁGUA COM AÇÚCAR?

(36) TOMOU CHÁ?

\section{QUESTÕES 37 À 47}

FAZER AS PERGUNTAS DO QUADRO ABAIXO APENAS QUANDO O ACOMPANHANTE DA CRIANÇA FOR A MÃE

Essas questões somente serão feitas quando a criança estiver acompanhada de sua mãe. Caso não seja a mãe, agradeça e encerre a entrevista.

(37) QUAL É A SUA IDADE?

Anotar a idade da mãe em anos completos.

(38) ESTA CRIANÇA É SEU PRIMEIRO FILHO? Considere apenas filhos nascidos vivos.

\section{(39) A SRA SABE LER E ESCREVER?}

Se a mãe responder que sabe um pouco, procure saber se ela consegue ler ou escrever uma carta. Se ela responder que sim, considere que ela sabe ler e escrever.

(40) A SRA. ESTÁ ESTUDANDO?

Se a resposta for sim passe para a questão 42.

(41) JÁ FREQUENTOU A ESCOLA?

Se a mãe já freqüentou uma vez a escola, assinalar "sim". Caso a resposta seja não passe para a questão 44.

(42) QUAL A ÚLTIMA SÉRIE QUE COMPLETOU? (43) E GRAU?

Exemplo 1: Se a mãe responder: Estudei até a $5^{\text {a }}$ série, pergunte:

- Mas a Sra. chegou a terminar a $5^{a}$ série? 
Se a mãe responder $\underline{\text { SIM }}$ anote: $5^{\mathbf{a}}$ série do $1^{\circ} \mathrm{grau}$

Se a mãe responder $\underline{\mathrm{NÃO}}$ anote: $4^{\mathrm{a}}$ série do $1^{\circ} \mathrm{grau}$.

Exemplo 2: Se a mãe responder: - Estou estudando atualmente, estou fazendo a $7^{a}$ série, anote a última série que a mãe concluiu:

$$
6^{\mathrm{a}} \text { série do } 1^{\circ} \mathrm{grau}
$$

(44) A SRA TRABALHAVA FORA DE CASA QUANDO ENGRAVIDOU DESTA CRIANÇA?

"Trabalhava fora de casa" significa que quando a mãe ficou grávida da criança em estudo, ela tinha um emprego remunerado, que fazia com que ela ficasse longe da criança pelo menos um dia por semana.

\section{(45) SE TRABALHOU DURANTE A GRAVIDEZ, TEVE LICENÇA MATERNIDADE?}

Licença maternidade é o afastamento remunerado do trabalho por 4 meses que as gestantes têm direito. Se a resposta for não passe para a questão 47. Se a mãe não teve um emprego durante a gravidez e não teve a licença, responda não se aplica. Caso a reposta seja sim perguntar (46) AINDA ESTÁ DE LICENÇA MATERNIDADE? Para verificar se a mãe ainda está afastada do trabalho.

(46) AINDA ESTÁ DE LICENÇA MATERNIDADE?

(47) ATUALMENTE A SRA ESTÁ TRABALHANDO FORA DE CASA?

"Trabalha fora de casa" significa que no momento, a mãe tem um emprego remunerado, que faça com que ela fique longe da criança pelo menos um dia por semana. 
ANEXO 3 


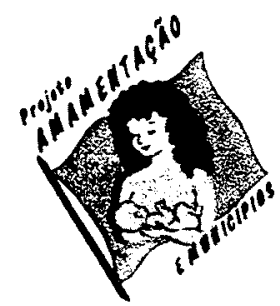

\section{FORMULÁRIO PARA AVALIAÇÃO DE AÇÕES DE PROTEÇÃO PROMOÇÃO E APOIO A AMAMENTAÇÃO NO MUNICIPIO}

No seu município:

1. Existe algum HOSPITAL AMIGO DA CRIANÇA? () sim () não () não sabe

2. Se não tem um HOSPITAL AMIGO DA CRIANÇA, algum hospital passou pela pré avaliação da Iniciativa Hospital Amigo da Criança? () sim () não () não sabe

3. Existe algum banco de Leite Humano? () sim () não () não sabe

4. Já foram realizados O CURSO DE 18 HORAS do UNICEF ou O CURSO DE ACONSELHAMENTO em amamentação da OMS? () sim () não () não sabe

5. Participam da SEMANA MUNDIAL DA AMAMENTAÇÃO? () sim () não () não sabe

6. Há monitorização da NORMA BRASILEIRA PARA COMERCIALIZAÇÃO DE ALIMENTOS PARA LACTENTES? () sim () não () não sabe

7. Já foi realizado algum diagnóstico da situação do Aleitamento Materno nos últimos dois anos? () sim () não () não sabe

8.Existem ações específicas junto aos escolares/ adolescentes promovendo a amamentação? () $\operatorname{sim}$ () não () não sabe

9. Existe um núcleo multiprofissional dedicado à promoção e lou à pesquisa sobre amamentação? () $\operatorname{sim}$ () não () não sabe

10. Existe uma política municipal de proteção e/ou promoção da amamentação (Portaria, Programa ou outra estratégia)? () sim () não () não sabe 
ANEXO 4 
Instituto de Saúde/SES/SP - NUPENS/FSP/USP

Projeto Amamentação e Municipios

Avaliação de Práticas Alimentares no Primeiro Ano de Vida

em Dias Nacionais de Vacinação

$\mathbf{N}^{\circ} \mathrm{\square} \square 00$

01-DATA $\frac{1}{\text { 02-ENTREVISTADOR:_ }}$
03-MUNICIPIO

FAZER AS PERGUNTAS DO QUADRO ABAIXO PARA TODAS AS CRLANCAS COM MENOS DE 1 ANO DE IDADE QUE COMPARECEREM À VACINACCÁO

05-A SRA. (SR.) PODE ME DIZER O NOME DESTA CRIANÇA? (Anote apenas $01^{\circ}$ nome)

06-DATA DE NASCIMENTO DA CRIANÇA 1 (Anote da carteira de vacinaçăo)

07-A SRA E A MÃE DA CRIANÇA? 1ISim $2 \square$ Nảo

A SENHORA (OU SR) PODE ME DIZER QUAIS ALIMENTOS ESTA CRIANÇA TOMOU OU COMEU DESDE ONTEM DE MANHĀ ATÉ HOJE DE MANHĀ? EU VOU FALANDO O NOME DE CADA ALIMENTO E A SRA. (SR.) ME RESPONDE SIM OU NÃO, ESTA BEM?

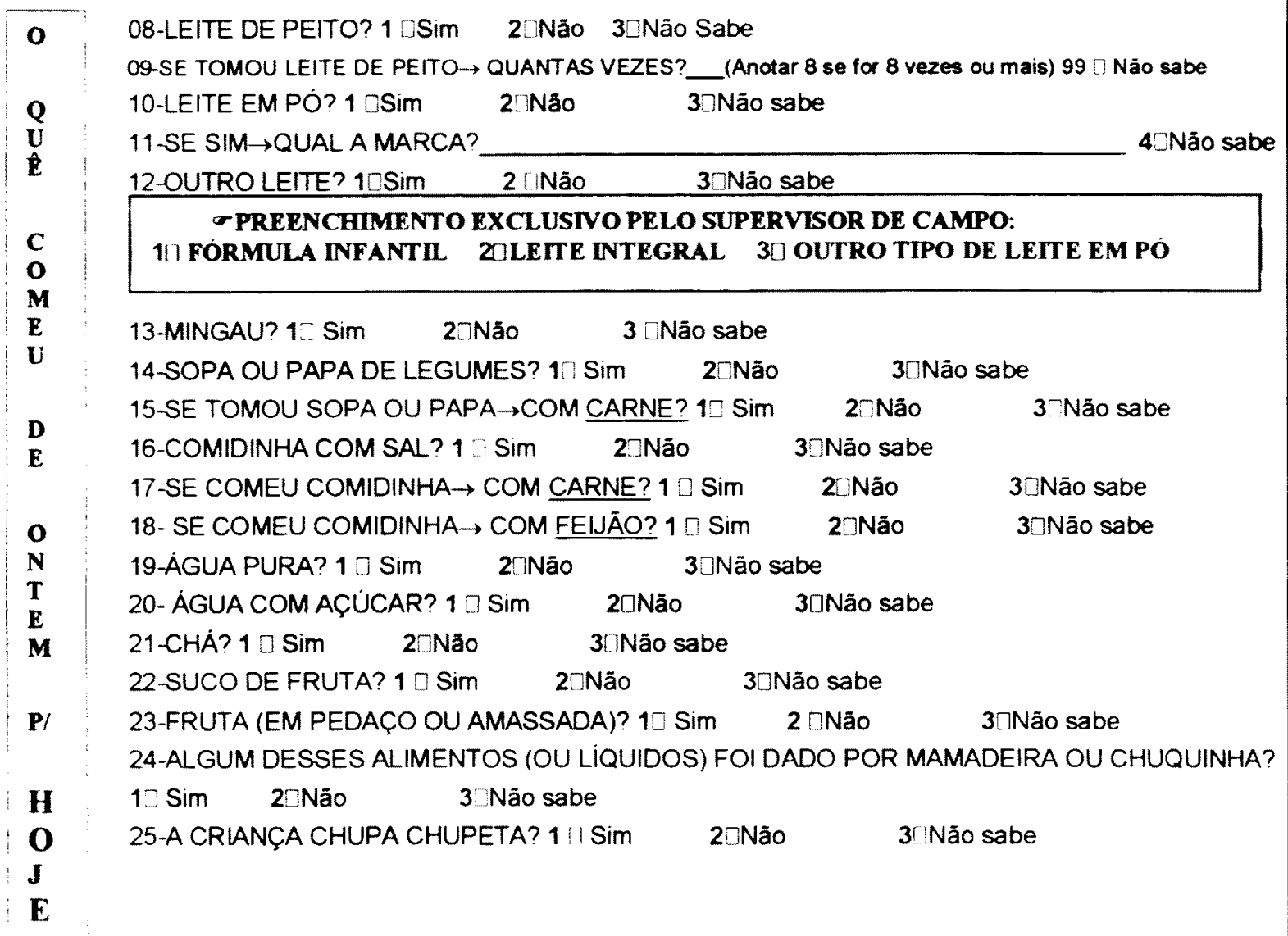


FAZER AS PERGUNTAS DO QUADRO ABAIXO PARA TODAS AS

CRIANÇAS MENORES DE 1 ANO

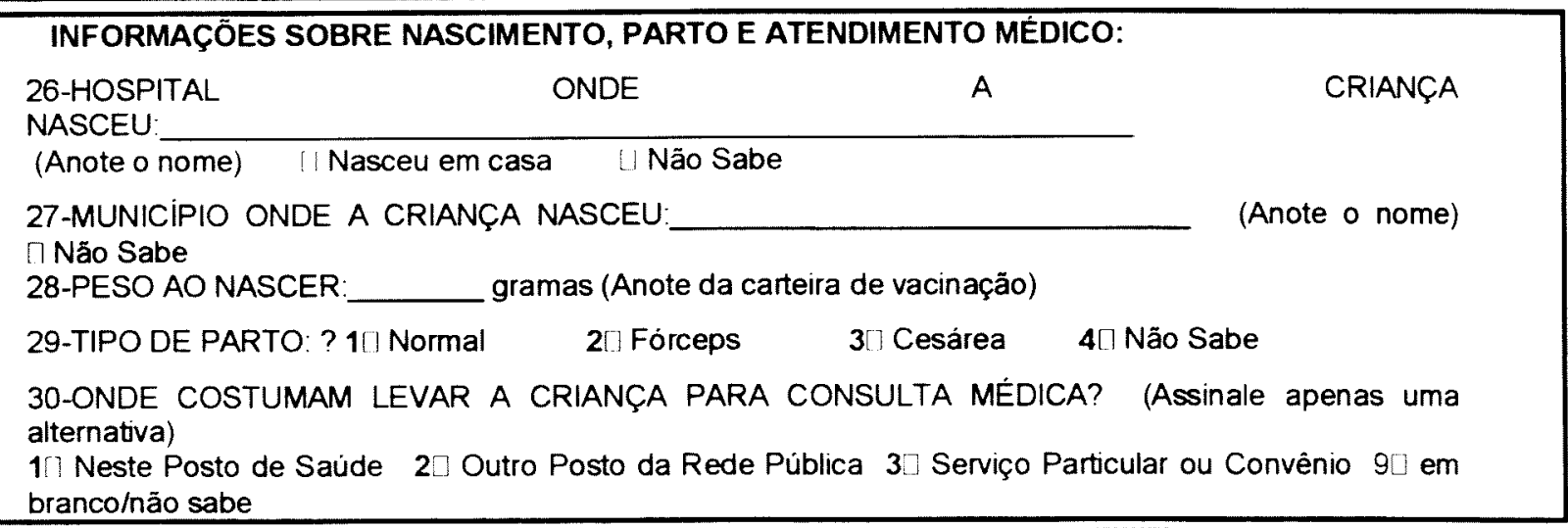

FAZER AS PERGUNTAS DO QUADRO ABAIXO APENAS PARA AS CRIANÇAS MENORES DE 4 MESES

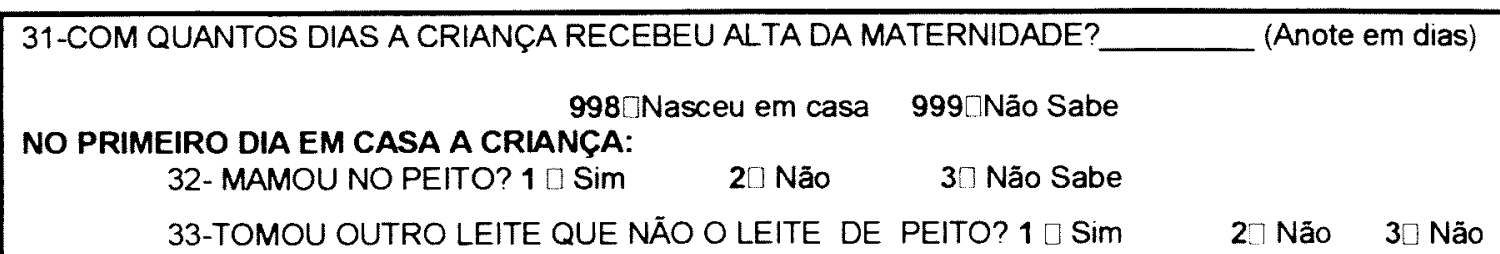

Sabe
34-TOMOU ÁGUA? $10 \mathrm{Sim}$
$2[$ Não
3 ㅁāo Sabe
35-TOMOU ÁGUA COM AÇÚCAR? $1[\mathrm{Sim}$
2! Não
31] Não Sabe
36-TOMOU CHÁ? $1 \square$ Sim
$2 \square$ Não
$3 \square$ Não Sabe

FAZER AS PERGUNTAS DO QUADRO ABAIXO APENAS QUANDO O ACOMPANHANTE DA CRIANÇA FOR A MÃE

37-QUAL É A SUA IDADE? (Anos)

38-ESTA CRIANÇA É SEU PRIMEIRO FILHO? 1 1 Sim $\quad 2 \square$ Não (Considere apenas filhos nascidos vivos)

39-A SRA. SABE LER E ESCREVER? $1 \square \operatorname{Sim} \quad 2 \square$ Não

40-A SRA. ESTA ESTUDANDO? $1 \Pi$ Sim (Passe para a questão 42) 2] Não

41-A SRA. JA FREQÜENTOU A ESCOLA? $1 \square \operatorname{Sim} \quad 2 \square$ Não (Passe para questão 44)

42-QUAL A ÚLTIMA SÉRIE QUE COMPLETOU?

43-E GRAU?

44-A SRA. TRABALHAVA FORA DE CASA QUANDO ENGRAVIDOU DESTA CRIANÇA? $1[$ Sim $2 \square$ Não

45-SE TRABALHOU DURANTE A GRAVIDEZ, TEVE LICENÇA MATERNIDADE?

$1 \square \mathrm{Sim} \quad 2 \square$ Não (Passe para a questão 47) $3 \square$ Não se aplica (Passe para a questão 47)

46-AINDA ESTA DE LICENÇA MATERNIDADE? $1 \square \mathrm{Sim} \quad 2 \square$ Não

47-ATUALMENTE A SRA. ESTÁ TRABALHANDO FORA DE CASA? 1】 Sim $2 \square$ Não

Observaçōes: 
ANEXO 5 


\section{Projeto Amamentação e Municípios - 1999 Instalação e uso do Programa de Digitação}

Atenção: Entre em contato com a Coordenação do Projeto para Pedir senha de liberação, antes de começar a digitação

O digitador deve estar atento a esses recursos, pois assim se acostumará rapidamente com a entrada de dados e seu trabalho será mais produtivo.

Para agilizar ainda mais, o primeiro bloco de variáveis se repetirá, registro a registro, até que o digitador mude um de seus dados, que se repetirá até nova troca (tais como data, entrevistador, municipio e local de vacinaçăo).

$\mathrm{Na}$ barra de botōes acima do formulário de digitaçāo, serão encontrados botōes para (respectivamente): Inserir um novo questionário, ir para o primeiro, ir para o anterior, ir para o posterior. ir para o último e excluir o questionário exibido no momento.

Se tiver dúvidas em localizá-los, apenas posicione o mouse por sobre cada um deles e o sistema exibirá sua função. Bom trabalho

A próxima seqüência de botões é padrão Windows e de uso mais avançado, mas os mais importantes são o "Binóculo" que permitirá encontrar o(s) questionário(s) que possuirem (no campo que você clicou antes de apertar esse botão) o valor que você ingressar

Os botōes seguintes: $A->Z$ e $Z->A$ ordenarāo os registros pelo campo que vocé escolheu antes de apertar os mesmos, de forma ascendente e descendente (respectivamente)

Jà o botão representado por um "funil" e um relâmpago (filtrar por seleçāo), filtrará apenas os registros que contiverem, no campo que vocé escolheu, o valor que foi selecionado pelo mouse (iluminado).

Por Ex: lluminando o nome de um determinado posto e clicando no referido botão, apenas os registros deste posto de saúde serăo exibidos.

$E$ possivel fazer isso com quase todos os campos $e$ o número de registros encontrados nessa condição será exibido no campo "Total de Registros" no topo do formulário de digitação.

Além disso as condiçōes de filtragem são cumulativas, isto é, se vocé filtrar dois ou trés campos, cada qual com o seu valor, o número de registros ativos vai diminuindo (observe no "Total de Registros")

Obs.: Os dados não são, em momento algum perdidos, apenas fitrados de acordo com suas condições, isso pode ser útll em pequenas contagens ou na procura de algum questionário para correcão. Para desativar o fittro, existe um botão próprio ao lado do botão de filtro, o "Remover Filtro" (o funil com o "X" vermelho) que fará todos os Registros "aparecerem" de novo!

\section{Relatórios}

Quase três dezenas de relatórios foram incluidos no sistema para tabulação de dados simples, porém mais significativos, uma vez selecionados, serảo exibidos em tela para sua apreciação e, se for 0 caso impressão. Quando visualizados, o botão com a estilização de uma impressora, se encarregará de passar o que é exibido em tela, para a impressora padrāo de seu computador.

$\dot{E}$ natural que os relatórios não cubram todas os anseios dos usuários, para facilitar outros possiveis relatórios, o sistema exporta os dados para o MSExcel para outras tabulações ou para migração em pacotes estatísticos (Veja item 6.Backup).

Obs.: Os relatórios e gráficos só são impressos no nivel "Supervisor" e sempre pedem o ano de referência dos dados (Ex.: 1999).

3. Gráficos

Alguns gráficos também são exibidos a toque de botão" e tem a apresentação e utilização parecida com os relatórios, são exibidos em tela para a simples observação e/ou impressão.

Vale salientar, que o gráfico que exibe a média móvel (AME e AMP) necessita de um número representativo de crianças em cada faixa de tempo, para exibir linhas que representem os valores esperados ou próximo disso. $O$ número discrepante de crianças nas faixas de tempo de vida analisadas nesse gráfico pode fazer com que o mesmo tenha aspecto muito irregular. Por isso o mesmo não é exibido quando o número de crianças é menor do que 120 no total ou quando alguma faixa de tempo analisada tem número de crianças igual a zero. Ainda assim discrepâncias podem ocorrer

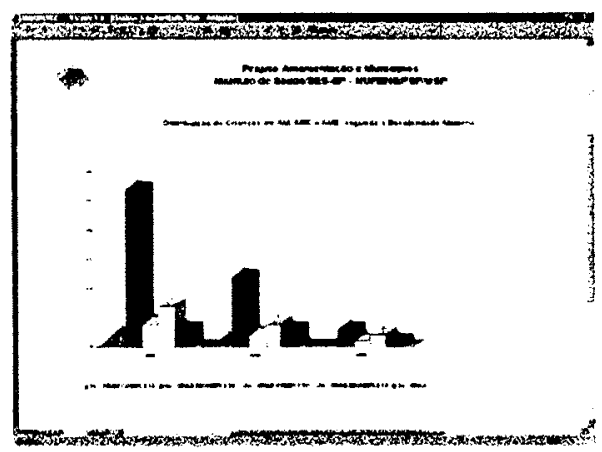

4. \& 5. Equipes

Os itens quatro e cinco exibem informações sobre o projeto, equipe técnica do mesmo, seus patrocinadores, formas de contato, a empresa que fez o programa, seus profissionais envolvidos requisitos do sistema e também formas de contato th equipe que montou o sistema.

\section{Backup}

Este módulo está previsto para permitir a gravação dos dados da pesquisa em disquete e criar cópias de segurança das informações incluídas ao longo do processo de digitação, diariamente, se assim for desejado (aconselhável!). Ainda nesse módulo é possivel exportar os dados para o MS-Excel para outras tabulaçסes

Solicitamos que, quando for concluida a digitaçāo do banco de dados, uma cópia do mesmo seja encaminhada à coordenação do projeto. Para tal, basta inserir um disquete clicar duas vezes no icone BACKUP, criado durante o processo de instalaçáo do programa na tela de entrada do WINDOWS. O programa de BACKUP também pode ser acessado pelo C:ISIBACKUP.

Dica: É prudente fazer cópias em vários disquetes (um por dia ou, um para dias pares e outros para ímpares) de forma que possa haver recuperação em vários niveis.

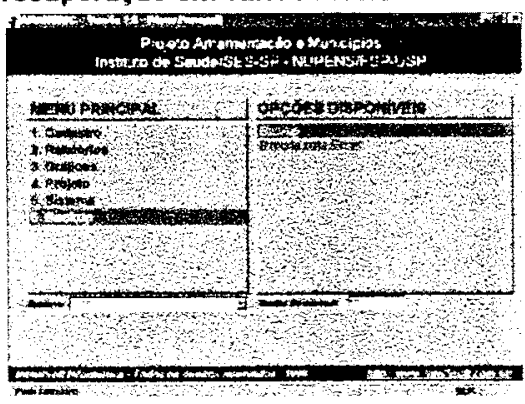

Obs.: O módulo 6.Backup, só funciona no nível "Supervisor". Bom trabalho! 


\section{Projeto Amamentação e Municipios - 1999 Instalação e uso do Programa de Digitação}

\section{Atenção: Entre em contato com a Coordenação do Projeto para Pedir senha de liberação, antes de começar a digitação}

\section{Instalacäo}

Requisitos: Pentium $100 \mathrm{Mhz}$ ou superior. $16 \mathrm{Mb}$ memória RAM, 20Mb de espaço em disco, drive de $1.44 \mathrm{Mb}$, Windows 95 ou 98 e Access 97

Para proceder a instalação, basta clicar duas vezes no arquivo "instalar.exe", abrir-se-á uma tela onde deve-se pressionar o botão "Unzip" para que os arquivos sejam descompactados. Não indique o diretório onde ele deve ser instalado, ele o fará sozinho e instalará os arquivos em Cilislamamunic, criando atalhos no fundo de tela de seu computador. Se tudo correr bem durante a descompactação (que é muito rápida), basta clicar no botāo "OK" e, em seguida, no botão "Close" para que a janela de instalação seja desativada.

Procure o icone chamado Amamunic para executar - programa, tanto no Desktop (fundo de tela do Windows), como no menu Iniciar, uma vez achado, um duplo clique sobre o icone chamará o programa. Use o mesmo procedimento para a instalação do arquivo BACKUP que servirà para que vocês nos enviem a copia de seu banco de dados.

\section{Senha}

- Sistema é protegido por senhas em dois niveis, Supervisor e Usuário. A senha do nivel "Usuário" permite que o operador ingresse os dados mas năo imprima relatórios e tảo pouco proceda o Backup e Exportação dos dados que só é permitido pela senha do supervisor.

Sendo assim, escolha o nivel "usuário" no retângulo inferior esquerdo e digite a senha ANGRA, clique e cadastre sua unidade ( ${ }^{\circ}{ }^{\circ}$ fornecido em anexo). Volte para a pagina inicial e entre com a senha nivel Usuario fornecida pela equipe do Projeto. Com a senha digitada, basta clicar no menu para visualizar as opçōes disponiveis.

Clique nos itens da esquerda (Menu Principal) e as opçōes disponiveis aparecerão à direita, para selecionar uma das opçöes da direita é necessário um duplo-clique.

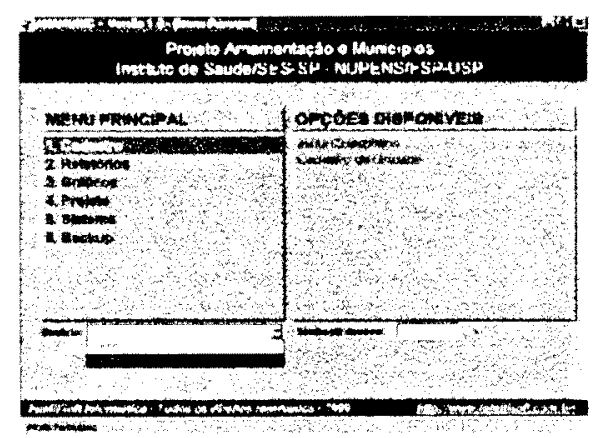

\section{Cadastro}

A opção cadastro, è utilizada para incluir questionários e a identificação da unidade que coleta os dados do seu municipio. É importante que sejam cadastrados os dados da unidade de coleta antes dos questionários. $E$ esse cadastro passa pela obtenção de uma senha de acesso a

esse módulo e um número de código para unidade,

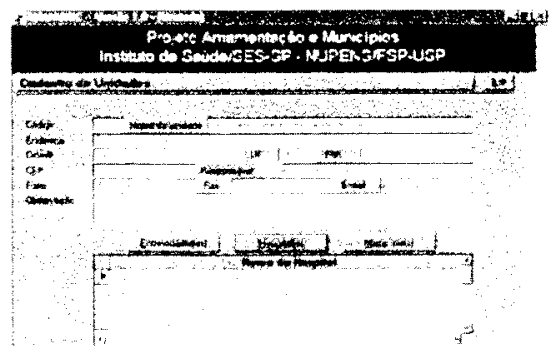

junto à coordenaçāo. O objetivo é nāo misturar seus dados com os de outros municipios quando os

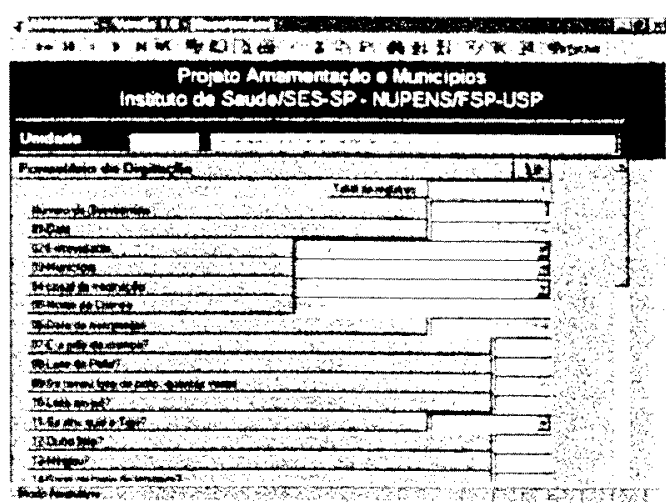

dados forem agregados.

Quando for cadastrar esses dados o sistema pedirá a senha para acessar a tela e em seguida, um número para seu municipio ambos dados pela coordenaçăo.

Ainda nessa tela de cadastro inclua os entrevistadores que procederam a coleta dos dados (botão "Entrevistadores"), o Nome dos Hospitais de nascimento das crianças encontrados nas fichas de coleta (Botão "Hospitais") e o municipios onde foram coletados os dados (Botão "Municipios"), no caso dessa pesquisa, apenas o nome de seu municipio.

Esses dados serão utilizados para facilitar a inclusão das informaçōes por parte do digitador. permitir uma melhor consistência dos dados $e$ ajudar na tabulação dos mesmos.

Se algum Hospital ou Entrevistador for esquecido, volte neste cadastro e inclua-o(s), caso contrário, não estarão disponiveis como opçōes de digitação.

Dica: $O$ botão com um ícone representando uma porta e uma seta para a esquerda, no canto superior direito, serve para sair da tela atual e voltar ao menu principal, estará presente em todas as telas de entrada ou exibição de dados, exceto em relatórios e gráficos, onde será exibido um botão com a palavra "Fechar" para executar a mesma tarefa.

\section{Digitando questionários}

Uma vez incluidos os dados da Unidade, é possivel proceder a digitaçāo dos questionários ("Inclui Questionário"), que apresenta uma tela como a exibida acima.

O digitador precisará atribuir um número ao questionário, para facilitar sua identificação, caso haja necessidade de encontrar um determinado formulário para conferência o número ingressado na tela deve ser o mesmo adotado na ficha

Os campos abertos precisarão de poucas letras ou números para se auto-preencher, caso o mesmo valor já tenha sido ingressado, como se fosse um endereço internet digitado, eles vão "aprendendo" os valores ingressados de forma a ajudar e a padronizar a digitação, caso queira consultar o que já existe na lista, clique com o mouse no triangulo invertido no limite direito desses campos ou pressione "Alt+Seta para Baixo".

Os campos fechados (valores numéricos), exibirão os valores possiveis sempre que um valor inválido for ingressado.

Tambem serāo omitidos os campos que não precisam ser digitados caso uma variável que condicione o seu preenchimento seja negada. 
ANEXO 6 


\section{Modelo linear multinivel com variância simples}

No modelo de regressão linear tradicional, a relação entre a resposta e as variáveis explanatórias é geralmente escrita como

$\gamma_{i}=\alpha+\beta_{1} x_{1 i}+\beta_{2} x_{2 i}+\ldots+\beta_{p} x_{p i}+e_{i}$

onde

$\gamma_{1}=$ a resposta para cada um dos $n$ indivíduos $(i=1, \ldots, n)$

$\alpha=$ termo constante

$\beta_{1}$ a $\beta_{p}=$ coeficientes dos fatores em estudo

$e=$ residuo (ou erro) para cada indivíduo

Classicamente, assume-se que os $e_{i}$ têm média zero, que sua variância é constante e que eles são independentes:

$E\left(e_{i}\right)=0, \operatorname{var}\left(e_{i}\right)=\delta^{2}, \operatorname{cov}\left(e_{i}, e_{j}\right)=0$, para todo $i \neq j$

Suponhamos que estamos avaliando um índice antropométrico de crianças freqüentando diferentes creches, e que por enquanto estamos interessados apenas em um fator que está no nível da criança. Para construir um modelo de 
dois níveis é necessário adicionar um termo aleatório representando a contribuição das creches (unidades de nível 2) para a resposta (índice antropométrico). Os índices $j$ serão usados agora para identificar as creches e os índices $i$ para as crianças dentro das creches. Assim, $\gamma_{i j}$ representa 0 índice antropométrico da criança $i$ da creche $j$, e dizemos que há $n_{j}$ crianças em cada uma das $m$ creches. O modelo básico é escrito como

$\gamma_{i j}=\alpha_{0}+\alpha_{j}+\beta_{1} x_{i j}+\beta_{2} x_{2 i}+e_{i j}$

onde

$\alpha_{o}=$ termo constante

$\alpha_{j}=$ contribuição de cada creche

Da mesma forma que a contribuição do nível 1, a contribuição do nível 2 pode ser explicada por fatores (número de crianças na creche, por exemplo):

$\alpha_{j}=\lambda+y w_{j}+y w_{j}$

onde

$\lambda=$ termo constante

$w_{j}=o$ fator ao nivel da creche 
$y=$ coeficiente ao nivel da creche

$u_{j}=$ residuo que representa a variação entre as creches

Substituindo $\alpha_{j}$ na equação 3 temos:

$\gamma_{i j}=\alpha+\beta x_{i j}+y_{\mathrm{ij}}+_{j}\left(\mathrm{u}_{j}+e_{i j}\right)$

onde os termos entre parênteses são referidos como a parte aleatória e o resto com a parte fixa do modelo. Os dois termos constantes, $\alpha_{0}$ e $\lambda$ foram combinados em $\alpha$. O modelo especificado desta forma tem agora duas fontes de variabilidade, $e_{i j}$, no nível 1 (da criança no exemplo) e $u_{j}$ no nivel 2 (no exemplo, nível da creche). Vamos agora assumir que

$\operatorname{var}\left(e_{i j}\right)=\delta_{e}^{2}, \operatorname{var}\left(u_{j}\right)=\delta_{u}{ }^{2}$

de forma que a variância das observações é

$\operatorname{var}\left(\gamma_{i j} \mid \alpha, \beta, \gamma, x, w,\right)=\operatorname{var}\left(u_{j}+e_{i j}\right)=\delta_{u}{ }^{2}+\delta_{e}{ }^{2}$

e a covariância entre duas observações numa mesma unidade do nivel 2 é

$\operatorname{cov}\left(u_{j}+e_{i j}, u_{j}+e_{i k}\right)=\operatorname{cov}\left(u_{j}, u_{j}\right)=\delta_{u}{ }^{2}$ 
A correlação intra-grupo (intra-creche, no exemplo) é, então, definida por

$\rho=\delta_{u}^{2} / \delta_{u}^{2}+\delta_{e}^{2}$

a proporção da variância total explicada pelo agrupamento no nivel 2 . É importante ressaltar que nessa formulação estamos assumindo que os resíduos entre unidades do mesmo nivel pertencentes a diferentes unidades de nível superior (por exemplo, crianças em creches diferentes) são independentes.

A generalização do modelo para três ou mais niveis segue diretamente o que foi apresentado para dois niveis. No caso de três níveis, sua equação seria

$\gamma_{i j k}=\alpha+\beta x_{i j k}+y w_{j k}+\delta z_{k}+\left(v_{k}+u_{j k}+e_{i j k}\right)$

onde

$k=$ unidades do nível 3

j = unidades do nivel 2

i= unidades do nível 1

$z=$ variável explanatória do nivel 3

Estes modelos, que são chamados modelos de componentes da variância, nos permitem incorporar correlação entre unidades que formam a hierarquia (BARROS, 2001). 
Aplicações especiais do Modelo de Regressão Multinível: quando a variável resposta é dicotômica

O modelo discutido anteriormente assume uma variável dependente quantitativa contínua e uma distribuição normal de erros. Se a variável dependente é uma escala na qual as respostas a um grande número de questões são sumarizadas em um único escore, os dados geralmente se aproximam da normalidade. Porém, existem situações nas quais o pressuposto da normalidade é claramente violado. Por exemplo, nos casos em que a variável dependente é dicotômica, os pressupostos de escores contínuos e da normalidade são obviamente falsos. A resolução do problema de variáveis que não têm distribuição normal e dos erros relacionados à heterocedasticidade consiste na transformação para alcançar a normalidade e reduzir a heterocedasticidade. (HOX, 1995).

Modelos estatísticos aplicados a esse tipo de situação são denominados "modelos lineares generalizados". Um modelo de dois niveis pode ser escrito, de forma geral

$\pi_{i j}=f\left(X_{i j} \beta_{j}\right)$

onde $\pi_{i j}$ é o valor esperado da resposta para a $i-j$ ésima unidade de nível 1 e $f$ é uma função não-linear de um 'preditor linear' $X_{i j} \beta_{j}$. Permitem-se coeficientes aleatórios para o nivel 2. O modelo é completado especificando-se a distribuição 
para resposta observada $y_{i j} \backslash \pi_{i j}$. Quando a resposta é uma proporção, tipicamente a distribuição utilizada é a binomial, e quando é uma 'contagem' a distribuição tomada é a de Poisson.

Considerando os componentes de variância um modelo de dois niveis, com uma variável explanatória única, onde a proporção esperada é modelada utilizando uma função logito

$\pi_{i j}=\left\{1+\exp \left(-\left[\beta_{0}+\beta_{1} x_{1 i j}+u_{0 i}\right]\right)\right\}^{-1}$

As respostas observadas $y_{i j}$ são proporções com o pressuposto de que têm uma distribuição binomial

$y_{i j} \sim \operatorname{Bin}\left(\pi_{i j}, n_{i j}\right)$

onde, $n_{i j}$ é o denominador para a proporção. Também temos $\operatorname{var}\left(y_{i j} \backslash \pi_{i j}\right)=\pi_{i j}\left(1-\pi_{i j}\right) / n_{i j}$

Podemos escrever o modelo de forma padronizada incluindo a variação do nivel 1 como

$$
y_{i j}=\pi_{i j}+e_{i j} z_{i j}, \quad z_{i j}=\pi_{i j}\left(1-\pi_{i j}\right) / n_{i j}, \delta^{2}=1
$$


Utilizando essa variável explanatória $Z$ e limitando a variância de nível a ela associada como sendo 1 , obtemos a variância binomial necessária na equação. Quando se ajusta um modelo também é possivel permitir que a variância do nivel 1 possa ser estimada e comparando-se a variância estimada com o valor 1, obtendo-se um teste para variação extra-binomial. Essa variação pode aparecer em uma série de situações. Se tivermos omitido um nível no modelo, por exemplo, ignorando o conglomerado domiciliar em uma pesquisa com um ou mais individuos incluídos na amostra nesse domicílio, esperariamos uma variação maior do que a variação binomial ao nível do indivíduo. Da mesma forma, suponhamos que indivíduos e domicilios foram agrupados dentro de áreas e optou-se por classificar os indivíduos segundo gênero e três classes sociais obtendo-se seis células em cada área. Se as tratarmos como unidades de nivel 1 de tal forma que a resposta é uma proporção, não teremos uma variância binomial uma vez que essas proporções são baseadas na soma de variáveis binomiais separadas com diferentes probabilidades. Aqui a variância para a célula $j$ dentro de uma área deveria ter a forma

$$
\left[E\left(\pi_{j}\right)\left(1-E\left(\pi_{j}\right)\right)-\sigma_{1}^{2}\right] / n_{j}
$$

onde $n_{j}$ é o tamanho da célula. Para ajustar este modelo nós poderíamos especificar uma variável explanatória extra de nivel 1 igual a $1 / \sqrt{n_{j}}$ para a jésima célula, com parâmetro de variância no nivel 1 que pudesse ser negativa. Mais comumente, nós podemos ajustar um modelo com um parâmetro extra-binomial junto com um termo adicional como abaixo para dar a estrutura de variância de nivel 1 seguinte 


$$
\left[\sigma_{0}^{2} \pi(1-\pi)+\sigma_{1}^{2}\right] / n
$$

Obviamente, os valores de $\pi_{i j}$ ou $\pi_{j}$ não são conhecidos, de forma que em cada iteração são utizados estimadores baseados sobre os valores correntes dos parâmetros. Pelo fato de utilizar-se somente a média e a variância da distribuição binomial para calcular o estimador, a estimativa é conhecida como um "quasilikelihood" (GOLDSTEIN 1995). 
ANEXO 7 


\section{CONSENTIMENTO INFORMADO DO MUNICIPIO}

Nós, representantes do município solicitamos integrar o projeto "Amamentação e Municipios", do NISMC/Instituto de Saúde/SES e NUPENS/Faculdade de Saúde Pública/USP, no qual as instituições ora citadas nos prestarão assessoria na coleta de dados da pesquisa "Avaliação de práticas alimentares no primeiro ano de vida", na análise dos dados (fornecendo gratuitamente um software elaborado para esse fim) e na discussão sobre políticas municipais pró-amamentação.

Autorizamos a inclusão dos dados da pesquisa realizada em nosso município em um Banco de Dados Central do Instituto de Saúde, que possibilita a avaliação da situação da amamentação no Estado de São Paulo, bem como a divulgação dos mesmos.

Nos dispomos, da mesma forma, a divulgar os dados desta pesquisa de acordo com os interesses de nosso município, citando a fonte "Projeto Amamentação e Municípios: Avaliação de Práticas Alimentares no Primeiro Ano de Vida em Dias Nacionais de Vacinação".

São Paulo, de de 1999. 
ANEXO 8 
Prevalência da amamentação exclusiva (AME) na faixa etária de 0-4 meses em 111 municípios do Estado de São Paulo, 1999.

\begin{tabular}{|c|c|c|c|}
\hline Municipio & $\mathbf{n}$ & $\%$ AME 0-4 meses & $I_{95 \%}$ \\
\hline Alambari & 12 & 16,7 & $2,1-48,4$ \\
\hline Aluminio & 85 & 25,9 & $17,0-36,5$ \\
\hline Analândia & 23 & 21,7 & $7,5-43,7$ \\
\hline Apiai & 164 & 16,5 & $11,1-23,0$ \\
\hline Araçoiaba da Serra & 95 & 12,6 & $6,7-21,0$ \\
\hline Araras & 364 & 8,2 & $5,7-11,7$ \\
\hline Assis & 324 & 17,9 & $14,0-22,6$ \\
\hline Atibaia & 457 & 16,6 & $13,4-20,4$ \\
\hline Auriflama & 68 & 5,9 & $1,6-14,4$ \\
\hline Barueri* & 427 & 8,4 & $5,1-11,8^{\star \star}$ \\
\hline Bauru* & 310 & 12,6 & $8,3-16,87^{\star \star}$ \\
\hline Bilac & 19 & 15,8 & $3,4-39,6$ \\
\hline Bom Sucesso de Itareré & 37 & 2,7 & $0,1-14,2$ \\
\hline Botucatu & 420 & 22,6 & $18,8-27,0$ \\
\hline Bragança Paulista* & 292 & 20,2 & $17,0-23,4^{\star \star}$ \\
\hline Brejo Alegre & 17 & 5,9 & $0,1-28,7$ \\
\hline Buritama & 73 & 1,4 & $0,0-7,4$ \\
\hline Capela do Alto & 39 & 12,8 & $4,3-27,4$ \\
\hline Capivari & 188 & 12,2 & $7,9-17,8$ \\
\hline Caraguatatuba & 495 & 18,6 & $15,3-22,4$ \\
\hline Carapicuiba* & 327 & 11,3 & $6,0-16,8^{\star \star}$ \\
\hline Cerquilho & 138 & 25,4 & $18,3-33,5$ \\
\hline Charqueada & 73 & 4,1 & $0,9-11,5$ \\
\hline Clementina & 31 & 6,5 & $0,8-21,4$ \\
\hline Conchas & 62 & 12,9 & $5,7-23,9$ \\
\hline Cordeirópolis & 96 & 9,4 & $4,4-17,1$ \\
\hline Coroados & 10 & 10,0 & $0,3-44,5$ \\
\hline Cosmópolis & 229 & 26,2 & $20,6-32,4$ \\
\hline Cruzeiro & 399 & 23,3 & $19,3-27,8$ \\
\hline Cubatão & 264 & 36,4 & $30,6-42,5$ \\
\hline Diadema* & 410 & 24,6 & $20,9-28,4^{\star \star}$ \\
\hline Elias Fausto & 88 & 19,3 & $11,7-29,1$ \\
\hline Emilianópolis & 11 & 36,4 & $10,9-69,2$ \\
\hline Espírito Santo do Pinhal & 185 & 24,3 & $18,3-31,2$ \\
\hline Ferraz de Vasconcelos ${ }^{\star}$ & 326 & 15,0 & $12,1-17,9^{\star *}$ \\
\hline Franca & 119 & 12,3 & $10,5-14,3$ \\
\hline Gabriel Monteiro & 6 & 0,0 & - \\
\hline Glicério & 23 & 52,2 & $30,6-73,2$ \\
\hline Guararapes & 125 & 24,0 & $16,8-32,5$ \\
\hline
\end{tabular}




\begin{tabular}{|c|c|c|c|}
\hline & & & cont. \\
\hline Guareí & 60 & 15,0 & $7,1-26,6$ \\
\hline Guarujá* & 451 & 53,2 & $48,5-57,9^{\star \star}$ \\
\hline Guzolândia & 29 & 6,9 & $0,8-22,8$ \\
\hline Ibiúna & 278 & 9,7 & $6,5-13,8$ \\
\hline lepê & 37 & 10,8 & $3,0-25,4$ \\
\hline Ilhabela & 144 & 36,1 & $28,3-44,5$ \\
\hline Iperó & 86 & 8,1 & $3,3-16,1$ \\
\hline Ipeúna & 24 & 0,0 & - \\
\hline Iracemápolis & 64 & 7,8 & $2,6-17,3$ \\
\hline ltaberá & 120 & 21,7 & $14,7-30,1$ \\
\hline Itapeva & 530 & 18,5 & $15,3-22,1$ \\
\hline Itapira & 247 & 42,5 & $36,3-48,9$ \\
\hline Itapirapuã Paulista & 33 & 15,2 & $5,1-31,9$ \\
\hline Itapura & 22 & 9,1 & $1,1-29,2$ \\
\hline Itararé & 290 & 23,8 & $19,0-29,1$ \\
\hline Itarin & 78 & 30,8 & $20,8-42,2$ \\
\hline Itatinga & 77 & 16,9 & $9,3-27,1$ \\
\hline Itobi & 32 & 28,1 & $13,7-46,7$ \\
\hline $\mathrm{Itu}^{\star}$ & 301 & 21,3 & $13,7-28,9^{\text {** }}$ \\
\hline Limeira & 667 & 11,7 & $9,4-14,4$ \\
\hline Lourdes & 11 & 0,0 & - \\
\hline Luiziânia & 16 & 18,8 & $4,0-45,6$ \\
\hline Mairinque & 290 & 18,6 & $14,3-23,6$ \\
\hline Martinópolis & 121 & 17,4 & $11,1-25,3$ \\
\hline Mauá* & 330 & 10,9 & $7,8-14,0^{* *}$ \\
\hline Mogi-Guaçu & 652 & 15,0 & $12,4-18,1$ \\
\hline Mogi-Mirim & 351 & 21,9 & $17,8-26,7$ \\
\hline Morro Agudo & 145 & 16,6 & $10,9-23,6$ \\
\hline Narandiba & 13 & 15,4 & $1,9-45,4$ \\
\hline Nova Campina & 61 & 19,7 & $10,6-31,8$ \\
\hline Nova Guataporanga & 10 & 20,0 & $2,5-55,6$ \\
\hline Osasco* & 240 & 17,5 & $11,0-24,0^{\star \star}$ \\
\hline Ourinhos & 435 & 9,9 & $7,3-13,2$ \\
\hline Paraguaçu Paulista & 233 & 11,6 & $7,8-16,4$ \\
\hline Paranapanema & 86 & 3,5 & $0,7-9,9$ \\
\hline Pardinho & 26 & 15,4 & $4,4-34,9$ \\
\hline Pedro de Toledo & 59 & 52,5 & $39,1-65,7$ \\
\hline Piacatu & 25 & 4,0 & $0,1-20,4$ \\
\hline Piedade & 227 & 10,1 & $6,5-14,8$ \\
\hline Pilar do Sul & 170 & 29,4 & $22,7-36,9$ \\
\hline Piracicaba* & 399 & 10,3 & $6,8-13,7^{\star *}$ \\
\hline Piraju & 113 & 19,5 & $12,6-28,0$ \\
\hline Pirapora do Bom Jesus & 36 & 0,0 & - \\
\hline Pirapozinho & 103 & 14,6 & $8,4-22,9$ \\
\hline Pirassuninga & 279 & 15,1 & $11,1-19,8$ \\
\hline
\end{tabular}




\begin{tabular}{|c|c|c|c|}
\hline & & & cont. \\
\hline Poá* & 259 & 12,4 & $6,8-17,9$ \\
\hline Praia Grande* & 299 & 33,1 & $26,1-40,2$ \\
\hline Presidente Epitácio & 154 & 11,0 & $6,6-17,1$ \\
\hline Registro & 263 & 39,9 & $34,0-46,1$ \\
\hline Ribeirão Branco & 127 & 17,3 & $11,2-25,0$ \\
\hline Ribeirão Grande & 42 & 28,6 & $15,7-44,6$ \\
\hline Ribeirão Preto* & 540 & 18,5 & $14,5-22,6$ \\
\hline Riversul & 45 & 2,2 & $0,1-11,8$ \\
\hline Salto & 398 & 15,6 & $12,2-19,6$ \\
\hline Santa Gertrudes & 48 & 12,5 & $4,7-25,2$ \\
\hline Santo André ${ }^{\star}$ & 331 & 21,8 & $16,7-26,8$ \\
\hline São Bernardo do Campo* & 336 & 29,5 & $22,9-36,0^{\star \star}$ \\
\hline São Carios* & 338 & 14,8 & $10,1-19,4$ \\
\hline São João da Boa Vista & 380 & 31,6 & $27,0-36,6$ \\
\hline São João do Pau D'Alho & 7 & 14,3 & $0,4-57,9$ \\
\hline São José do Rio Preto* & 332 & 11,1 & $8,0-14,3^{\star \star}$ \\
\hline São Miguel Arcanjo & 183 & 21,9 & $16,1-28,6$ \\
\hline São Sebastiäo & 359 & 40,1 & $35,0-45,4$ \\
\hline Suzano* & 394 & 7,9 & $4,7-11,0$ \\
\hline Taboão da Serra* & 343 & 23,0 & $16,4-29,6$ \\
\hline Taquarivaí & 38 & 31,6 & $17,5-48,7$ \\
\hline Tupã & 224 & 20,1 & $15,0-25,9$ \\
\hline Turiúba & 5 & 40,0 & $5,3-85,3$ \\
\hline Valinhos & 217 & 25,8 & $20,1-32,2$ \\
\hline Valparaíso & 71 & 5,6 & $1,6-13,8$ \\
\hline Vargem Grande do Sul & 106 & 9,4 & $4,6-16,7$ \\
\hline Votuporanga & 234 & 43,2 & $36,7-49,8$ \\
\hline TOTAL & 21984 & 19,2 & $18,6-19,7$ \\
\hline
\end{tabular}


Prevalência da amamentação exclusiva (AME) na faixa etária de 0-6 meses em 111 municipios do Estado de São Paulo, 1999.

\begin{tabular}{|c|c|c|c|}
\hline Município & $\mathbf{n}$ & $\%$ AME 0-6 meses & $\mathrm{IC}_{95 \%}$ \\
\hline Alambari & 16 & 12,5 & $1,6-38,3$ \\
\hline Aluminio & 134 & 17,9 & $11,8-25,5$ \\
\hline Analândia & 28 & 17,9 & $6,1-36,9$ \\
\hline Apiai & 260 & 11,9 & $8,2-16,5$ \\
\hline Araçoiaba da Serra & 144 & 9,0 & $4,9-14,9$ \\
\hline Araras & 559 & 5,7 & $4,0-8,1$ \\
\hline Assis & 498 & 11,8 & $9,2-15,1$ \\
\hline Atibaia & 682 & 12,2 & $9,9-14,9$ \\
\hline Auriflama & 108 & 3,7 & $1,0-9,2$ \\
\hline Barueri* & 644 & 6,4 & $4,2-8,5^{\star \star}$ \\
\hline Bauru $^{\star}$ & 495 & 8,5 & $5,8-11,2^{\star *}$ \\
\hline Bilac & 41 & 7,3 & $1,5-19,9$ \\
\hline Bom Sucesso de Itararé & 49 & 2,0 & $0,1-10,9$ \\
\hline Botucatu & 643 & 16,5 & $13,7-19,6$ \\
\hline Bragança Paulista* & 482 & 14,9 & $12,9-17,0^{\star \star}$ \\
\hline Brejo Alegre & 24 & 4,2 & $0,1-21,1$ \\
\hline Buritama & 122 & 2,5 & $0,5-7,0$ \\
\hline Capela do Alto & 62 & 8,1 & $2,7-17,8$ \\
\hline Capivari & 283 & 8,5 & $5,5-12,4$ \\
\hline Caraguatatuba & 745 & 14,1 & $11,7-16,8$ \\
\hline Carapicuíba* & 533 & 7,3 & $3,9-10,7^{\star \star}$ \\
\hline Cerquilho & 218 & 18,3 & $13,4-24,1$ \\
\hline Charqueada & 109 & 2,8 & $0,6-7,8$ \\
\hline Clementina & 46 & 4,3 & $0,5-14,8$ \\
\hline Conchas & 110 & 8,2 & $3,8-15,0$ \\
\hline Cordeirópolis & 156 & 5,8 & $2,7-10.7$ \\
\hline Coroados & 19 & 5,3 & $0,1-26,0$ \\
\hline Cosmópolis & 365 & 19,5 & $15,6-24,0$ \\
\hline Cruzeiro & 620 & 17,7 & $14,9-21,0$ \\
\hline Cubatão & 453 & 27,8 & $23,8-32,2$ \\
\hline Diadema* & 621 & 18,0 & $14,9-21,2^{\star \star}$ \\
\hline Elias Fausto & 128 & 15,6 & $9,8-23,1$ \\
\hline Emilianópolis & 18 & 22,2 & $6,4-47,6$ \\
\hline Espírito Santo do Pinhal & 277 & 17,7 & $13,4-22,7$ \\
\hline Ferraz de Vasconcelos ${ }^{\star}$ & 470 & 11,3 & $9,2-13,4^{\star \star}$ \\
\hline Franca & 185 & 8,5 & $7,3-9,9$ \\
\hline Gabriel Monteiro & 11 & 0,0 & - \\
\hline Glicério & 37 & 32,4 & $18,0-49,8$ \\
\hline Guararapes & 209 & 15,8 & $11,1-21,5$ \\
\hline Guareí & 84 & 10,7 & $5,0-19,4$ \\
\hline Guarujá* & 696 & 44,7 & $41,0-48,5^{\star \star}$ \\
\hline
\end{tabular}




\begin{tabular}{|c|c|c|c|}
\hline & & & Cont \\
\hline Guzolândia & 42 & 4,8 & $0,6-16,2$ \\
\hline Ibiúna & 433 & 7,6 & $5,4-10,6$ \\
\hline lepê & 57 & 7,0 & $1,9-17,0$ \\
\hline Ilha Bela & 214 & 31,8 & $25,6-38,5$ \\
\hline Iperó & 125 & 5,6 & $2,3-11,2$ \\
\hline Ipeúna & 40 & 0,0 & - \\
\hline Iracemápolis & 93 & 5,4 & $1,8-12,1$ \\
\hline Itaberá & 182 & 15,4 & $10,5-21,5$ \\
\hline Itapeva & 806 & 13,6 & $11,4-16,3$ \\
\hline Itapira & 409 & 29,6 & $25,3-34,3$ \\
\hline Itapirapuã Paulista & 50 & 10,0 & $3,3-21,8$ \\
\hline Itapura & 39 & 5,1 & $0,6-17,3$ \\
\hline Itararé & 455 & 17,4 & $14,1-21,2$ \\
\hline Itariri & 123 & 24,4 & $17,1-33,0$ \\
\hline Itatinga & 112 & 11,6 & $6,3-19,0$ \\
\hline Itobi & 52 & 17,3 & $8,2-30,3$ \\
\hline$I t u^{\star}$ & 490 & 14,7 & $9,7-19,7^{\star \star}$ \\
\hline Limeira & 1065 & 7,8 & $6,3-9,6$ \\
\hline Lourdes & 16 & 0,0 & - \\
\hline Luiziânia & 23 & 13,0 & $2,8-33,6$ \\
\hline Mairinque & 433 & 12,9 & $10,0-16,5$ \\
\hline Martinópolis & 180 & 12,2 & $7,8-17,9$ \\
\hline Mauá* & 511 & 8,6 & $6,0-11,2^{\star \star}$ \\
\hline Mogi Guaçu & 988 & 11,2 & $9,4-13,4$ \\
\hline Mogi Mirim & 529 & 16,1 & $13,1-19,5$ \\
\hline Morro Agudo & 234 & 11,5 & $7,7-16,3$ \\
\hline Narandiba & 26 & 11,5 & $2,4-30,2$ \\
\hline Nova Campina & 92 & 16,3 & $9,4-25,5$ \\
\hline Nova Guataporanga & 17 & 11,8 & $1,5-36,4$ \\
\hline Osasco* & 375 & 13,1 & $7,7-18,4^{\star \star}$ \\
\hline Ourinhos & 673 & 6,7 & $5,0-8,9$ \\
\hline Paraguaçu Paulista & 357 & 8,4 & $5,8-11,9$ \\
\hline Paranapanema & 116 & 2,6 & $0,5-7,4$ \\
\hline Pardinho & 47 & 8,5 & $2,4-20,4$ \\
\hline Pedro de Toledo & 92 & 39,1 & $29,1-49,9$ \\
\hline Piacatu & 38 & 2,6 & $0,1-13,8$ \\
\hline Piedade & 367 & 7,9 & $5,4-11,3$ \\
\hline Pilar do Sul & 245 & 21,6 & $16,6-27,3$ \\
\hline Piracicaba* & 670 & 7,2 & $4,9-9,4^{\star \star}$ \\
\hline Piraju & 173 & 14,5 & $9,6-20,6$ \\
\hline Pirapora do Bom Jesus & 52 & 0,0 & - \\
\hline Pirapozinho & 159 & 10,7 & $6,4-16,6$ \\
\hline Pirassununga & 425 & 10,4 & $7,7-13,7$ \\
\hline Poá* & 431 & 9,0 & $5,5-12,6^{\star \star}$ \\
\hline Praia Grande* & 491 & 24.8 & $19,4-30,2^{\star \star}$ \\
\hline Presidente Epitácio & 232 & 7,3 & $4,3-11,5$ \\
\hline
\end{tabular}




\begin{tabular}{|c|c|c|c|}
\hline & & & Cont \\
\hline Registro & 444 & 28,2 & $24,1-32,6$ \\
\hline Ribeirão Branco & 187 & 12,8 & $8,4-18,5$ \\
\hline Ribeirão Grande & 59 & 20,3 & $11,0-32,8$ \\
\hline Ribeirão Preto* & 828 & 12,5 & $10,1-15,0^{\star *}$ \\
\hline Riversul & 68 & 1,5 & $0,0-7,9$ \\
\hline Salto & 654 & 10,7 & $8,5-13,4$ \\
\hline Santa Gerturdes & 77 & 9,1 & $3,7-17,8$ \\
\hline Santo André* & 526 & 16,3 & $12,4-20,2^{\star \star}$ \\
\hline São Bernardo do Campo* & 531 & 22,4 & $17,6-27,2^{\star *}$ \\
\hline São Carlos* & 543 & 10,1 & $7,0-13,2^{\star *}$ \\
\hline São João da Boa Vista & 564 & 22,5 & $19,2-26,2$ \\
\hline São João do Pau D'Alho & 10 & 10,0 & $0,3-44,5$ \\
\hline São José do Rio Preto* & 568 & 7,2 & $5,3-9,0^{\star \star}$ \\
\hline São Miguel Arcanjo & 285 & 14,7 & $10,8-19,4$ \\
\hline São Sebastião & 550 & 29,3 & $25,5-33,3$ \\
\hline Suzano* & 604 & 6,0 & $3,7-8,2^{\star \star}$ \\
\hline Taboão da Serra* & 560 & 16,8 & $12,2-21,3^{\star \star *}$ \\
\hline Taquarivai & 68 & 19,1 & $10,6-30,5$ \\
\hline Tupã & 384 & 12,8 & $9,7-16,6$ \\
\hline Turiuba & 11 & 27,3 & $6,0-61,0$ \\
\hline Valinhos & 368 & 17,1 & $13,5-21,4$ \\
\hline Valparaiso & 113 & 3,5 & $1,0-8,8$ \\
\hline Vargem Grande do Sul & 178 & 6,7 & $3,5-11,5$ \\
\hline Votuporanga & 428 & 28,3 & $24,1-32,8$ \\
\hline TOTAL & 34435 & 13,9 & $13,6-14,3$ \\
\hline
\end{tabular}


ANEXO 9 
Comparação de indicadores sociodemográficos dos municípios que realizaram a pesquisa sobre aleitamento materno utilizando amostras tendo como fontes o SINASC (1998) e o Projeto Amamentaçăo e Municipios (1999).

\begin{tabular}{|c|c|c|c|c|c|c|c|c|}
\hline \multirow[t]{2}{*}{ Municipio } & \multicolumn{2}{|c|}{$\%$ males com $1^{\circ} \mathrm{grau}$ incompleto } & \multicolumn{2}{|c|}{ \% Baixo peso ao nascer } & \multicolumn{2}{|c|}{ \% Mães adolescentes } & \multicolumn{2}{|c|}{ \% Partos vaginais } \\
\hline & SINASC & $\begin{array}{l}\text { Pesquisa } \\
\end{array}$ & SINASC & Pesquisa & SINASC & Pesquisa & SINASC & Pesquisa \\
\hline Barueri & 55,6 & $\begin{array}{l}45,5 \\
(41,6-49,4)\end{array}$ & 8,0 & $\begin{array}{l}7,1 \\
(5,3-9,5)\end{array}$ & 20,9 & $\begin{array}{l}17,1 \\
(14,3-20,3)\end{array}$ & 51,7 & $\begin{array}{l}55,1 \\
(51,2-59,0)\end{array}$ \\
\hline Bauru & $\overline{45}, 5$ & $\begin{array}{l}39,0 \\
34,7-43,5\end{array}$ & 8,8 & $\begin{array}{l}8,5 \\
6,3-11,4\end{array}$ & $22, \overline{9}$ & $\begin{array}{l}17,6 \\
14,4-21,3\end{array}$ & 37,2 & $\begin{array}{l}44,2 \\
39,8-48,7\end{array}$ \\
\hline Bragança Paulista & 57,6 & $\begin{array}{l}47,1 \\
(42,6-51,7)\end{array}$ & 10,0 & $\begin{array}{l}8,1 \\
(5,9-11,0)\end{array}$ & 21,6 & \begin{tabular}{|l|}
$16,4,2$ \\
$(13,1-19,8)$
\end{tabular} & 48,6 & $\begin{array}{l}48,1 \\
(43,6-52,7)\end{array}$ \\
\hline Carapicuíba & 46,3 & $\begin{array}{l}40,0 \\
(35,8-44,3)\end{array}$ & 9,1 & $\begin{array}{l}11,1 \\
(8,6-14,1)\end{array}$ & 20,5 & $\begin{array}{l}17,3 \\
(14,2-20,8)\end{array}$ & 54,7 & $\begin{array}{l}57,6 \\
(53,3-61,8)\end{array}$ \\
\hline Diadema & 56,2 & $\begin{array}{l}44,9 \\
(41,0-48,9)\end{array}$ & 8,6 & $\begin{array}{l}8,9 \\
(6,8-11,4)\end{array}$ & 19,8 & $\begin{array}{l}15,1 \\
(12,5-18,3)\end{array}$ & 54,2 & $\begin{array}{l}51,2 \\
(47,2-55,2)\end{array}$ \\
\hline Ferraz de Vasconcelos & 52,9 & $\begin{array}{l}40,2 \\
(35,8-44,8)\end{array}$ & 8,6 & $\begin{array}{l}6,8 \\
(4,8-9,6)\end{array}$ & 18,2 & $\begin{array}{l}17,7 \\
(14,4-21,5)\end{array}$ & 59,5 & $\begin{array}{l}57,0 \\
(52,4-61,5)\end{array}$ \\
\hline Guarujá & 60,3 & $\begin{array}{l}44,1 \\
(40,4-47,9)\end{array}$ & 9,3 & $\begin{array}{l}7,2 \\
(5,4-9,4)\end{array}$ & 22,8 & $\begin{array}{l}21,7 \\
(18,7-25,0)\end{array}$ & 52,8 & $\begin{array}{l}53,7 \\
(49,9-57,5)\end{array}$ \\
\hline Itu & 52,2 & $\begin{array}{l}48,8 \\
(44,3-53,3)\end{array}$ & 8,4 & $\begin{array}{l}7,6 \\
(5,4-10,4)\end{array}$ & 21,0 & $\begin{array}{l}19,2 \\
(15,8-23,0)\end{array}$ & 65,8 & $\begin{array}{l}66,7 \\
(62,3-70,9)\end{array}$ \\
\hline Mauá & 46,0 & $\begin{array}{l}46,4 \\
(42,0-50,8)\end{array}$ & 9,1 & $\begin{array}{l}6,8 \\
(4,9-9,5)\end{array}$ & 18,8 & $\begin{array}{l}12,3 \\
(9,7-15,6)\end{array}$ & 51,2 & $\begin{array}{l}54,0 \\
(49,6-58,4)\end{array}$ \\
\hline Osasco & 47,7 & $\begin{array}{l}40,0 \\
(36,6-43,4)\end{array}$ & 8,3 & $\begin{array}{l}8,5 \\
(6,0-11,9)\end{array}$ & 18,7 & $\begin{array}{l}16,0 \\
(12,5-20,2)\end{array}$ & 55,7 & $\begin{array}{l}53,6 \\
(48,4-58,7)\end{array}$ \\
\hline Piracicaba & 56,4 & $\begin{array}{l}41,8 \\
(38,0-45,6)\end{array}$ & 8,1 & $\begin{array}{l}6,6 \\
(4,9-8,8)\end{array}$ & 21,0 & $\begin{array}{l}18,1 \\
(15,3-21,2)\end{array}$ & 32,9 & $\begin{array}{l}40,7 \\
(37,0-44,6)\end{array}$ \\
\hline Poá & 48,2 & $\begin{array}{l}38,1 \\
(33,5-42,8)\end{array}$ & 7,6 & $\begin{array}{l}8,1 \\
(5,8-11,2)\end{array}$ & 17,0 & $\begin{array}{l}15,3 \\
(12,1-19,1)\end{array}$ & 52,6 & $\begin{array}{l}55,2 \\
(50,4-60,0)\end{array}$ \\
\hline Praia Grande & 46,2 & $\begin{array}{l}43,4 \\
(39,0-47,9)\end{array}$ & 9,1 & $\begin{array}{l}7,1 \\
(5,1-9,9)\end{array}$ & 20,6 & $\begin{array}{l}15,7 \\
(12,6-19,3)\end{array}$ & 58,6 & $\begin{array}{l}61,1 \\
(56,5-65,4)\end{array}$ \\
\hline Ribeirăo Preto & 42,6 & $\begin{array}{l}40,0 \\
(36,6-43,4)\end{array}$ & 10,0 & $\begin{array}{l}8,8 \\
(7,0-11,0)\end{array}$ & 17,0 & $\begin{array}{l}15,3 \\
(13,0-18,0)\end{array}$ & 40,1 & $\begin{array}{l}47,0 \\
(43,5-50,4)\end{array}$ \\
\hline Santo André & $\overline{32,6}$ & $\begin{array}{l}38,2 \\
(34,1-42,5)\end{array}$ & 8,1 & $\begin{array}{l}9,3 \\
(7,0-12,2)\end{array}$ & 16,1 & $\begin{array}{l}12,5 \\
(9,9-15,8)\end{array}$ & 38,1 & $\begin{array}{l}40,9 \\
(36,7-45,2)\end{array}$ \\
\hline São Bernardo & 41,3 & $\begin{array}{l}36,0 \\
(31,9-40,2)\end{array}$ & 8,3 & $\begin{array}{l}9,4 \\
(7,1-12,3)\end{array}$ & 17,9 & $\begin{array}{l}13,9 \\
(11,2-17,2)\end{array}$ & 45,2 & $\begin{array}{l}46,7 \\
(42,4-51,1)\end{array}$ \\
\hline São Carlos & 46,4 & $\begin{array}{l}33,7 \\
(29,8-37,9)\end{array}$ & 9,9 & $\begin{array}{l}8,7 \\
(6,5-11,4)\end{array}$ & 19,4 & $\begin{array}{l}17,1 \\
(14,1-20,6)\end{array}$ & 34,9 & $\begin{array}{l}36,5 \\
(32,4-40,7)\end{array}$ \\
\hline São José Rio Preto & 48,6 & $\begin{array}{l}36,1 \\
(32,2-40,2)\end{array}$ & 7,9 & $\begin{array}{l}8,8 \\
(7,0-11,0)\end{array}$ & 19,2 & $\begin{array}{l}19,4 \\
(16,2-22,9)\end{array}$ & 20,1 & $\begin{array}{l}37,0 \\
(33,0-41,1)\end{array}$ \\
\hline Suzano & 39,3 & \begin{tabular}{|l|}
$(32,6-40,2)$ \\
$(37,6-45,6)$
\end{tabular} & 7,9 & $\begin{array}{l}7,8 \\
(5,8-10,3)\end{array}$ & 21,5 & 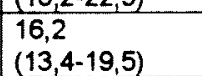 & 60.1 & $\begin{array}{l}58,4 \\
(54,4-62,4)\end{array}$ \\
\hline Taboão da Serra & 40,2 & $\begin{array}{l}46,4 \\
(42,2-50,7)\end{array}$ & 7,8 & $\begin{array}{l}10,0 \\
(7,7-12,9)\end{array}$ & 19,8 & $\begin{array}{l}18,6 \\
(15,5-22,1)\end{array}$ & 55,5 & $\begin{array}{l}54,8 \\
(50,6-59,0)\end{array}$ \\
\hline
\end{tabular}

